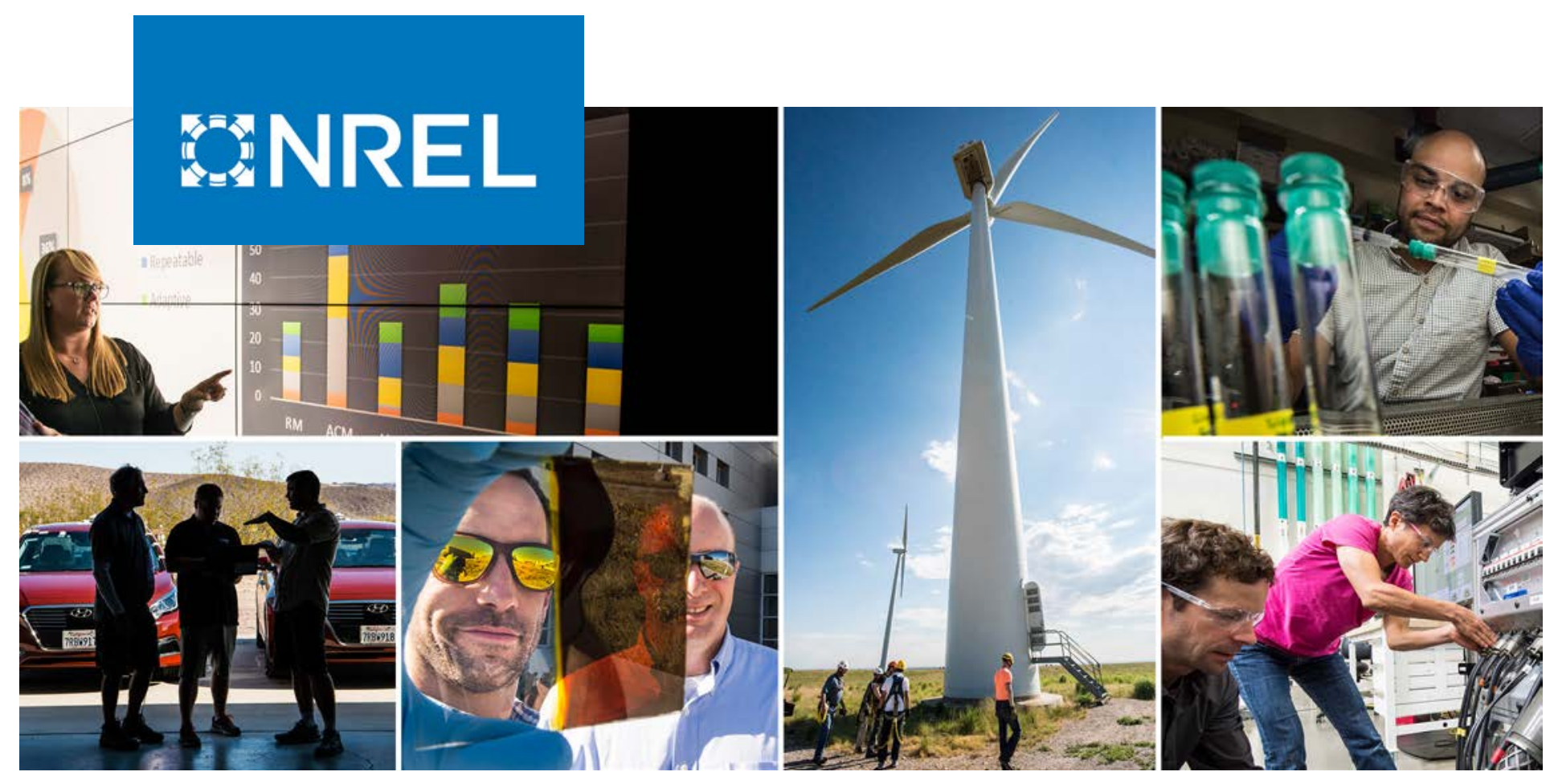

\title{
Increasing Wind Turbine Tower Heights: Opportunities and Challenges
}

Eric Lantz, ${ }^{1}$ Owen Roberts, ${ }^{1}$ Jake Nunemaker, ${ }^{1}$ Edgar DeMeo, ${ }^{2}$ Katherine Dykes, ${ }^{1}$ and George Scott ${ }^{1}$

1 National Renewable Energy Laboratory

2 Renewable Energy Consulting Services, Inc.

NREL is a national laboratory of the U.S. Department of Energy

Office of Energy Efficiency \& Renewable Energy

Operated by the Alliance for Sustainable Energy, LLC

This report is available at no cost from the National Renewable Energy Laboratory (NREL) at www.nrel.gov/publications.
Technical Report

NREL/TP-5000-73629

May 2019 


\section{EAREL}

\section{Increasing Wind Turbine Tower Heights: Opportunities and Challenges}

\section{Eric Lantz, ${ }^{1}$ Owen Roberts, ${ }^{1}$ Jake Nunemaker, ${ }^{1}$ Edgar DeMeo, ${ }^{2}$ Katherine Dykes, ${ }^{1}$ and George Scott ${ }^{1}$}

1 National Renewable Energy Laboratory

2 Renewable Energy Consulting Services, Inc.

\section{Suggested Citation}

Lantz, Eric, Owen Roberts, Jake Nunemaker, Edgar DeMeo, Katherine Dykes, and George Scott. 2019. Increasing Wind Turbine Tower Heights: Opportunities and Challenges. Golden, CO: National Renewable Energy Laboratory. NREL/TP-5000-73629. https://www.nrel.gov/docs/fy19osti/73629.pdf.

NREL is a national laboratory of the U.S. Department of Energy Office of Energy Efficiency \& Renewable Energy Operated by the Alliance for Sustainable Energy, LLC

This report is available at no cost from the National Renewable Energy Laboratory (NREL) at www.nrel.gov/publications.

Contract No. DE-AC36-08GO28308
Technical Report NREL/TP-5000-73629 May 2019

National Renewable Energy Laboratory 15013 Denver West Parkway Golden, CO 80401 303-275-3000 • www.nrel.gov 


\section{NOTICE}

This work was authored [in part] by the National Renewable Energy Laboratory, operated by Alliance for Sustainable Energy, LLC, for the U.S. Department of Energy (DOE) under Contract No. DE-AC3608GO28308. Funding provided by the U.S. Department of Energy Office of Energy Efficiency and Renewable Energy Wind Energy Technologies Office. The views expressed herein do not necessarily represent the views of the DOE or the U.S. Government.

This report is available at no cost from the National

Renewable Energy Laboratory (NREL) at

www.nrel.gov/publications.

U.S. Department of Energy (DOE) reports produced

after 1991 and a growing number of pre-1991

documents are available

free via www.OSTI.gov.

Cover Photos by Dennis Schroeder: (clockwise, left to right) NREL 51934, NREL 45897, NREL 42160, NREL 45891, NREL 48097, NREL 46526.

NREL prints on paper that contains recycled content. 


\section{Acknowledgments}

This work was supported by the U.S. Department of Energy (DOE) under Contract No. DEAC36-08GO28308 with the National Renewable Energy Laboratory (NREL). Funding for the work was provided by the DOE Office of Energy Efficiency and Renewable Energy, Wind Energy Technologies Office. The authors thank Rick Damiani (NREL) for input and contributions to the Tower Systems Engineering simulations portion of this work as well as Eric Smith (Keystone Tower Systems), Jason Cotrell (RCAM Technologies), and Ryan Wiser (Lawrence Berkeley National Laboratory) for reviewing prior versions of this manuscript. We also thank Rich Tusing (NREL) and Patrick Gilman (DOE) for their strategic input and guidance in the development and execution of this work. Finally, thanks to Sheri Anstedt (NREL) for editing support and Nicholas Gilroy (NREL) for cartography. Opinions represented in this article are the authors' own and do not reflect the view of the U.S. Department of Energy or the U.S. government. Of course, any remaining errors or omissions are the sole responsibility of the authors. 


\section{List of Abbreviations}

1P
3P
BAR
BAU
BOS
CapEx
CSM
GW
IEC
kN
kNm
kW
LandBOSSE
LCOE
LDST
MWh
OEM
O\&M
R\&D
RNA
TowerSE
Wind
WTT

rotor rotational frequency

blade passing frequency

big adaptive rotor

business as usual

balance of station

capital expenditures

Cost and Scaling Model

gigawatts

International Electrotechnical Commission

kilonewton

kilonewton-meter

kilowatt

Land Balance of Station Systems Engineering

levelized cost of energy

large-diameter steel tower

megawatt-hour

original equipment manufacturer

operation and maintenance

research and development

rotor nacelle assembly

Tower Systems Engineering

Wind Integration National Dataset Toolkit

Wind Tower Technologies 


\section{Executive Summary}

This report presents the opportunities, challenges, and potential associated with increasing wind turbine tower heights, focusing on land-based wind energy technology. Our principal conclusions are as follows:

- Wind resource quality improves significantly with height above ground. Over large portions of the country, our mesoscale resource data indicate an increase in annual average wind speed of 0.5 to 1.0 meters per second $(\mathrm{m} / \mathrm{s})$ when moving from 80 to 110 meters $(\mathrm{m})$ and 1.0 to $1.5 \mathrm{~m} / \mathrm{s}$ when moving from 80 to $160 \mathrm{~m}$.

- Wind speed differences translate to sizable capacity factor improvements. Although the observed variance is broad, median capacity factor gains with higher hub heights are estimated at approximately 2 to 4 percentage points when going from 80 to $110 \mathrm{~m}$ and an additional 2 to 4 percentage points when going from 110 to $140 \mathrm{~m}$. Between 140 and $160 \mathrm{~m}$, median capacity factor gains are approximately 1 percentage point. Relatively larger gains occur east of the Rocky Mountains, with the greatest gains sprinkled throughout the Heartland, the Midwest, and the Northeast.

- Based on first-order cost estimates informed by current technology, the most wind-rich regions of the country generally show an economic preference for the lowest considered tower height; higher hub heights (e.g., $110 \mathrm{~m}$ and $140 \mathrm{~m}$ ) are often preferred in more moderate wind speed regions. This result is consistent with industry experience to date.

- Higher nameplate and lower specific power turbines (e.g., 150 to 175 watts per square meter) also show a general economic preference for the lowest considered tower height; however, these larger turbines require tower heights of at least $110 \mathrm{~m}$. Tower heights of $140 \mathrm{~m}$ and in some cases $160 \mathrm{~m}$ tend to be preferred in more moderate wind speed areas.

- The highest nameplate capacity turbine we considered (4.5 megawatts) has a relatively greater preference for 140-m hub heights than similar 3-megawatt-class turbines. This observation is driven by the proportionally lower cost associated with taller towers and tall tower installations in dollars per kilowatt $(\$ / \mathrm{kW})$ for larger turbines and indicates that turbine scaling (which offers additional cost saving potential) and taller tower deployment is likely to occur in parallel.

- Future tower innovations could make higher hub heights more attractive. In a tower cost-bounding scenario, where we apply a fixed $\$ 200 / \mathrm{kW}$ tower cost for each turbine at all hub heights, we see an economic preference for 160 -m tower heights in $70 \%$ to $90 \%$ of sites, depending on the specific turbine configuration.

- Reducing the cost of realizing taller towers is critical to capturing the value of higher wind speeds at higher above ground levels as well as for increasing the viability of wind power in all regions of the country.

- Additional factors that could impact tower height include blade tip clearance requirements, balance-of-station costs, turbine nameplate capacity, and specific power. Turbines with higher specific power ratings experience more energy gain for a given change in wind resource. Larger wind turbines tend to have an economic advantage for tall tower applications and offer additional cost saving potential in balance-of-station and turbine-level 
economies of scale. Ultimately, wind turbine design reflects an optimization across an array of potential criteria; focusing on tower height alone may result in suboptimal outcomes.

- When pursuing higher tower heights, a system-level incremental capital cost of less than $\$ 500 / \mathbf{k W}$ for low specific power turbines and potentially as low as $\$ 200 / \mathrm{kW}$, particularly for higher specific power turbine configurations, could support a levelized cost of energy reduction across much of the country, and might also push less-energetic wind resource regions further along the path to economic competitiveness. Depending on the specific focus regions and turbine configurations under consideration, variance from this general guidance could be merited.

- To realize taller wind turbine towers, an array of potential concepts remain in play. These concepts rely on various materials spanning rolled tubular steel (currently the most widely used option), concrete, and lattice steel, for space frame designs, as well as hybrid designs that use a combination of concepts. Although there are clear advantages and disadvantages to each known concept, the future design of tall wind turbine towers remains to be determined. At the same time, our examination suggests that tubular towers can continue to be viable at the higher above-ground heights, particularly with continued advances in control technology that allow for reliable use of soft-soft designs. Tower erection strategies and innovation may also be a determining factor in the viability of future tall tower concepts.

Notable caveats in this analysis include uncertainty in the underlying resource data, which increases at higher above ground levels, coupled with high sensitivity in terms of the analysis results to the assumed wind shear. In addition, our capital expenditure and levelized cost of energy estimates are based on cost characterizations that generally reflect modern state-of-the-art technology and do not consider the potential for future innovations to alter the capital expenditures required to achieve a given tower height. Finally, the tower height economic preference analysis is limited to tower heights of $80 \mathrm{~m}, 110 \mathrm{~m}, 140 \mathrm{~m}$, and $160 \mathrm{~m}$; in many cases, real-world economically preferred tower heights will likely fall between these points.

Future research needs elicited from this work include activities that quantify and ultimately reduce the uncertainty of the wind resource data, particularly at higher above ground levels. More robust cost assessments and analysis including more sensitivities as well as evaluation of specific technology opportunities and alternative turbine configurations would also be valuable and further inform the potential for innovative solutions to capture value from taller towers. 


\section{Table of Contents}

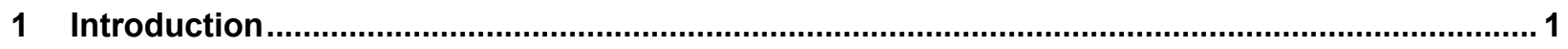

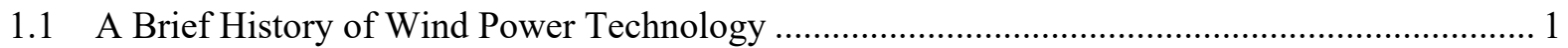

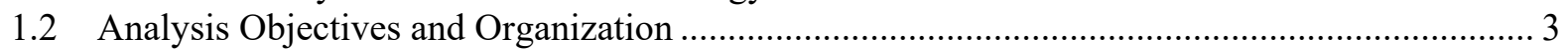

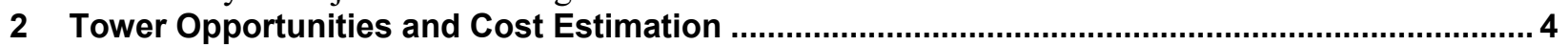

2.1 Wind Speed Change with Height Above Ground Level ........................................................... 4

2.2 Capacity Factor Change with Height Above Ground Level ......................................................... 6

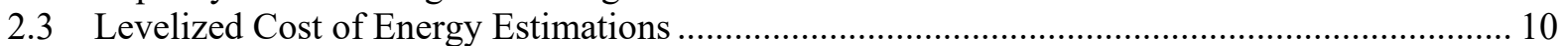

2.4 Breakeven Cost Analysis for Turbines with Taller Towers .................................................. 22

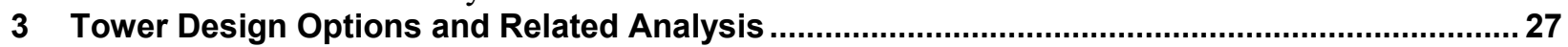

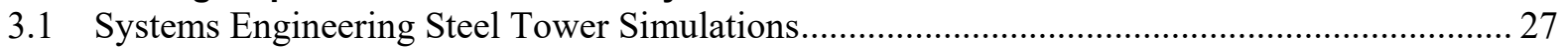

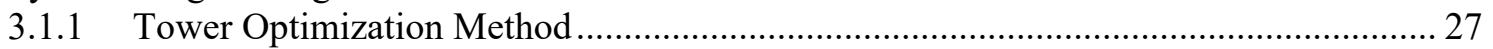

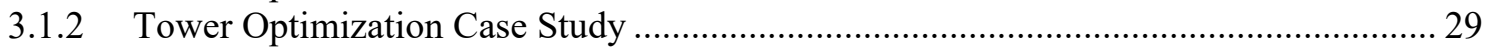

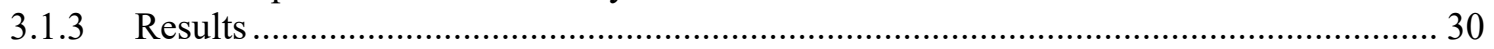

3.2 Innovation Opportunities for Additional Alternative Tall Tower Technologies........................ 32

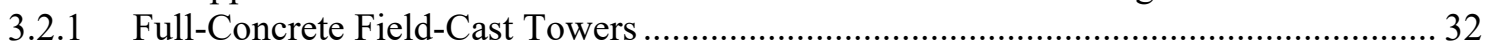

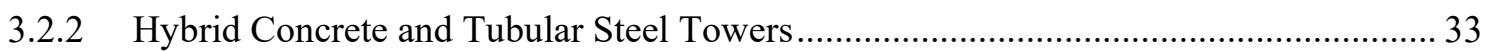

3.2.3 Lattice/Space Frame.......................................................................................... 34

3.2.4 Comparing and Contrasting Competing Tower Alternatives .................................... 35

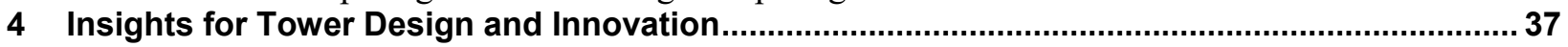

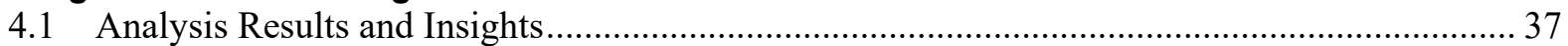

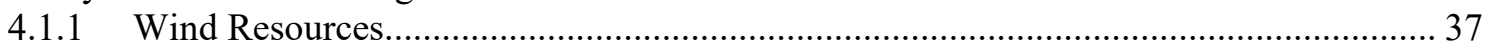

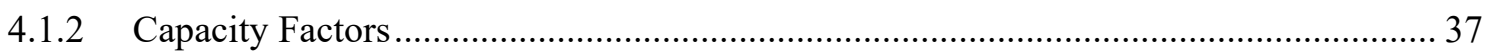

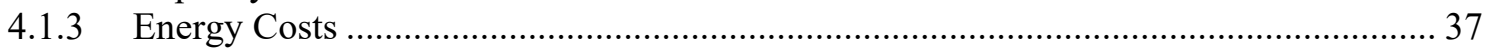

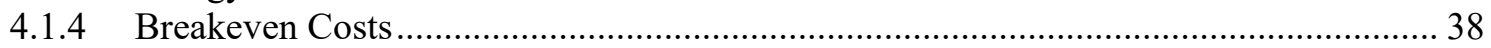

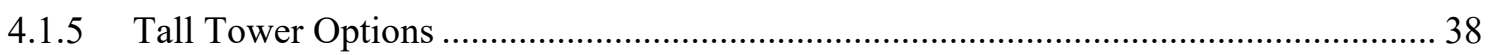

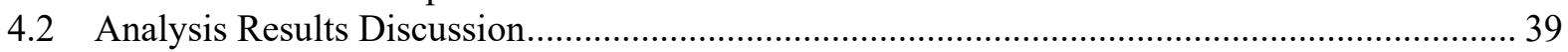

4.3 Lessons Learned for Evaluating Tall Tower Opportunities .............................................. 40

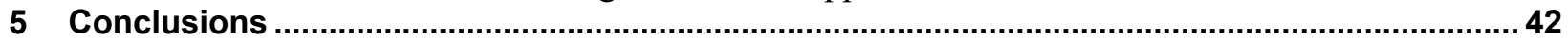

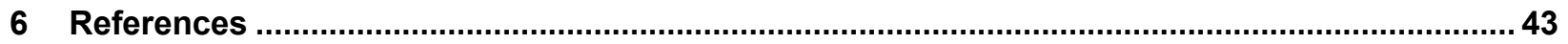




\section{List of Figures}

Figure 1. Difference in mean annual wind speed at $110 \mathrm{~m}$ above ground level relative to $80 \mathrm{~m}$, based on the Wind Toolkit....

Figure 2. Difference in mean annual wind speed at $160 \mathrm{~m}$ above ground level relative to $80 \mathrm{~m}$, based on the Wind Toolkit

Figure 3. Estimated net capacity factor, all turbines and hub heights.

Figure 4. Estimated difference in net capacity factor, all turbines and hub heights, relative to the Today turbine at $80 \mathrm{~m}$ (percentage points)

Figure 5. Estimated difference in net capacity factor, all turbines and hub heights, relative to the lowest hub height available per platform (percentage points)

Figure 6. Estimated total installed capital cost by turbine and hub height ................................... 13

Figure 7. Estimated LCOE for each Wind Toolkit pixel, assuming the Low-SP 4.5-MW turbine at a

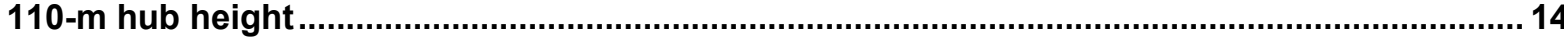

Figure 8. Estimated LCOE for each Wind Toolkit pixel, assuming the Low-SP 4.5-MW turbine at a

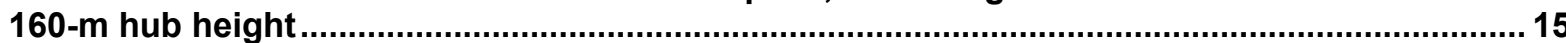

Figure 9. Estimated LCOE for each Wind Toolkit pixel; all turbines and all applicable hub heights

.

Figure 10. Estimated LCOE differences for each Wind Toolkit pixel, relative to the Today turbine

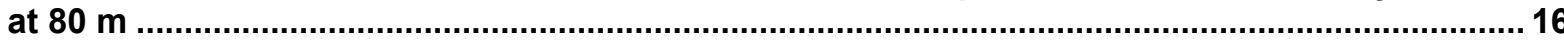

Figure 11. Calculated preferred hub height by turbine configuration, based on estimated performance and costs .............................................................................................................. 18

Figure 12. Calculated economically preferred hub heights for the Today turbine, based on estimated costs and performance

Figure 13. Calculated economically preferred hub heights for the BAU turbine, based on estimated costs and performance ...................................................................................................... 19

Figure 14. Calculated economically preferred hub height for the Low-SP 3.25-MW turbine, based

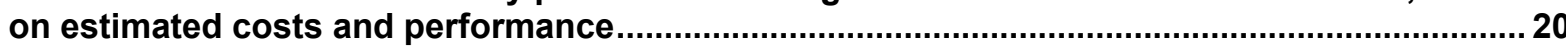

Figure 15. Calculated economically preferred hub height for the Low-SP 4.5-MW turbine, based on estimated costs and performance ........................................................................................ 20

Figure 16. Estimated LCOE differences for each Wind Toolkit pixel, assuming $\$ 200 / \mathrm{kW}$ tower

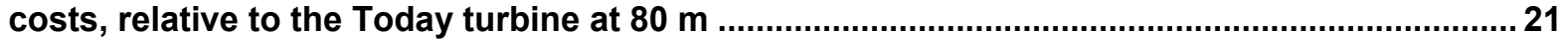

Figure 17. Calculated preferred hub height by turbine configuration, based on estimated

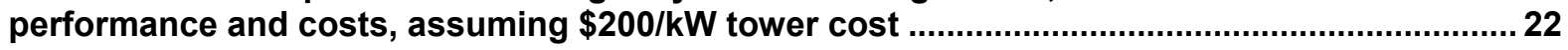

Figure 18. Breakeven costs for all turbines and all hub heights ................................................... 23

Figure 19. Estimated LCOE for the Today turbine at the 80 -m hub height ....................................... 24

Figure 20. Breakeven costs for the BAU turbine at the 110-m hub height ...................................... 25

Figure 21. Breakeven costs for the BAU turbine at the 140-m hub height ......................................25

Figure 22. Breakeven costs for the Low-SP 4.5-MW turbine at the 110-m hub height ...................... 26

Figure 23. Breakeven costs for the Low-SP 4.5-MW turbine at the 140-m hub height ..................... 26

Figure 24. Optimization results for soft-stiff tower design cases.................................................... 30

Figure 25. Optimization results for soft-soft tower design cases.................................................. 31 


\section{List of Tables}

Table 1. Turbine Configurations Used To Estimate Capacity Factors at Higher Hub Heights .......... 7

Table 2. Tower Design Variables ................................................................................................. 28

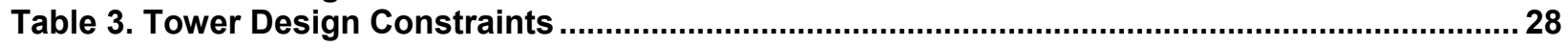

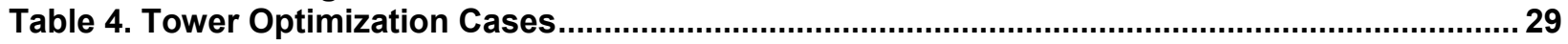

Table 5. IEA Wind Task 37 Land-Based Low Wind Speed Turbine Configuration Data ................... 29

Table A1. Detailed Levelized Cost of Energy Cost Inputs .................................................................46

Table A2. Net Capacity Factor Change Statistics, Relative to the Today Turbine at $80 \mathrm{~m} \ldots \ldots \ldots \ldots . . . . .47$

Table A3. Net Capacity Factor Breakpoints .............................................................................. 48

Table A4. Levelized Cost of Energy Summary Statistics (\$/megawatt-hour [MWh]) ........................ 49

Table A5. Levelized Cost of Energy Breakpoints ............................................................................ 50

Table A6. Average State Levelized Cost of Energy (\$/MWh) ........................................................ 51

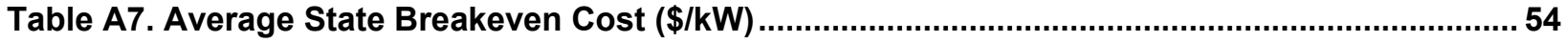




\section{Introduction}

Wind power is one of the fastest-growing sources of new electricity generation in the United States. Since the early 2000s, annual investments in new wind capacity have exceeded the billion-dollar threshold, with investments in recent years often more than $\$ 10$ billion annually. Cumulative installed capacity was estimated at more than 96 gigawatts (GW) at year-end 2018 (American Wind Energy Association [AWEA] 2019) and wind power supplied approximately $6.6 \%$ of total electricity generation in 2018 (Energy Information Administration 2019). The recent growth of the wind power industry has been spurred, in part, by innovation and subsequent reductions in costs coupled with state and federal policy support.

Looking ahead, further cost reduction is anticipated to be critical to continued economic competitiveness. This is due, in part, to competitive pressure from low-cost natural gas and solar photovoltaics (Mai et al. 2017; Dykes et al. 2017). Notably, however, with continued cost reduction, economic deployment of wind energy through 2050 could be more than $430 \mathrm{GW}$ and possibly as high as $550 \mathrm{GW}$, with wind power supplying between $38 \%$ and $46 \%$ of total electricity generation (Mai et al. 2017). Moreover, the quantity of available wind energy resource is such that the opportunity for capturing thousands of terawatt-hours of low-cost, clean wind energy remains of significant interest.

Key technology attributes enabling cost reductions realized to date include advancements that have resulted in the capture of turbine, balance of station (BOS), and operation and maintenance $(\mathrm{O} \& \mathrm{M})$ economies of scale as well as increased energy production per turbine and per unit of installed capacity. More specifically, increased energy production has been realized with taller towers that place turbines into higher-quality resource regimes as well as larger rotors that enable more of the wind passing by the turbine to be converted into electricity. Basic science research and development $(\mathrm{R} \& \mathrm{D})$ coupled with industry innovation has allowed tower height and turbine rotors to grow and increase energy capture while simultaneously eliminating excess material, improving production processes, and maintaining reliability, enabling this increased energy to be achieved at little to no capital cost penalty.

To further drive down costs, wind turbine researchers, designers, and engineers continue to pursue strategies that could use even higher hub heights to be economically attractive. Higher hub heights remain of interest due to the more energetic wind resource that exists at higher above ground levels as well as the need to provide additional clearance for increasingly long blades that maximize energy capture per turbine. In this context, the current analysis seeks to understand and explore the potential opportunity space around tall wind turbine tower technologies. We also demonstrate a new approach to analyzing technology opportunity and potential across a broad geographic area, in this case the contiguous United States. This approach is useful when evaluating wind technology given the significant spatial variability in resource quality and the impact that spatial variability has on optimal technology design.

\subsection{A Brief History of Wind Power Technology}

In the 1980s, a commercial wind turbine was approximately 100 kilowatts $(\mathrm{kW})$ in nameplate capacity and had a hub height and rotor diameter that were both on the order of 20 meters $(\mathrm{m})$. By the early 1990s, a typical commercial turbine was approximately $300 \mathrm{~kW}$ in nameplate capacity and had a hub height and rotor diameter that were both on the order of $30 \mathrm{~m}$. By the 
early 2000s, machines had achieved a nameplate capacity in excess of 1 megawatt (MW) and a rotor diameter and hub height of approximately $70 \mathrm{~m}$. Most recently, wind turbines installed in the United States in 2018 had a nameplate capacity averaging 2.4 MW, rotor diameters averaging $116 \mathrm{~m}$, and hub heights averaging about $88 \mathrm{~m}$ (AWEA 2019). In Germany, where the wind resource is often of lower quality and developable land area is more limited, designers are forced to consider energy production per unit of land area as well as cost per unit of energy among other factors, with optimums favoring larger turbines. The average nameplate capacity for projects commissioned in 2017 in Germany was $2.97 \mathrm{MW}$; average rotor diameter was $113 \mathrm{~m}$, and average hub height was $128 \mathrm{~m}$ (Deutsche WindGuard 2018). In the German context, larger machines and more design constraints (e.g., land area) have resulted in higher wind cost of energy relative to the United States (Hand et al. 2019; Vitina et al. 2015). Nonetheless, these larger turbines have proven preferable for German sites. Although design conditions and optimums in Germany differ from those in the United States and other parts of the world, the German data illustrate that under the right conditions a continued push toward higher hub heights provides value.

Driving trends in turbine configuration, scale, and cost of energy are fundamental economic considerations associated with wind turbine technology and design (Zayas et al. 2015). Historically, increased hub heights have resulted from a general trend of improved wind resource at levels higher above the ground that are less affected and slowed by surface roughness (e.g., trees, buildings) and local topography. At the fundamental level, hub height growth has been constrained by impacts on installation and erection cost, and the incremental cost of the taller tower relative to the additional energy that might be extracted from the improved wind resource quality found at higher above ground levels with the state-of-the-art turbine rotor nacelle assembly (RNA). More recently, hub height growth has also been impacted by transportation and logistics barriers that restrict the sectional tower diameter to fit under highway and railway underpasses. These transport constraints result in relatively inefficient tower designs from a material use and cost perspective, as compared to towers designed solely to meet their fundamental functional design requirements.

In the United States, there has been a partial plateau in tower or hub height scaling (Wiser and Bolinger 2018). The leveling off of tower height is in part a function of the excellent wind resource available in the interior region of the United States and a function of the logistics and transport trends noted earlier - which require substantially greater quantities of steel at higher hub heights to maintain sufficient stiffness while adhering to the transport-dictated sectional diameter constraints. With respect to the former, the world-class wind resource present in the interior region of the United States - even at levels of $80 \mathrm{~m}$ above ground level - has allowed projects using modern technology to achieve performance levels that support levelized cost of energy (LCOE) values at or below $\$ 40 /$ megawatt-hour (MWh) to $\$ 45 / \mathrm{MWh}$ (excluding the production tax credit). These performance levels have positioned wind to be competitive at $80-\mathrm{m}$ hub heights as a fuel-saving, electricity-generating technology over the past several years, with the federal production tax credit in place.

This is not to suggest that the incentives for continuing to pursue tall wind have diminished, rather that it simply has become more difficult to reap the rewards of turbine scaling as a result of additional constraints that must be addressed as well as the increasingly complex construction requirements of very large turbines. This is particularly true in regions that have very good 
resources at the heights above ground that are within reach of modern wind industry original equipment manufacturers (OEMs), as well as readily available transport and logistics capabilities. Evidence for the continued pursuit of tall wind in the United States exists in recent turbine offerings from the top-three global wind turbine OEMs: Vestas, GE, and Siemens. Combined, these three OEMs captured more than $90 \%$ of the U.S. market (AWEA 2017). In 2016, each of these OEMs began marketing turbines in the 3-MW class, with rotor diameter offerings from approximately $100 \mathrm{~m}$ to $140 \mathrm{~m}$, and tower heights from $75 \mathrm{~m}$ to $165 \mathrm{~m} .{ }^{1}$

\subsection{Analysis Objectives and Organization}

This report has two primary objectives. First, it seeks to inform the opportunities and potential associated with increasing wind turbine hub heights. It also explores the conditions and locations where taller towers offer the most significant potential to increase wind technology performance and reduce costs. This initial objective is discussed in Section 2. The second objective is to examine the status of tall tower technology as a key subcomponent of wind power advancement. This objective is discussed in Section 3, where we analyze the potential for continued innovation in tubular steel wind turbine towers and explore the status and potential for a select set of alternative tall tower technologies. Key findings and lessons learned are covered in Section 4. A brief summary and final conclusions are found in Section 5. The appendices include more resolved data on estimated LCOE, capacity factor change with height above ground, and breakeven cost.

\footnotetext{
${ }^{1}$ Recent increases in the turbine scale and hub heights now being offered by OEMs generally are perceived to have been made more feasible by advanced turbine controls that allow the machines to avoid certain portions of the operating envelope that resulted in more conservative design requirements. Looking ahead, the opportunities created by continued evolution of advanced controls deserve continued attention and tracking.
} 


\section{Tower Opportunities and Cost Estimation}

To begin to understand the potential for higher hub heights as a source of further wind power cost reduction, the authors assessed how taller towers could impact key indicators of wind energy viability across the nation. We begin by examining the change in wind speed that is achieved by increasing hub height from a baseline of $80 \mathrm{~m}$ typical of today's commercial installations to $110 \mathrm{~m}$ and $160 \mathrm{~m}$ across the contiguous United States. Second, we quantify the impact this wind speed change could have on wind power capacity factors by estimating wind energy production for four wind turbine configurations. We conclude this portion of the analysis by estimating LCOE for these four turbine configurations and evaluating which hub height for each configuration tends to have the lowest LCOE, using cost and scaling estimates informed by recent state-of-the-art technology. LCOE and tower height preferences are also estimated for a sensitivity scenario wherein wind turbine tower costs are fixed at levels of $\$ 200 / \mathrm{kW}$, even while turbines are able to scale and access hub heights up to $160 \mathrm{~m}$. This additional sensitivity helps to inform the potential LCOE and preferred tower heights that might be achieved if tower R\&D and innovations are very successful.

\subsection{Wind Speed Change with Height Above Ground Level}

As a first step in characterizing the opportunity offered by achieving higher hub heights than the typical 80-m hub height for turbines installed in the United States over the past decade, we utilized wind speed data from the National Renewable Energy Laboratory (NREL) Wind Integration National Dataset (Wind) Toolkit (https://www.nrel.gov/grid/wind-toolkit.html) to compare differences in mean annual wind speeds at each pixel or site within the contiguous United States. The Wind Toolkit is a mesoscale wind-resource data set that was funded by the U.S. Department of Energy, Office of Energy Efficiency and Renewable Energy, Wind Energy Technologies Office, and created through the collaborative efforts of NREL and 3TIER. ${ }^{2}$ The data set includes meteorological data, including wind speed for more than 1.85 million locations in the contiguous United States for a period of 7 years between 2007 and 2013. Each pixel in the Wind Toolkit represents a 2-km-by-2-km grid cell. The data are generated by meteorological models that have used real-world historical input data to recreate a complete suite of output data to be used in analysis and research. The Wind Toolkit has wind speed data for multiple hub heights. For this analysis, we consider hub heights of $80 \mathrm{~m}, 110 \mathrm{~m}, 140 \mathrm{~m}$, and $160 \mathrm{~m}$ above ground level, and relied on data from the 2012 calendar year.

A significant caveat to these results that extends throughout the analysis is that the uncertainty in the wind speed data from the Wind Toolkit is not fully understood or characterized, particularly as one moves to higher above ground levels (e.g., $140 \mathrm{~m}$ and $160 \mathrm{~m}$ ). Moreover, the analysis conducted here focuses only on the 2012 weather year. Some variability in the results therefore is likely when considering normal interannual resource variability. Anecdotal evidence from limited site-specific validation suggests that in some locations the uncertainty in the mesoscale data is large (e.g., potentially in excess of 1 meter per second $[\mathrm{m} / \mathrm{s}]$ ). Although the impact of this uncertainty is sizable and important and would undoubtedly impact the precise quantitative outcomes from the analysis, the broad trends and qualitative outcomes from the work are

\footnotetext{
${ }^{2}$ In the years since the Wind Toolkit was developed, 3TIER has been acquired by Vaisala http://knowledge.vaisala.com/3TIER (accessed March 6, 2019).
} 
generally useful in understanding the opportunity offered by further increases in hub heights for the wind turbines evaluated here.

Figure 1 and Figure 2 illustrate the difference in mean annual wind speed in the Wind Toolkit when comparing $80-\mathrm{m}$ and $110-\mathrm{m}$ hub heights and $80-\mathrm{m}$ and $160-\mathrm{m}$ hub heights, respectively. These data show that nearly all regions of the country observe wind speed increases when moving to $110 \mathrm{~m}$. Minor exceptions in this regard are in small isolated pockets in the Southwest and in California. These "negative" wind-shear locations have relatively rare topographical and meteorological patterns that drive these anomalies. West of the Rocky Mountains, the wind speed increase is largely in the $0-$ to $0.5-\mathrm{m} / \mathrm{s}$ increase category at $110 \mathrm{~m}$. With the exception of the mountainous regions (e.g., along the Appalachian Mountains; the Ouachita Mountains of West Central Arkansas) and Florida, the portion of the country that falls east of the Rocky Mountains primarily sees a wind speed increase of 0.5 - to $1.0-\mathrm{m} / \mathrm{s}$ when moving from 80 to 110 $\mathrm{m}$.

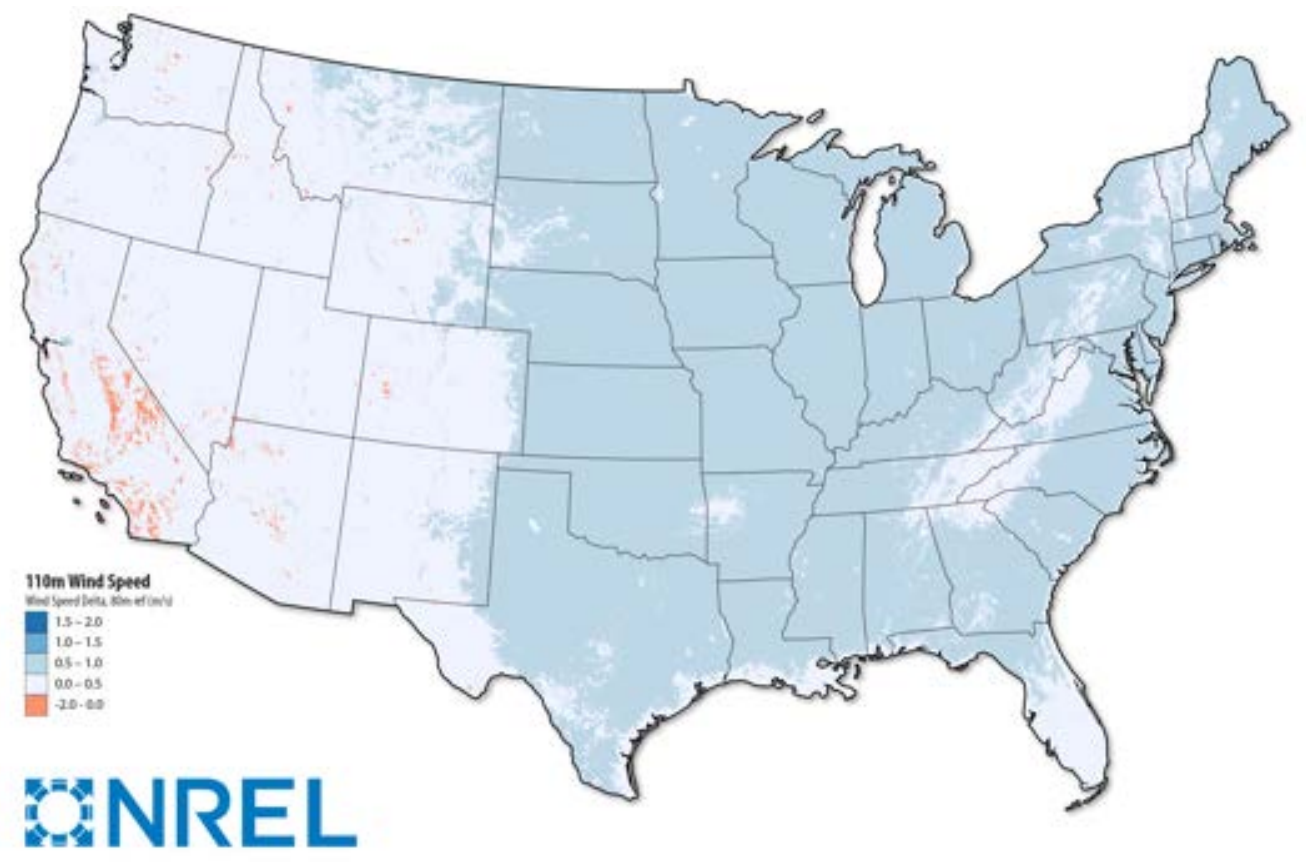

Figure 1. Difference in mean annual wind speed at $110 \mathrm{~m}$ above ground level relative to $80 \mathrm{~m}$, based on the Wind Toolkit 


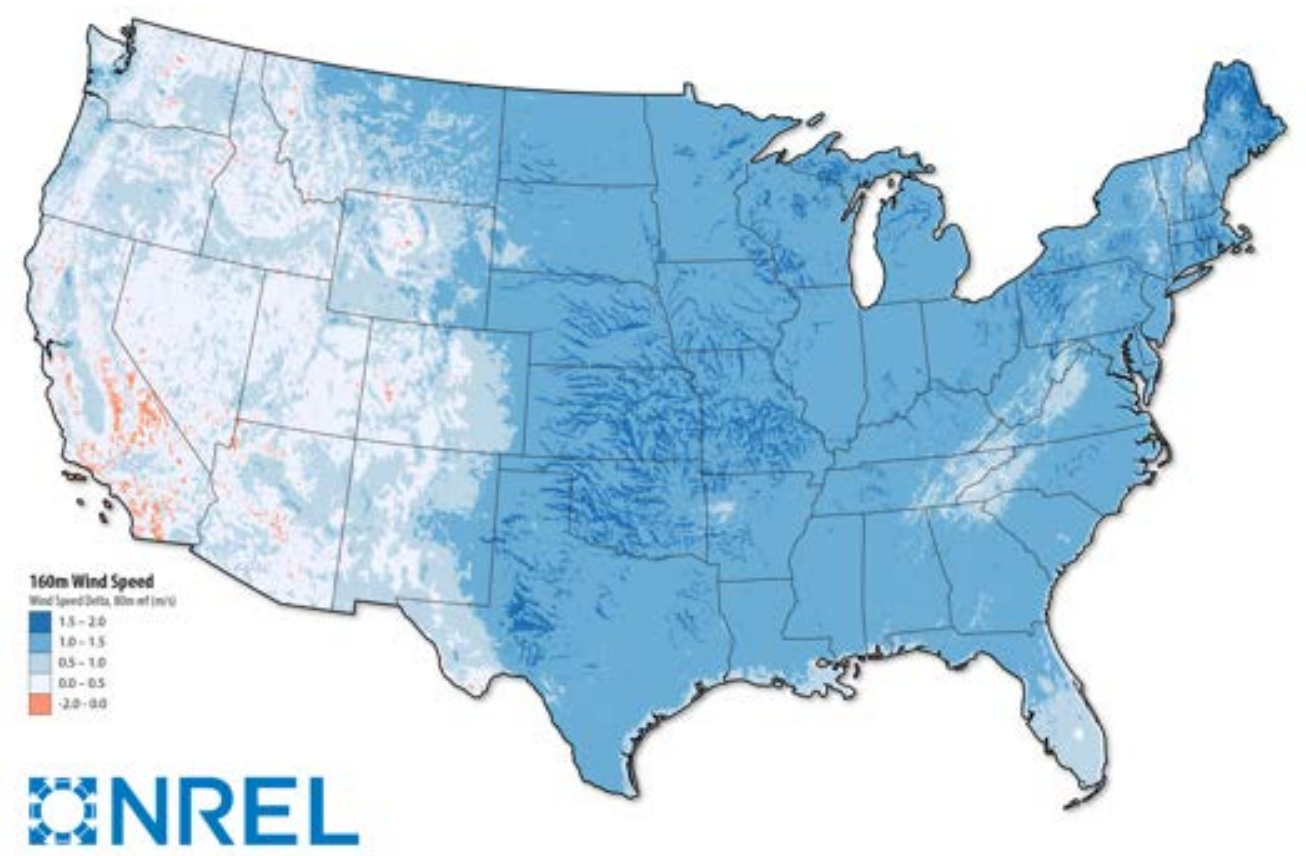

Figure 2. Difference in mean annual wind speed at $160 \mathrm{~m}$ above ground level relative to $80 \mathrm{~m}$, based on the Wind Toolkit

When moving from 80 to $160 \mathrm{~m}$, the results are more pronounced and heterogenous. In much of the Interior West between the Rockies and the Sierra Nevada ranges, the improvements are still in the 0 - to $0.5-\mathrm{m} / \mathrm{s}$ increase category but scattered throughout, and in a loose ring around this region significant portions see increases in wind speed that are in the $0.5-$ to $1.0-\mathrm{m} / \mathrm{s}$ category. Moving east from the Rocky Mountains, when comparing $80 \mathrm{~m}$ with $160 \mathrm{~m}$ greater increases $(1.5-2.0 \mathrm{~m} / \mathrm{s})$ can be observed in the lower-lying portions of the central plains, in particular in the river valleys of Oklahoma, Kansas, and Nebraska, as well as along the upper Mississippi River Valley on the borders of Minnesota, Wisconsin, and Iowa. Increases of this magnitude also show up in Southwestern Texas, Missouri, and parts of Arkansas. The remaining portions of the Great Plains generally are in the $1.0-$ to $1.5-\mathrm{m} / \mathrm{s}$ category.

Moving further east, the mountainous regions of Tennessee and surrounding states continue to exhibit a $0-0.5 \mathrm{~m} / \mathrm{s}$ increase in wind speed. These regions, however, are surrounded by larger areas that observe increases that are more broadly in the $1.0-$ to $1.5-\mathrm{m} / \mathrm{s}$ range. Pennsylvania, New York, and Maine see a broad range of increases, with some areas in the $0.5-$ to $1.0-\mathrm{m} / \mathrm{s}$ category, some in the $1.0-$ to $1.5-\mathrm{m} / \mathrm{s}$ category, and some in the $1.5-$ to $2.0-\mathrm{m} / \mathrm{s}$ category.

In general, these data suggest that the value of achieving higher hub heights - at least according to differences in mean annual wind speed - is widespread but most significant east of the Rocky Mountains. Within that region, the largest increase in wind speeds appear to be in the relatively low-lying areas that fall in otherwise very windy regions (e.g., the river valleys of the Great Plains).

\subsection{Capacity Factor Change with Height Above Ground Level}

As a second step in understanding the potential value associated with placing wind turbines at higher hub heights, we used hourly wind speed data from the Wind Toolkit coupled with four 
wind turbine power curves to estimate potential energy generation and capacity factors for these four turbines at multiple hub heights. Net capacity factors were estimated assuming a simple $16.7 \%$ losses adjustment, which reflects a combination of array and electrical losses as well as turbine downtime.

The four modeled turbines used to estimate capacity factors were intended to represent state-ofthe-art technology available today as well as potential turbines of tomorrow (Table 1). Our "Today," or reference turbine, was calculated from the average nameplate capacity and rotor diameter of turbines installed in the United States in 2017 (Stehly et al. 2018). This composite turbine was 2.3 MW and had a rotor diameter of $113 \mathrm{~m}$, resulting in a specific power of approximately 231 watts $(\mathrm{W}) / \mathrm{m}^{2}$. Our business as usual (BAU) turbine was intended to reflect turbine technology that under BAU or median conditions is expected to be the average turbine installed around the United States by 2030. This turbine was derived from the simple extrapolations of historical trends for turbines installed in the United States and has a nameplate capacity of 3.3 MW and a rotor diameter $156 \mathrm{~m}$, resulting in a specific power of approximately $173 \mathrm{~W} / \mathrm{m}^{2}$.

Two additional turbine concepts reflect potential future turbines in the 3-MW and 4- to 5-MW class, respectively, that are "low specific power," or Low-SP, turbines with specific power of approximately $150 \mathrm{~W} / \mathrm{m}^{2}$. These turbine configurations were selected based on recent trends suggesting continued pursuit by turbine designers and researchers of relatively low specific power wind turbines (Wiser and Bolinger 2018). Given these trends, we sought to understand how turbines with even lower specific power relative to our Today and BAU configurations might compare and contrast, in terms of their ability to extract value from higher hub heights. Including configurations in the 3- to 5-MW range also helps to illuminate potential value from coupled turbine scaling and hub height increase.

Table 1. Turbine Configurations Used To Estimate Capacity Factors at Higher Hub Heights

\begin{tabular}{lcccc}
\hline & Today & BAU & Low-SP 3.25 MW & Low-SP 4.5 MW \\
\hline Nameplate CapacitTy $(\mathbf{M W})$ & 2.32 & 3.30 & 3.25 & 4.50 \\
Rotor Diameter $(\mathbf{m})$ & 113 & 156 & 166 & 194 \\
Specific Power $\left(\mathbf{W} / \mathbf{m}^{2}\right)$ & 231 & 173 & 150 & 152 \\
\hline
\end{tabular}

To estimate the capacity factor change associated with each increased hub height, a turbine power curve was calculated for each defined turbine configuration. These power curves were then applied to the 2012 hourly wind speed data for each of the 1.85 million Wind Toolkit sites or "pixels." This process was completed at four hub heights for the Today turbine: $80 \mathrm{~m}, 110 \mathrm{~m}$, $140 \mathrm{~m}$, and $160 \mathrm{~m}$. Only three hub heights were considered for each of the other turbine configurations: $110 \mathrm{~m}, 140 \mathrm{~m}$, and $160 \mathrm{~m}$ to allow for ground clearance when the turbine blades come closest to the ground. Notably, the Low-SP 4.5-MW turbine with an approximately 95-m blade likely does not have sufficient ground clearance to be commercially deployed at a 110-m hub height. Nevertheless, these data were included in the analysis results to help us understand what the opportunity could be at this hub height. The resulting data were then plotted by capacity 
factor and frequency to understand the potential capacity factors across the continental United States for each turbine configuration and each hub height.

Spatially, capacity factor trends are closely aligned with the wind speed increases displayed in Section 2.1. Figure 3 illustrates the range and distribution of specific capacity factor improvements for the four modeled turbines at each of the respective hub heights where they were analyzed. Figure 4 illustrates the differences in capacity factor in percentage points for each location in the Wind Toolkit data set for each turbine configuration and hub height, relative to the Today turbine at $80 \mathrm{~m}$. In effect, these data illustrate the potential capacity factor difference relative to current state-of-the-art technology and project norms. Figure 5 is similar to Figure 4 except that in Figure 5 the change in capacity factor is calculated relative to the lowest available hub height for a given turbine platform. In general, increases in hub height shift the resulting capacity factors to higher values. In many cases, as hub height changes, the frequency of certain capacity factors is also changed. For the Today turbine, there is a noticeable shift to the right as one moves from $80 \mathrm{~m}$ to $110 \mathrm{~m}$ and to $140 \mathrm{~m}$. The increase between 140 and $160 \mathrm{~m}$ is more subtle. Similar trends are observed when moving between 140 and $160 \mathrm{~m}$ for the BAU and LowSP turbines.

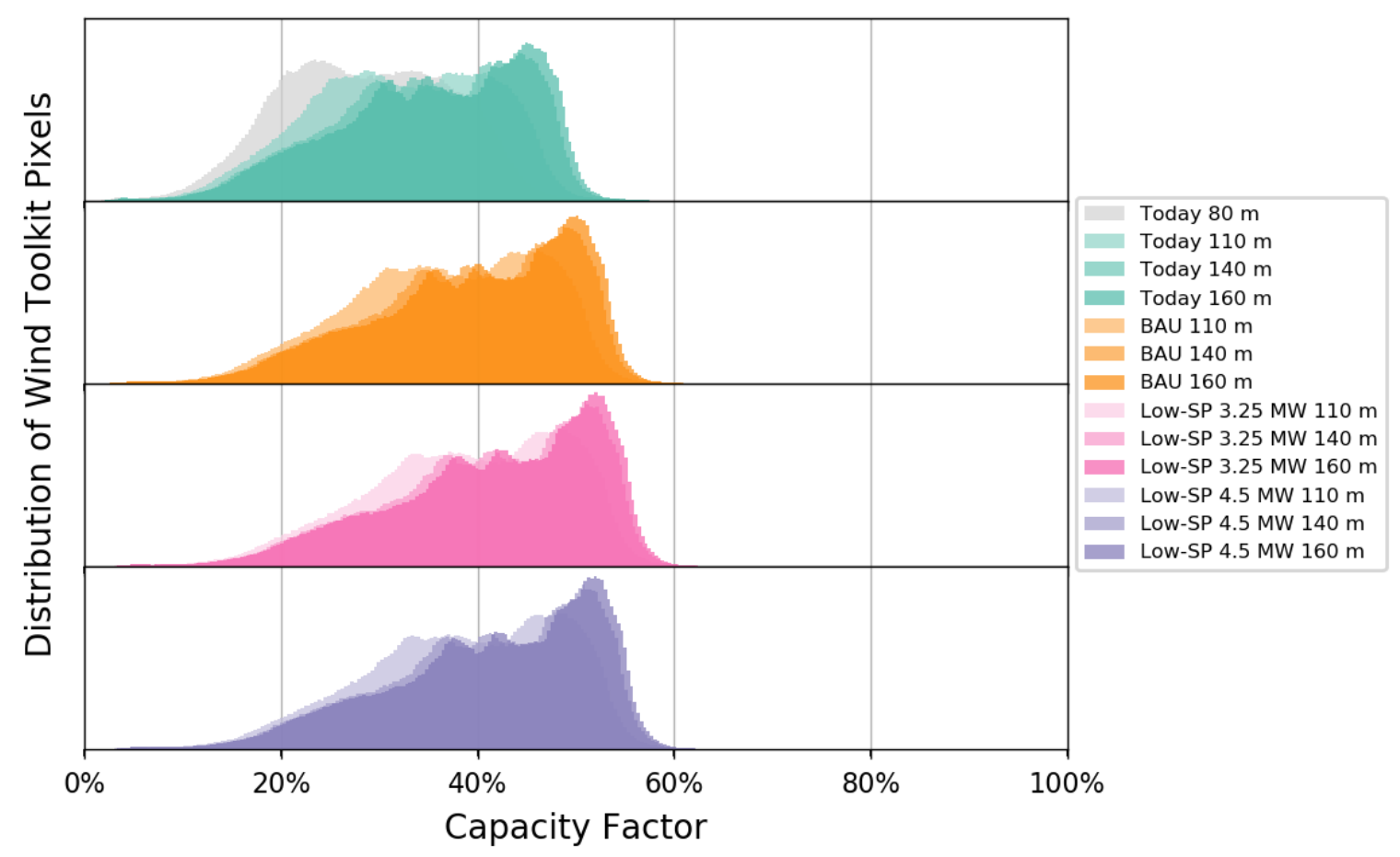

Figure 3. Estimated net capacity factor, all turbines and hub heights 


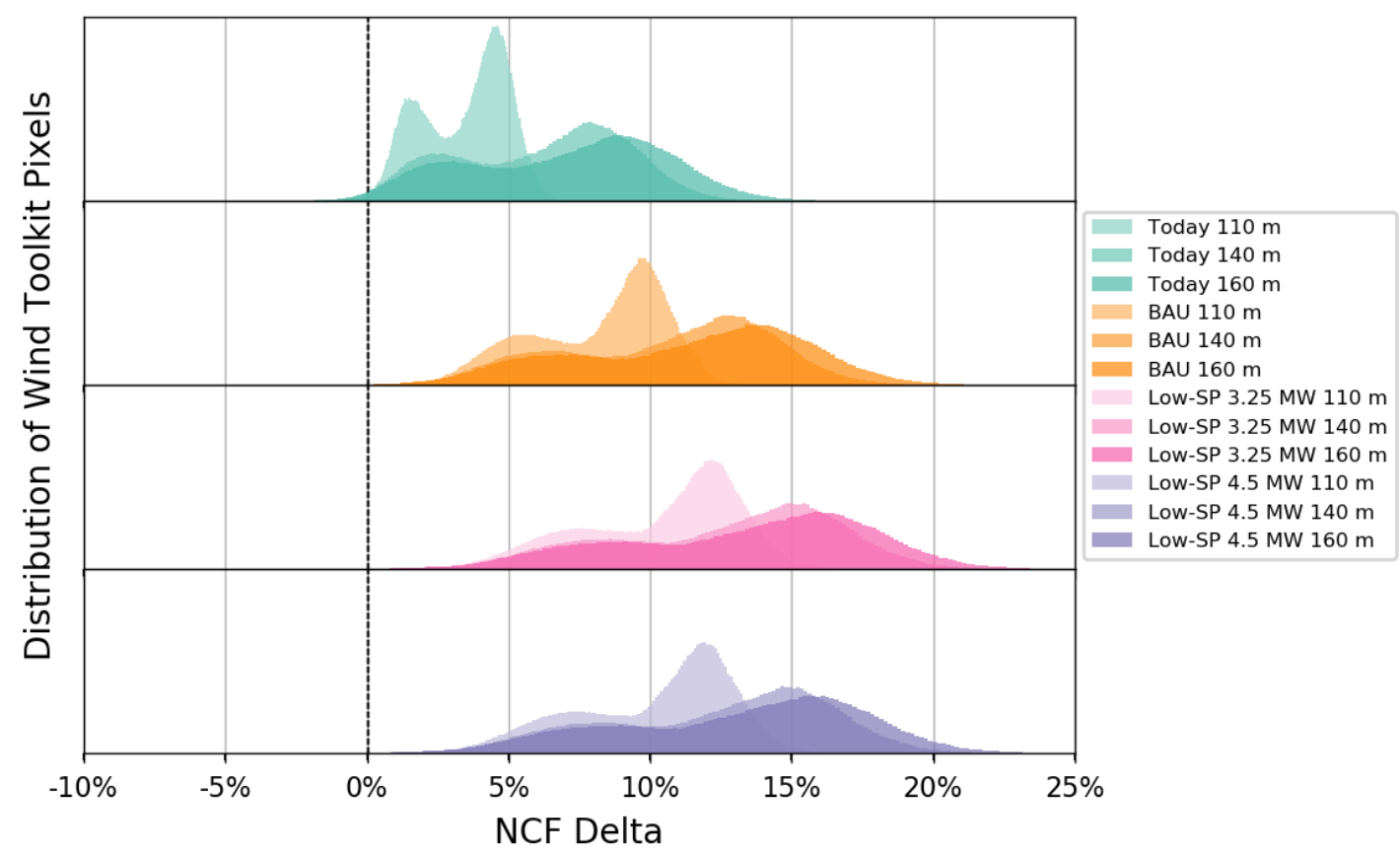

Figure 4. Estimated difference in net capacity factor, all turbines and hub heights, relative to the Today turbine at $80 \mathrm{~m}$ (percentage points)

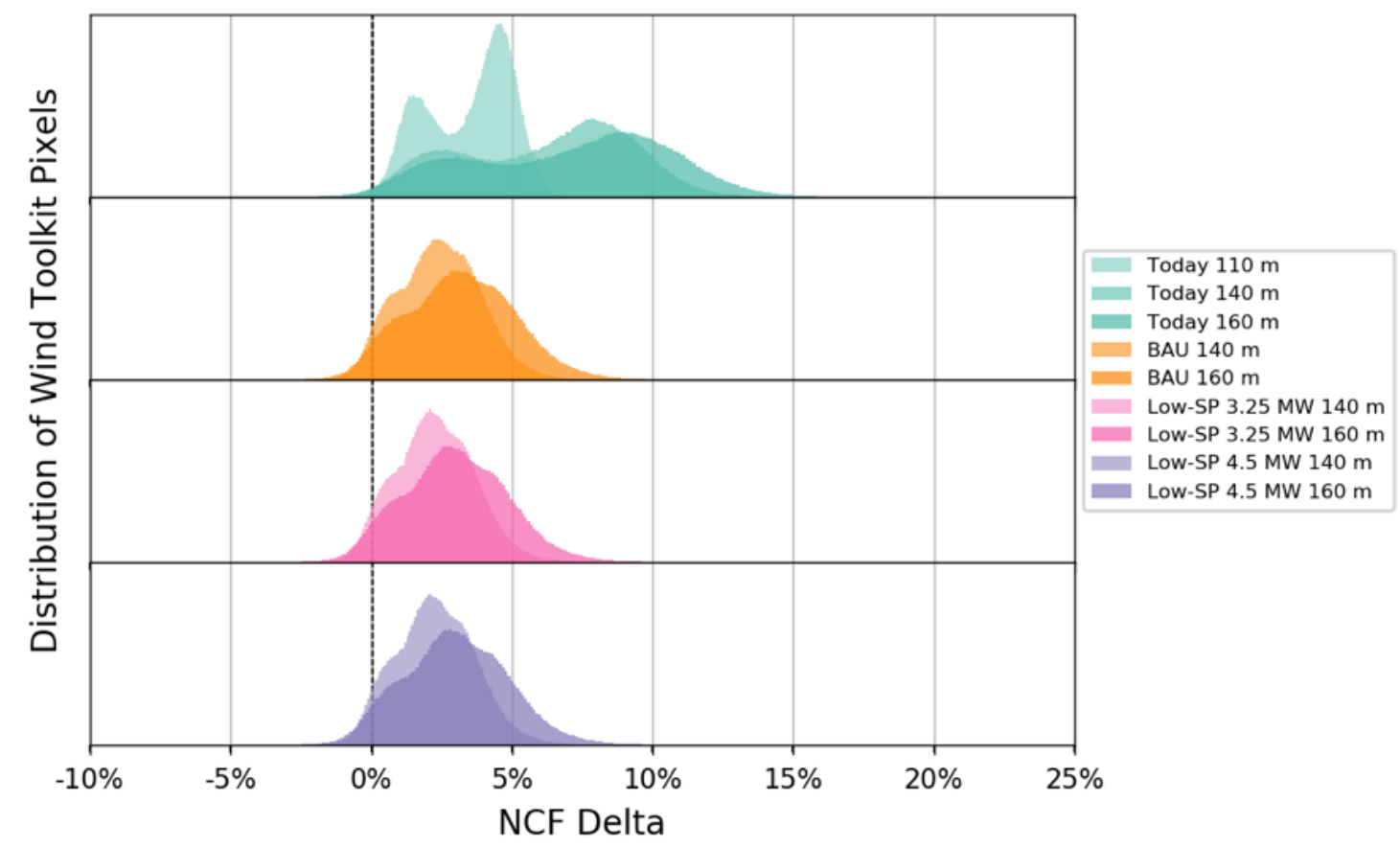

Figure 5. Estimated difference in net capacity factor, all turbines and hub heights, relative to the lowest hub height available per platform (percentage points)

Not surprisingly, the highest capacity factors are observed at $160 \mathrm{~m}$ and with the Low-SP turbines. Even at the higher specific power platforms of the Today and BAU turbines, however, the 160-m hub height yields substantial quantities of sites with $40 \%$ or greater capacity factors. For the Low-SP turbines, however, a significant number of sites have capacity factors even 
greater than $50 \%$; approximately $60 \%$ of the resource sites for these turbines have a capacity factor greater than $40 \%$.

In terms of capacity factor differences, the BAU turbine configuration has a large number of sites that are approaching a $10 \%$ increase in capacity factor relative to the Today turbine at $80 \mathrm{~m}-$ even with a move to only $110 \mathrm{~m}$. The Low-SP configurations see a large quantity of resource sites that exceed the $10 \%$ improvement level at $110 \mathrm{~m}$ relative to the Today turbine at $80 \mathrm{~m}$, and many sites approach a $15 \%$ increase at $140 \mathrm{~m}$. Based on the Wind Toolkit data, the benefit of achieving 160-m above-ground-level hub heights is estimated at approximately 1 percentage point in capacity factor, relative to $140 \mathrm{~m}$.

Focusing on the comparison in Figure 5, to the lowest available hub or tower height by platform, it is evident that the higher specific power Today turbine actually sees the largest magnitude of improvement in capacity factor from moving to higher hub heights. Although the lower specific power BAU and Low-SP turbines have higher absolute capacity factors, they also spend more time at full rated power, which limits their ability to increase annual energy production merely by increasing hub height. Of course, one must be cautious not to focus solely on the magnitude of the change as such characterizations can be overstated when comparing against a low value reference or starting point. Although somewhat more obscure, this effect can also be observed in the following LCOE analysis by noting that for a given platform, preferences for taller towers are somewhat lower with lower specific power.

\subsection{Levelized Cost of Energy Estimations}

Data and analysis presented thus far have focused on the energy production potential associated with realizing higher wind turbine hub heights. Achieving these higher hub heights, however, would - all else being equal — require additional capital cost expenditure because of additional tower material requirements and increased BOS cost increases associated with lifting the nacelle and rotor to these higher above-ground-level heights. ${ }^{3}$ It is this trade-off between incremental capital cost expenditure and incremental energy production, ${ }^{4}$ coupled with the overall cost of energy for a given site, that ultimately determines the hub heights for commercial wind farms. Here, our analysis begins to shed light on the potential outcomes of this trade-off, as a function of LCOE, for all resource sites in the Wind Toolkit.

Given significant uncertainty in the potential costs of the turbine technology and plants modeled, we do not anticipate our results to be the final word on LCOE or the relative competitiveness of tall wind towers. Instead, this section seeks to establish a method for examining the potential for higher hub heights from a continental perspective with computed LCOE results based on a firstorder set of cost assumptions. The results presented should be thought of more as scenarios with the findings contingent on the assumptions associated with the stated scenario. Additional follow-on work to further refine the cost characterizations and LCOE results is strongly

\footnotetext{
${ }^{3}$ Notably, this latter cost increase could be partially or fully offset by moving to a larger nameplate capacity (e.g., relative to the Today turbine), which for a fixed plant capacity results in fewer turbine lifts and roads and potentially reduced cabling requirements. Analysis to date suggests that indeed balance-of-station (BOS) cost savings associated with achieving higher nameplate capacity turbines could offset a potential BOS cost increase associated with installing nacelles and rotors on hub heights up to $160 \mathrm{~m}$.

${ }^{4}$ In reality, it is the balance between incremental cost and incremental power sales. Where there may be transmission capacity or energy constraints, the timing of any potential energy production increase is also important.
} 
encouraged. Notwithstanding these caveats, the results do provide an indicator of the potential value of achieving higher hub heights across the continental United States.

In addition to the uncertainty in the potential costs of future tall tower technologies and the evaluated tower heights, it is important to note that our cost estimates are primarily scaled from recent vintage wind turbine technology cost and scaling trends. They do not consider the potential for future innovations to impact cost and scaling functions for any turbine subsystem, including towers.

In effect, the analysis represents an LCOE assessment based on extrapolation from recent scaling trends. To the extent that these trends are not indicative of innovation potential for the tower, the results will be biased toward relatively shorter towers. In other words, these results reflect a technology and cost snapshot based on scaling relationships of recent technology; in this sense, they should be somewhat indicative of the calculations and decisions that the development community has made in the very recent past. However, they may be less indicative of the calculations and decisions made in the future, as innovations that improve upon recent technology could have greater preference for tall towers.

To evaluate potential LCOE impacts associated with increased hub heights, we first estimated the installed capital cost for each turbine configuration at each hub height analyzed in Section 2.2. To characterize turbine capital cost, we used the 2015 NREL Cost and Scaling Model (CSM), which is a part of the larger NREL Wind Plant Integrated Systems Design and

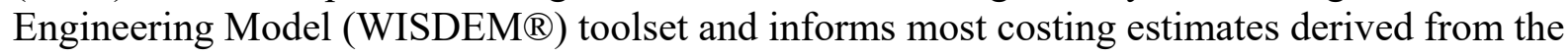
modeling toolset. The 2015 NREL CSM uses empirically derived-based on industry data points and semistructured interviews - component-level scaling relationships to ascertain the potential change in component costs associated with both higher hub heights and changes in rotor size. Given the vintage of the model and the related empirical data, these relationships are expected to be generally indicative of state-of-the-art technology from the 2012-2014 period.

One update made to the default scaling relationships was in the blade mass scaling exponent. For this analysis, we apply a mass-scaling exponent of 2.2. This is based on more recent (2018) direct input from turbine designers and blade manufacturers, acquired in the parallel and ongoing U.S. Department of Energy "Big Adaptive Rotor" project. Estimated tower costs calculated in the model are believed to be somewhat optimistic relative to historical turbine installations, but anecdotal evidence suggests they may be conservative relative to emerging tall tower solutions under development today. The estimated nacelle and drivetrain costs are believed to be conservative, particularly for larger turbines, given the applied empirical data in the model indicating that larger nameplate turbines may actually be more competitive than suggested here. An additional caveat in this cost characterization is that the 2015 NREL CSM does not consider potential changes in loads associated with these configurations. Changes in mass, and subsequently cost, are calculated based on the empirical scaling functions, not engineering analysis of specific designs or loads. Overall, this approach represents a relatively basic estimation of potential costs but provides an initial starting point for understanding LCOE impacts of these technological changes.

To characterize plant BOS costs, we used the NREL Land Balance of Station Systems Engineering (LandBOSSE) model. This model was developed in calendar year 2018 and, on 
December 20, 2018, initially was released to the public as version 1.0. To date, the model has been used and verified internally, and validated by a limited set of industry contacts during development. The LandBOSSE model is a process-based model that allows us to capture potential cost increases associated with lifting the rotor and nacelle to greater above-ground heights, as well as the potential cost savings associated with fewer lifts overall, as a function of increased turbine nameplate capacity.

The model in its current form is relatively comprehensive but has only simplistic collectionsystem cost algorithms and does not capture site access or transport and logistics costs.

Moreover, the modeling approach applied assumes flat terrain. Moving very large cranes capable of lifting components to $160 \mathrm{~m}$ is difficult and risky, and moving cranes in complex terrain could require complete disassembly and reassembly for each turbine installation. These additional costs for complex terrain were not captured here. Additionally, we assumed that the nacelle will be split into 80-ton lifts, as some of the world's largest mobile crawler cranes will be required for these lifts. Correspondingly, investigations into alternative erection technologies is suggested for future research. BOS estimates developed here assume 100 turbines in all cases but normalize costs to $\$ / \mathrm{kW}$ for the purposes of calculating total capital expenditures (CapEx). Depending on actual power plant sizes, this approach might overstate potential economies of scale for largercapacity facilities. Due diligence conducted since these results were developed suggests that the estimated economies of scale embedded in these results are not likely to impact the qualitative results as the captured economies of scale for larger turbines remain significant even when applied to a fixed-capacity plant. Nevertheless, based on these modeling simplifications and limitations, the BOS benefit from larger turbines can be characterized as somewhat optimistic, and future research on BOS cost impacts is encouraged.

Based on the version 1.0 LandBOSSE model and the simplifying assumptions noted earlier, we estimate that the Today turbine would require an approximate $11 \%$ increase in BOS cost to move from $80 \mathrm{~m}$ to $160 \mathrm{~m}$. The cost would change similarly for the BAU and Low-SP turbines to move from $110 \mathrm{~m}$ to $160 \mathrm{~m}$. For the BAU and Low-SP turbines, however, this cost essentially is offset by the reduced number of turbines required to achieve a fixed plant size (e.g., $100 \mathrm{MW}$ ). In fact, the estimated cost savings from increased turbine size drives a calculated net savings in BOS cost, at least on a $\$ / \mathrm{kW}$ basis, for the larger turbines, ranging from $10 \%$ for the BAU and Low-SP 3.25-MW turbines to nearly 35\% for the Low-SP 4.5-MW turbine-even at $160 \mathrm{~m}-$ relative to the Today turbine at $80 \mathrm{~m}$.

Estimated total CapEx values based on the first-order cost characterization described earlier are shown in Figure 6, with a more detailed tabular breakdown provided in Appendix A. Based on CapEx alone, these data show the relative competitiveness of the Today turbine at $80 \mathrm{~m}$ as well as the relative BOS savings associated with larger turbine nameplate capacities, particularly in moving toward the higher hub heights. These cost estimates are best utilized to provide a context for how the capacity factor benefits associated with higher hub heights might begin to translate into LCOE impacts assuming basic scaling of costs from recent vintage technology. 


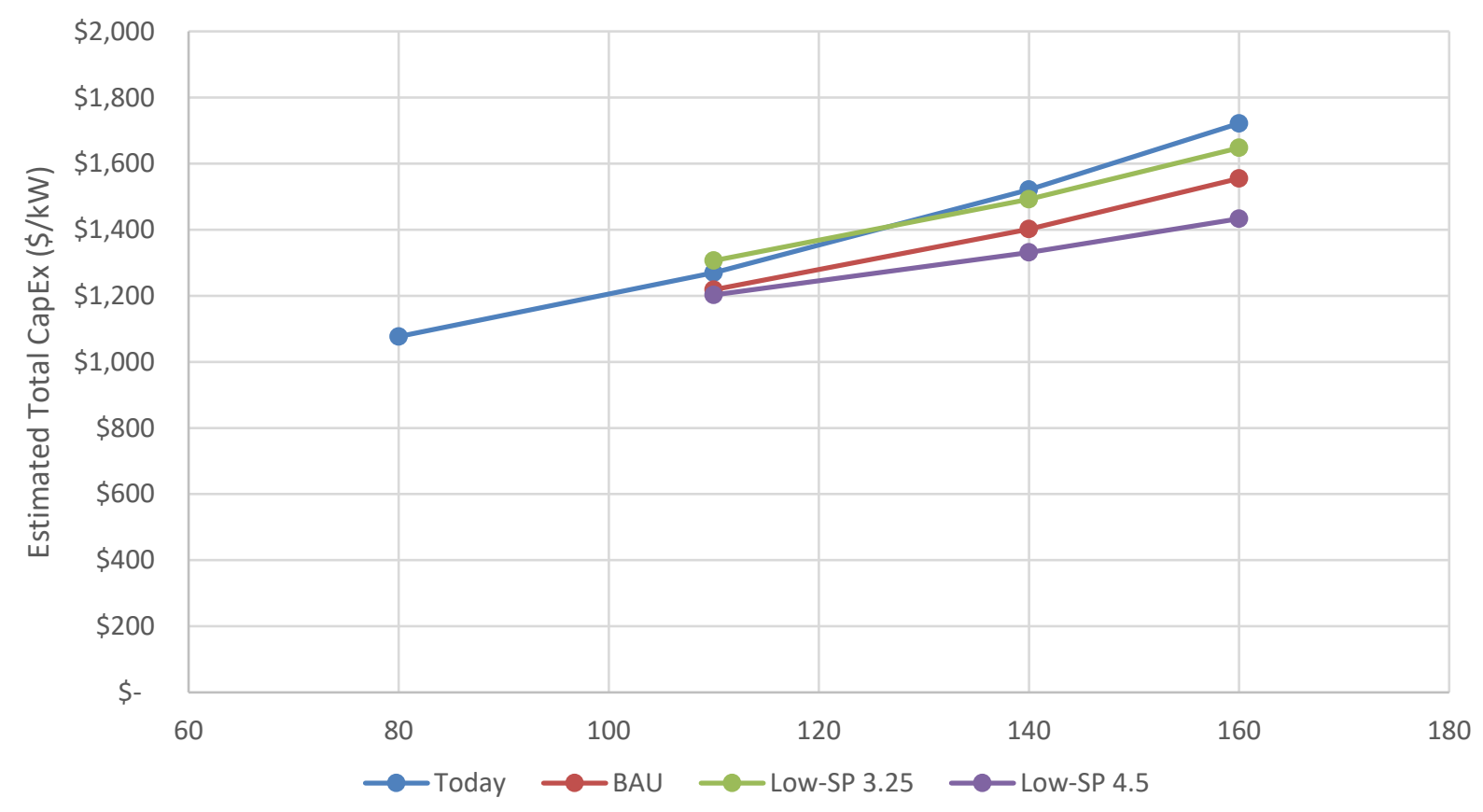

Figure 6. Estimated total installed capital cost by turbine and hub height

The next step in assessing potential LCOE impacts was to estimate the remaining LCOE input variables, specifically operational expenditures $(\mathrm{OpEx})$ and the fixed charged rate, a term that allows us to annualize the total capital cost estimate, considering the cost of capital (i.e., weighted-average cost of capital) as well as the relevant tax treatment, in terms of tax on assumed revenue and allowable depreciation. For these two values, we use an estimated $\$ 41 / \mathrm{kW}$ for OpEx, as informed by Wiser et al. (forthcoming) and Stehly et al. (2018) and 8\% for the real fixed charge rate, commensurate with an implied nominal, after-tax weighted-average cost of capital of approximately $6.4 \%$, and an implied real, after-tax weighted-average cost of capital of approximately $3.9 \%$. Note that OpEx could increase for higher hub heights assuming all else remains equal and no improvements in reliability, as larger component replacements - such as gearboxes, main bearings, and blades - require larger cranes or greater labor costs for up-tower repairs. Additional downtime and lost revenue could also erode the capacity factor benefit estimated here.

The final step in estimating LCOE values was to use these values along with the respective capacity factor data detailed in Section 2.2 to calculate site-specific LCOE for each Wind Toolkit resource pixel or site. The LCOE values were computed for each turbine configuration at each available hub height for all sites. Selected results from the LCOE calculations are illustrated in Figure 7 and Figure 8. Figure 7 shows the calculated LCOE for the Low-SP 4.5-MW turbine at a $110-\mathrm{m}$ hub height. Figure 8 shows the calculated LCOE for the Low-SP 4.5-MW turbine at 160 $\mathrm{m}$. Of course, changes in turbine configuration, estimated energy generation, CapEx, OpEx, and the fixed charge rate all could impact the results.

These results illustrate the potential competitiveness for 110- and 160-m hub heights based on the Low-SP 4.5-MW turbine. Based on the calculations applied here and this specific turbine configuration, much of the interior wind belt plausibly could support unsubsidized LCOE 
between $\$ 20 / \mathrm{MWh}$ and $\$ 35 / \mathrm{MWh}$ at 110-m hub heights. Moreover, large swaths of the eastern half of the continental United States could achieve unsubsidized LCOE in the $\$ 35 / \mathrm{MWh}$ to $\$ 50 / \mathrm{MWh}$ range with nontrivial pockets of potential at lower LCOE values. Results in the Intermountain West and Pacific are more mixed, with large areas falling into virtually all reported cost bins.

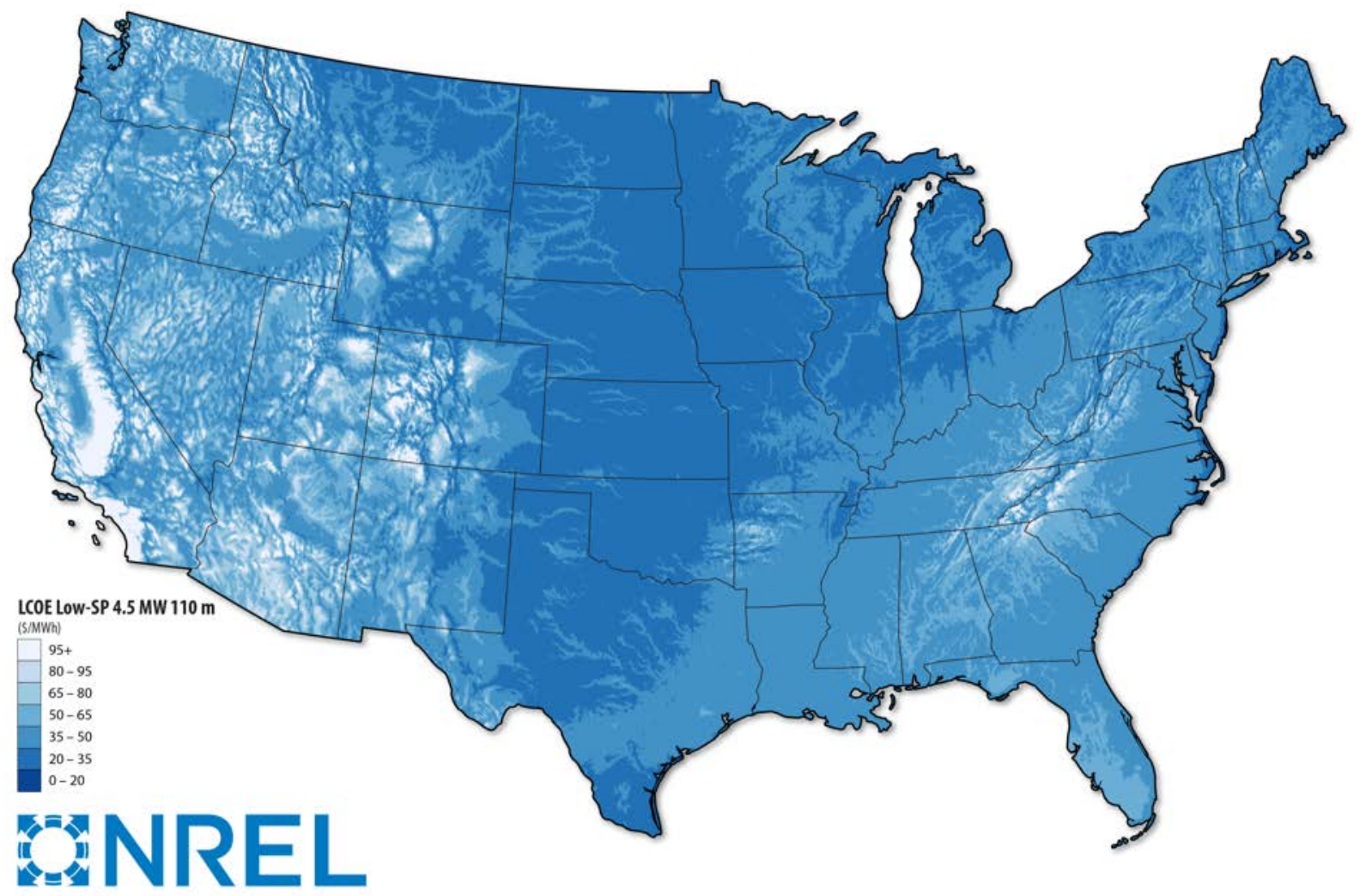

Figure 7. Estimated LCOE for each Wind Toolkit pixel, assuming the Low-SP 4.5-MW turbine at a 110-m hub height 


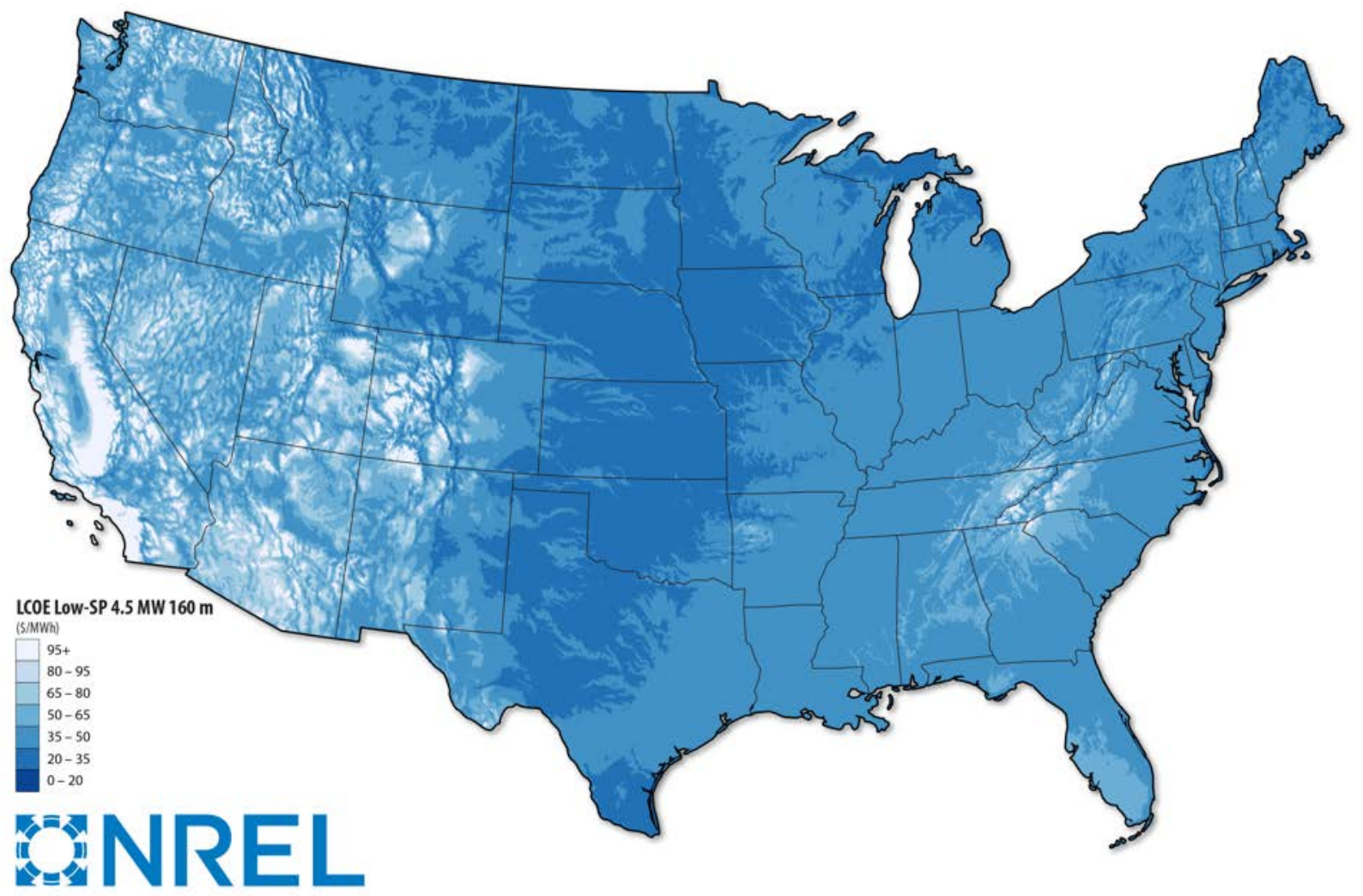

Figure 8. Estimated LCOE for each Wind Toolkit pixel, assuming the Low-SP 4.5-MW turbine at a 160-m hub height

Interestingly, at $160 \mathrm{~m}$, the area of $\$ 20 / \mathrm{MWh}$ to $\$ 35 / \mathrm{MWh} \mathrm{LCOE}$ is reduced, in the interior region, and the $\$ 50 / \mathrm{MWh}$ to $\$ 65 / \mathrm{MWh}$ is also reduced in parts of the east. This outcome is the result of the incremental estimated capital cost to realize 160 -m tower heights and indicates somewhat lower competitiveness for the 160-m tower height, under the current estimated costs and performance at $160 \mathrm{~m}$.

To further illustrate the potential impact on LCOE, Figure 9 and Figure 10 detail the distribution of LCOE values by turbine configuration and hub height. Recall that these LCOE values are indicative of recent vintage technology opportunities. Future innovation potential that may increase the relative competitiveness of a given turbine configuration or hub height would alter these results. Additional summary statistics of LCOE results are included in Appendix A. 


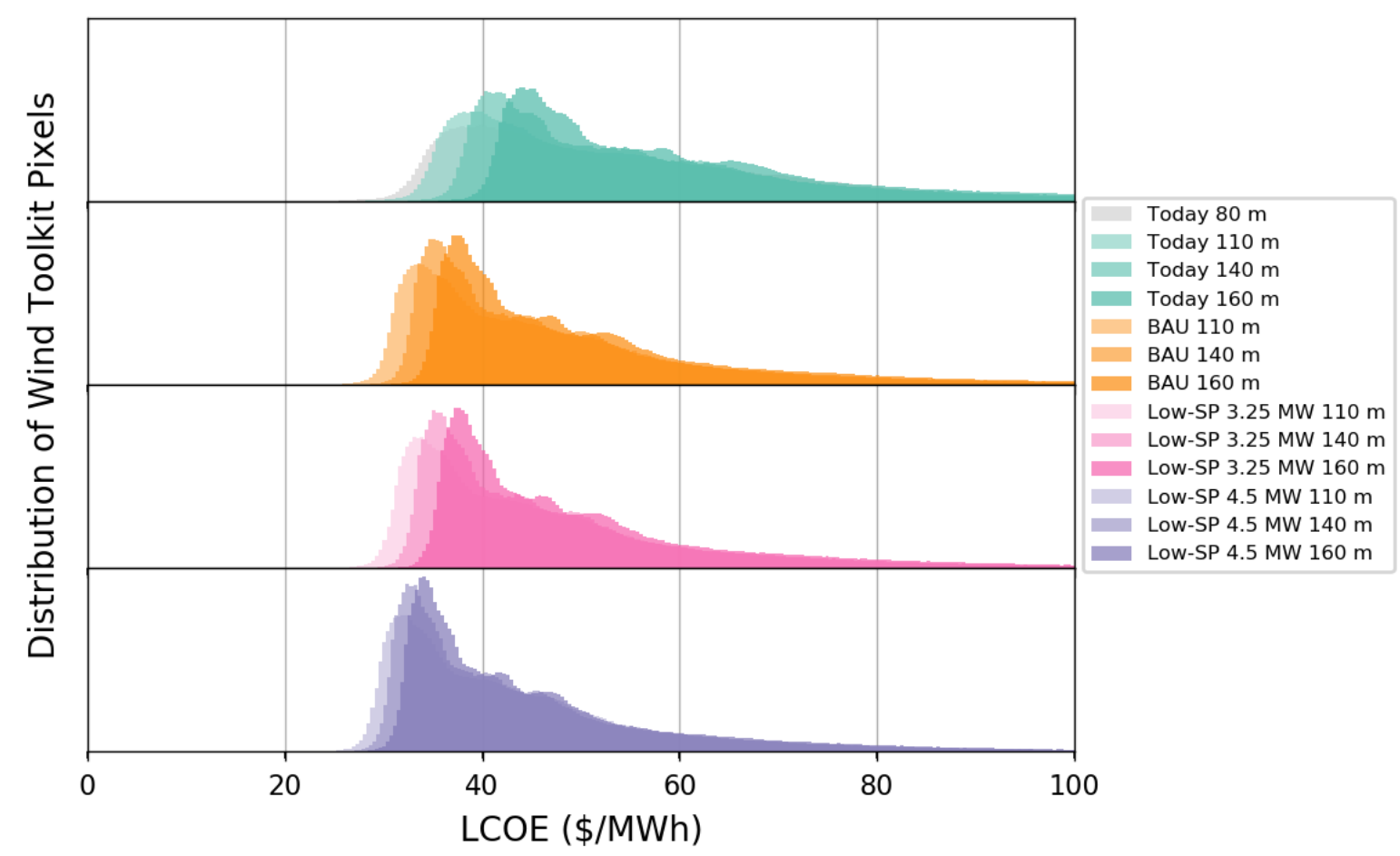

Figure 9. Estimated LCOE for each Wind Toolkit pixel; all turbines and all applicable hub heights

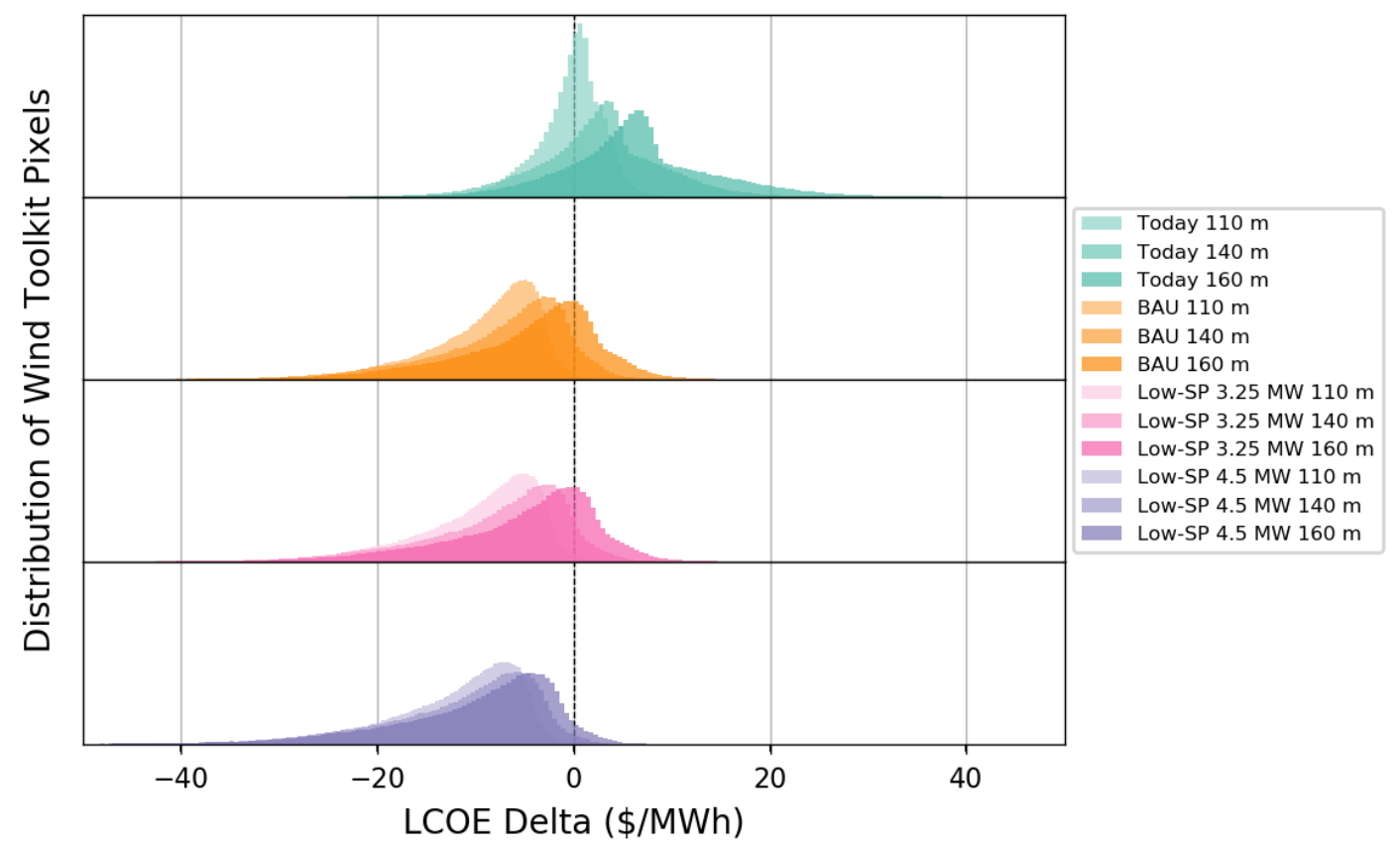

Figure 10. Estimated LCOE differences for each Wind Toolkit pixel, relative to the Today turbine at $80 \mathrm{~m}$

Given cost data that are indicative of recent technology scaling trends, (see also Appendix A), the largest quantity of low LCOE values and the most sizable LCOE reductions appear to be generally associated with the Low-SP 4.5-MW turbine at a 110-m hub height. The 3-MW BAU and Low-SP 3.25-MW turbines, however, also appear to offer nontrivial opportunities to drive 
down cost at $110 \mathrm{~m}$. The Today turbine LCOE results illustrate why current state-of-the-art commercial technology is most often deployed at a hub height of approximately $80 \mathrm{~m}$.

Real-world results will vary, of course, depending on the actual costs for these turbine platforms, including transport and logistics costs, which may disadvantage larger turbines with larger component sizes, relative to what is shown here. Moreover, these results are indicative of the national trends but may not correspond to subnational or regional economically preferred outcomes. Notwithstanding those caveats, these data suggest that if a single hub height was to be selected for deployments of tall tower technology based on our assumed cost and performance inputs, then $110 \mathrm{~m}$ would be preferred. Of course, in real-world commercial applications, developers could select the optimal hub height for a given site based on the available technology.

These conclusions can be further examined by a direct comparison of hub heights for each specific turbine configuration. Figure 11 shows that, for the Today technology, the 80-m hub height is most commonly preferred from an LCOE perspective, applying our current costing assumptions. For the larger turbines, however, the 110-m hub height, which is also the lowest option for these turbines, dominates, with $140 \mathrm{~m}$ holding a sizable minority share that varies from approximately $15 \%$ to $35 \%$ of Wind Toolkit pixels. In these results, preferences for $140 \mathrm{~m}$ are typically associated with lower wind speed sites at $80 \mathrm{~m}$ that have relatively higher shear. Variability in the share of $140-\mathrm{m}$ sites with the lowest LCOE is a function of the relative benefit that can be gained from a given turbine configuration achieving a higher hub height (i.e., the higher specific power of the BAU turbine means that it is able to extract relatively more benefit from $140 \mathrm{~m}$ ) and the proportionally lower tower and more limited BOS cost penalty associated with realizing taller towers for larger nameplate capacity machines (i.e., for the Low-SP 4.5 $\mathrm{MW})$.

Notwithstanding the analysis outcomes derived from the current assumptions, the uncertainties in the cost characterization and the magnitude of the differences in the estimated LCOE values suggest that there may not be a clear and dominant winner. More specifically, under our current assumptions, the 110-m height looks attractive but in fact is only economically preferred over the other turbine configurations by a few $\$ / M W h$ in many cases. Accordingly, if turbine scaling costs vary from recent trends in rotor diameter and specific power or if tower costs come in substantially lower than assumed, then the hub height distribution of future installations could diverge substantially from what is suggested in Figure 11. Moreover, given these differences, investments in tall tower technology that are intended to serve lower wind speed areas could, if successful, easily extend into higher wind speed areas based on the relatively small current advantages of shorter towers on an LCOE basis in those regions.

Finally, the analysis conducted here is somewhat coarse in that it only considers three potential hub heights for the BAU and Low-SP turbines. In reality, commercial developers and OEMs could have the ability to consider additional hub heights that might fall between the three primary focal points of the current analysis with potentially a broader mix of optimal turbine hub heights. 


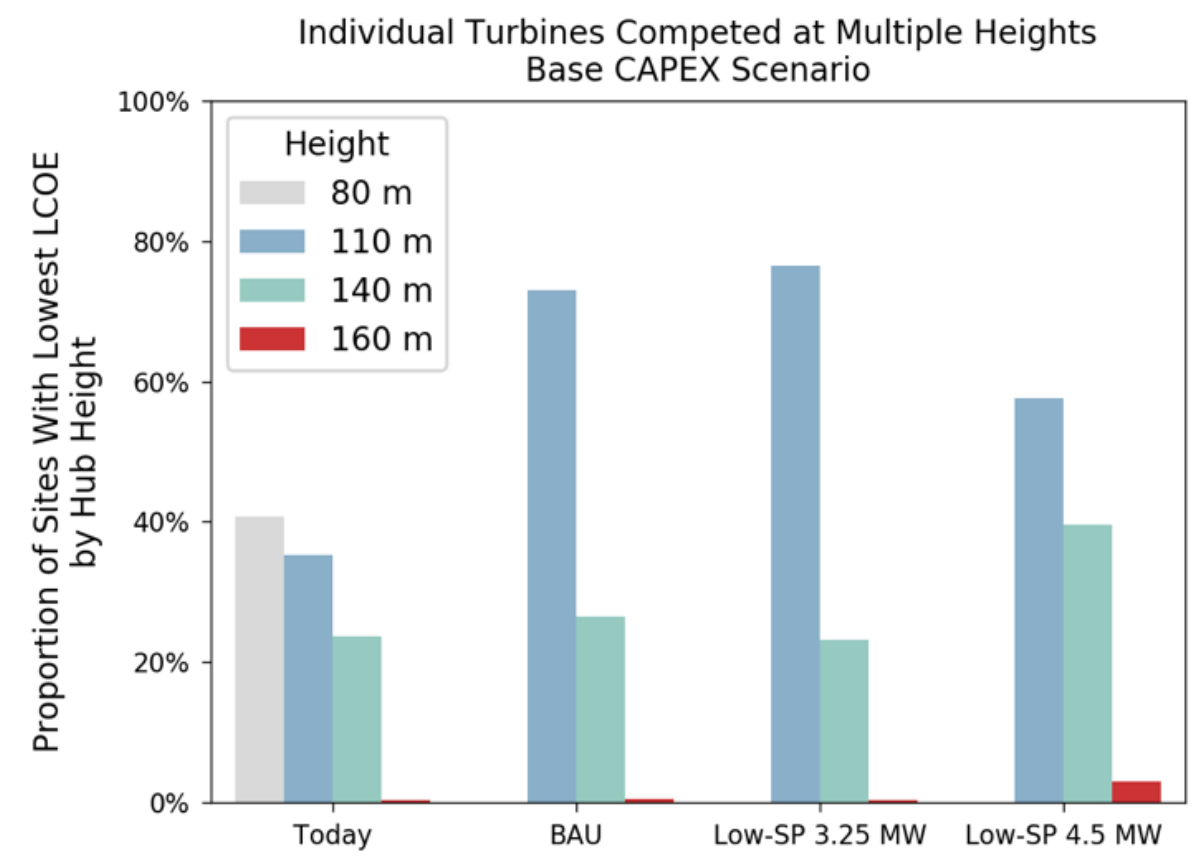

Figure 11. Calculated preferred hub height by turbine configuration, based on estimated performance and costs

Results presented thus far, with their focus on the contiguous United States, do not provide insights into the regions and locations where specific hub heights might prevail. In the same way that the wind speed differences varied geographically, the relative favorability of one hub height (per turbine configuration) or another also varies geographically. Figures 12 through 15 illustrate the economically preferred hub height by location for each of the four turbine configurations evaluated. Although the results presented in the figures are a function of the estimated cost and performance applied here, and therefore are subject to uncertainty, the relative consistency in the trends between turbines is indicative of areas where higher hub height applications will tend to be preferable. 


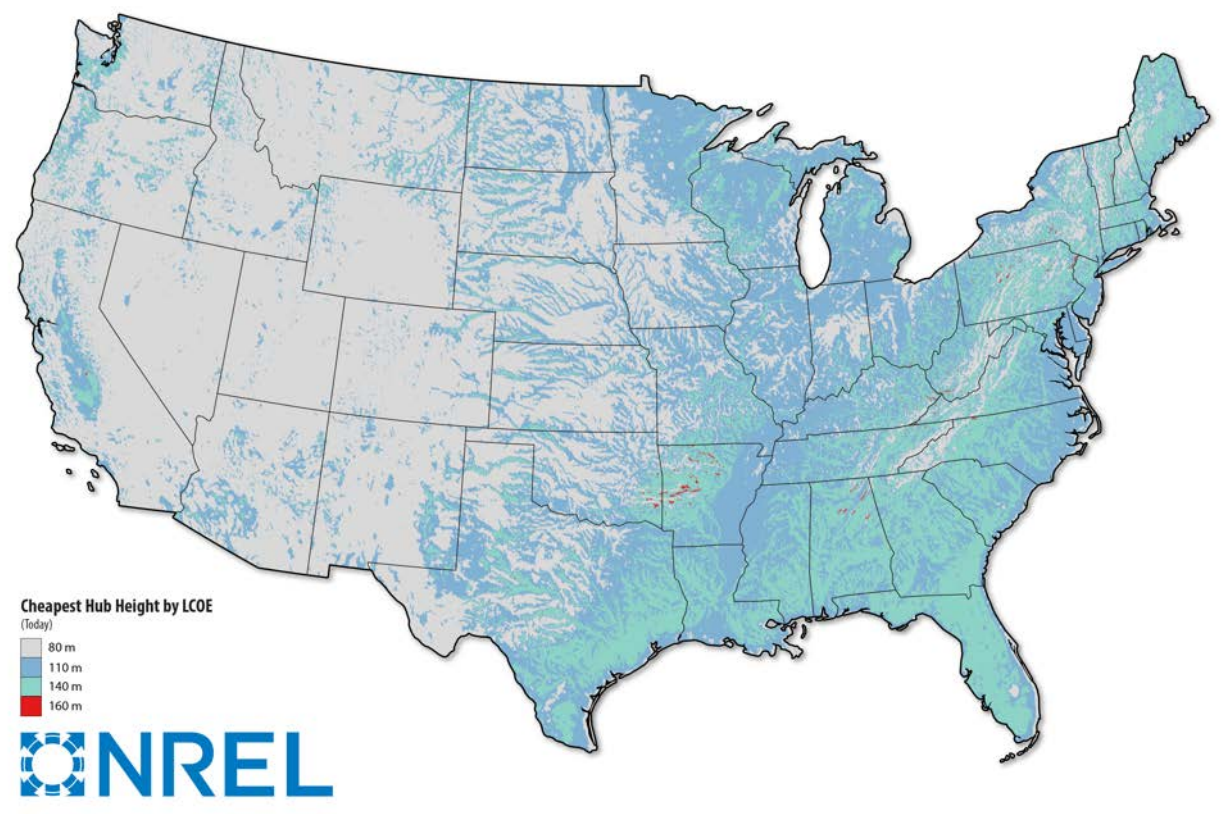

Figure 12. Calculated economically preferred hub heights for the Today turbine, based on estimated costs and performance

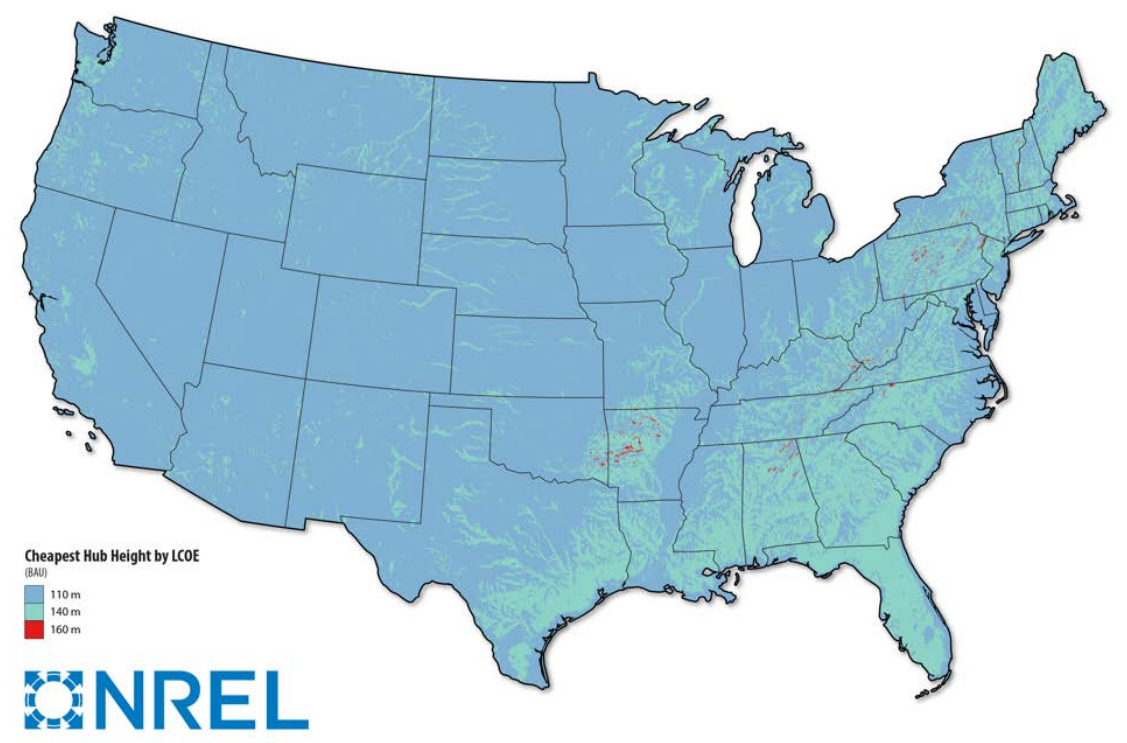

Figure 13. Calculated economically preferred hub heights for the BAU turbine, based on estimated costs and performance 


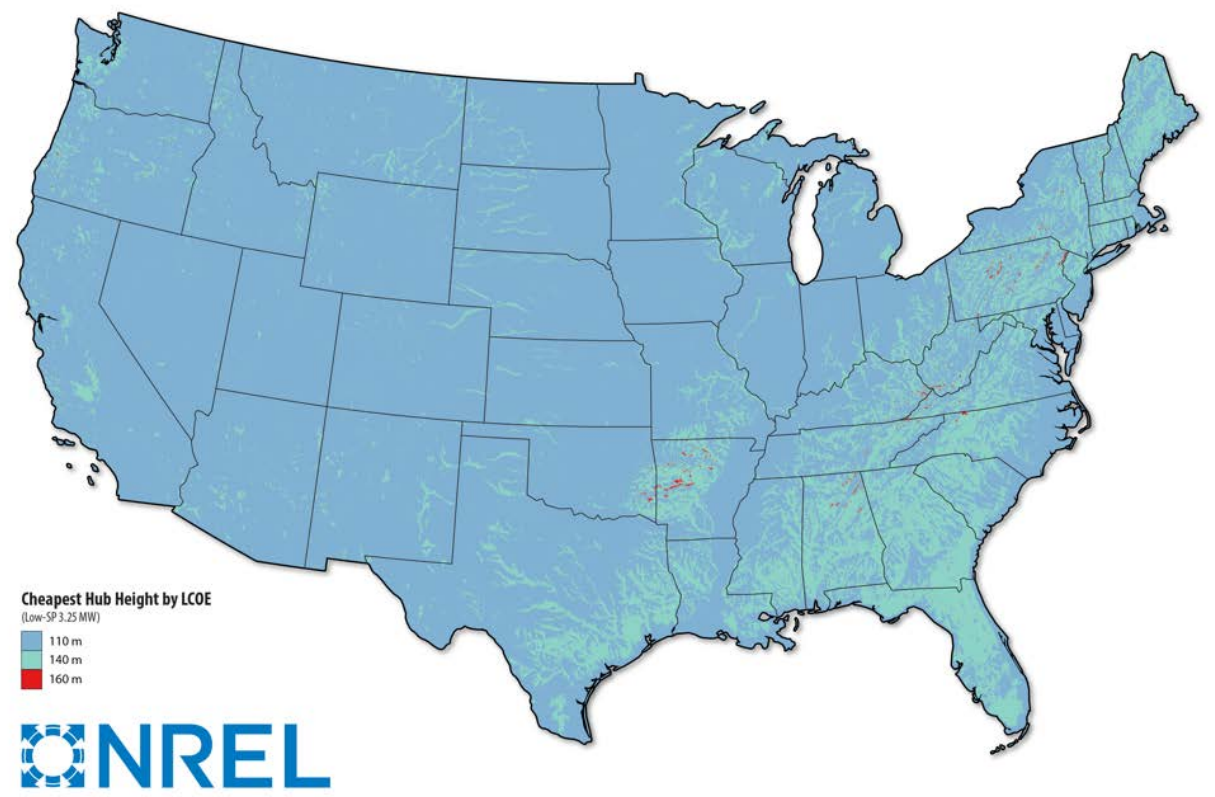

Figure 14. Calculated economically preferred hub height for the Low-SP 3.25-MW turbine, based on estimated costs and performance

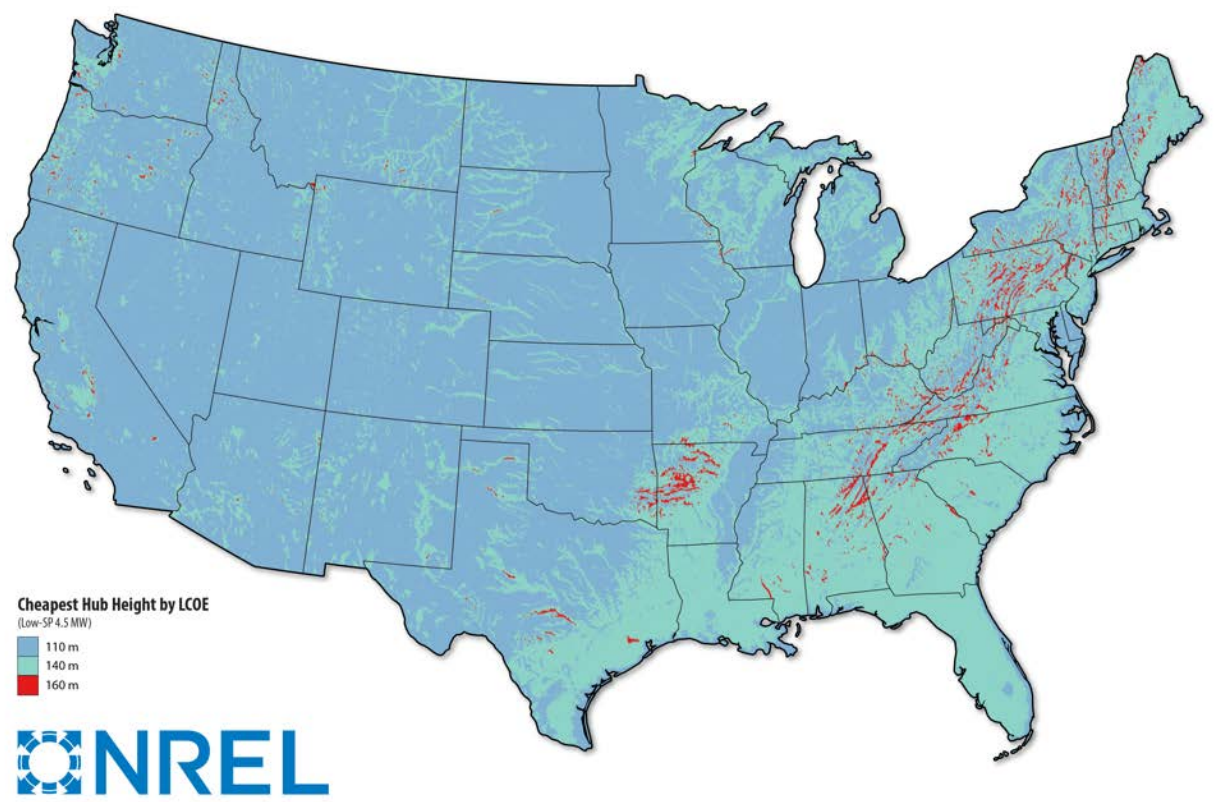

Figure 15. Calculated economically preferred hub height for the Low-SP 4.5-MW turbine, based on estimated costs and performance

The data mapped illustrate that higher hub heights are generally preferred in the east, but the extent of this preference depends on the turbine configuration considered and the estimated costs associated with that turbine. Based on the first-order cost characterization developed for this analysis and the Today turbine, regions experiencing commercial interest today largely fall into 
those categories where the $80-\mathrm{m}$ and $110-\mathrm{m}$ towers are preferred. This is consistent with the empirical market preferences observed to date. Locations further east suggest more favorable conditions for 140-m towers. Focusing on the BAU turbine and the costs assumed here, the 110$\mathrm{m}$ hub height dominates. Notably, this is the lowest hub height we analyzed for this turbine with an approximately 75-m blade. This suggests that, in many regions of the country, hub heights might be determined simply by requirements for sufficient ground clearance for a given rotor nacelle assembly. Focusing on the Low-SP 3.25-MW turbine, there are only very minor differences from the BAU turbine. Shifting to the Low-SP 4.5-MW turbine, at the assumed costs applied here, results in a modest increase in an area where 140- and 160-m turbines are determined to be economically preferred. Overall, however, the 110-m turbine continues to dominate, especially in the windiest regions of the country.

These results are a direct reflection of the inputs applied and do not account for the potential impact of future tower innovations that might make higher hub heights more attractive. To begin to ascertain the potential impact of tower technology R\&D and innovation, we conducted an additional tower cost sensitivity analysis. This sensitivity assumes that tower cost is fixed or static at $\$ 200 / \mathrm{kW}$ for all turbine configurations and tower heights. This cost is the approximate cost per kilowatt of the Today tower at $80 \mathrm{~m}$. Notably, although this approach fixes cost per kilowatt, it does allow for total tower cost to increase as nameplate capacity increases. This sensitivity scenario enables us to at least partially capture the potential change in competitiveness of the different tower heights, if innovation is able to limit tower cost changes as a function of tower height. The calculated LCOE differences associated with this sensitivity scenario are shown in Figure 16. This plot is an analog to Figure 9, albeit with tower costs fixed at $\$ 200 / \mathrm{kW}$ for all tower heights. Figure 17 illustrates the economically preferred tower height under these cost assumptions.

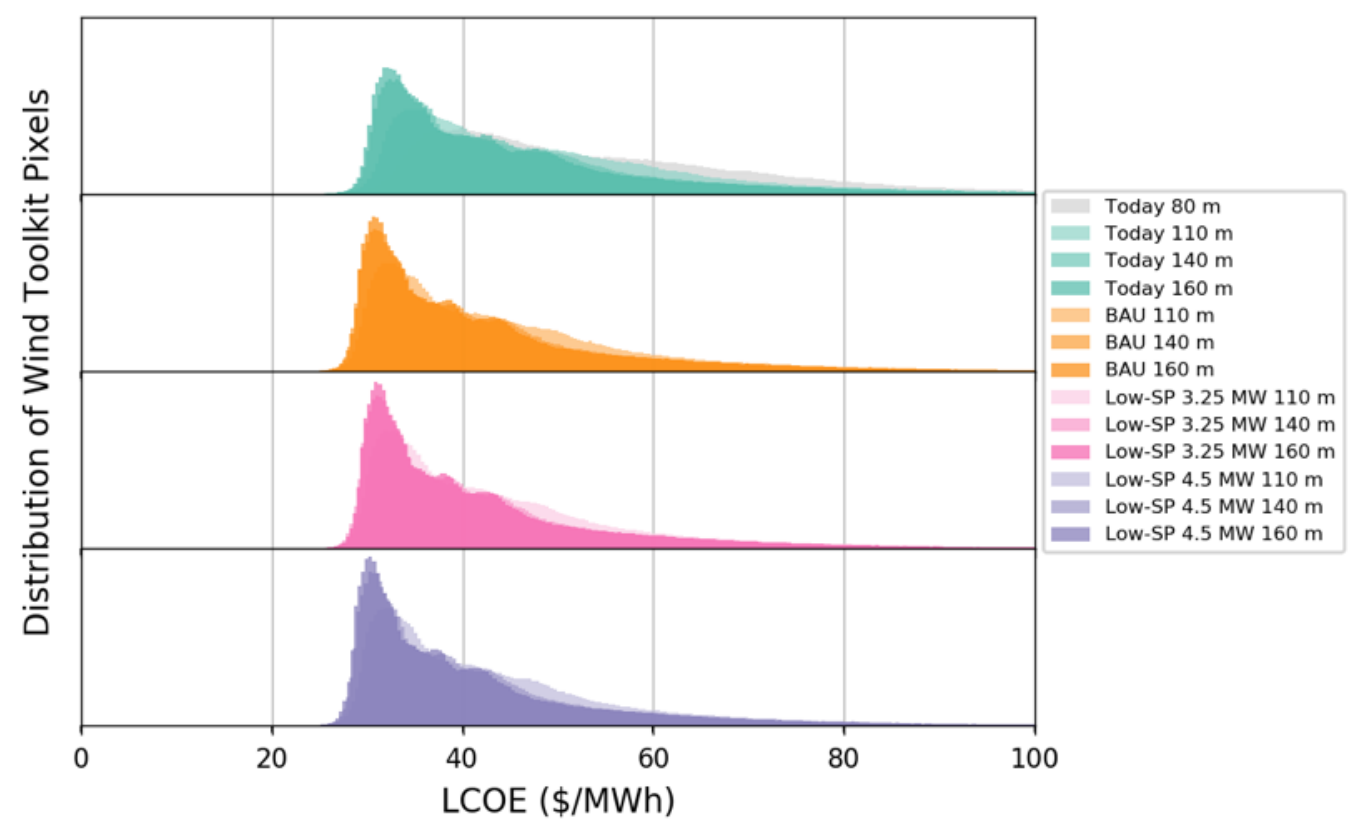

Figure 16. Estimated LCOE differences for each Wind Toolkit pixel, assuming $\$ 200 / \mathbf{k W}$ tower costs, relative to the Today turbine at $80 \mathrm{~m}$ 


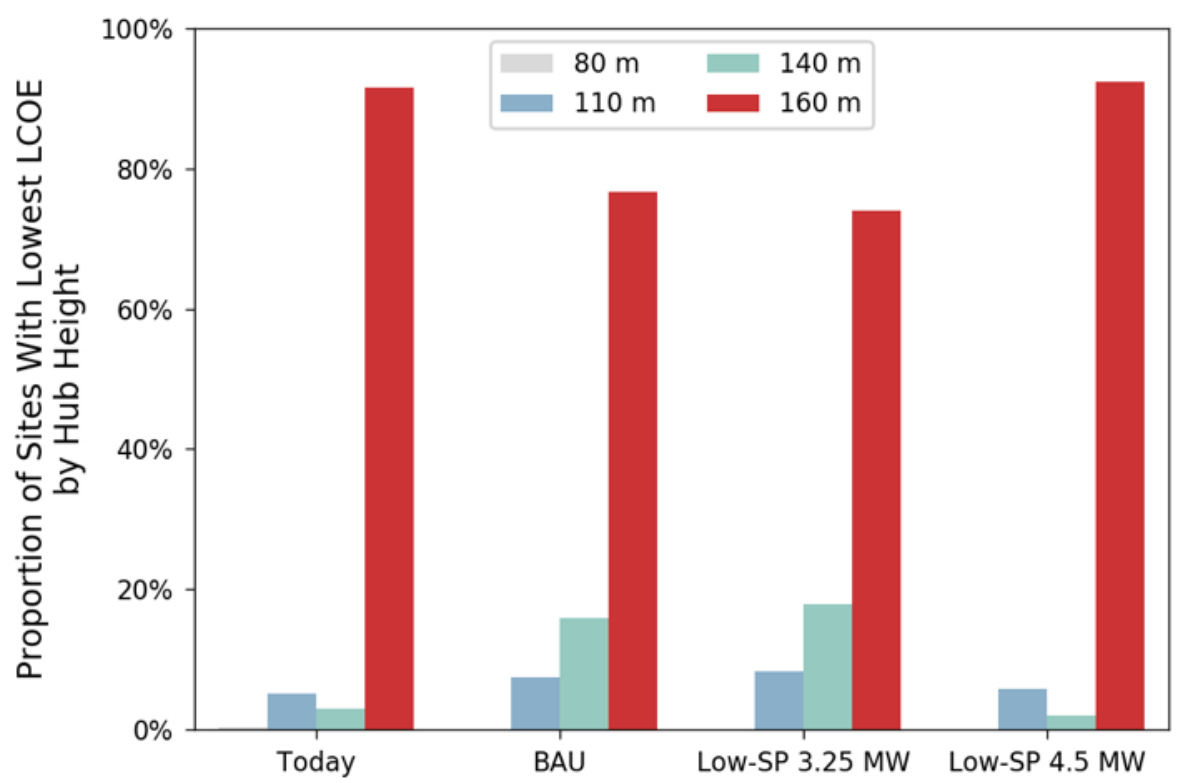

Figure 17. Calculated preferred hub height by turbine configuration, based on estimated performance and costs, assuming $\$ 200 / \mathrm{kW}$ tower cost

These results illustrate increased competitiveness for tall towers, especially the $160-\mathrm{m}$ tower height and highlight how differences in analysis assumptions and innovation potential could significantly alter preferences and demand for relatively shorter or taller towers. Future analysis would benefit from examination of additional sensitivities and could further parse these results.

\subsection{Breakeven Cost Analysis for Turbines with Taller Towers}

In addition to the analysis presented thus far, we sought to identify the potential cost targets that must be achieved to justify the application of these technologies at their respective hub heights. To identify these targets, we calculate the incremental price premium or breakeven cost $(\$ / \mathrm{kW})$ that can be incurred with the improved capacity factors afforded by these technologies and result in an equivalent LCOE as the Today technology at an 80-m hub height. If innovators are able to achieve a total installed capital cost that is at or below the sum of the Today technology capital cost and the breakeven cost, they will be competitive with technology that has recently been installed in the U.S market. In practice, the calculated breakeven cost reflects a potential $\$ / \mathrm{kW}$ cost adder on top of the estimated total CapEx for the Today technology. In regions where the LCOE of the Today technology at $80 \mathrm{~m}$ presently is insufficient for wind power to be competitive with other power-generation resources, additional cost reduction beyond the levels associated with the breakeven costs likely would be necessary to drive future wind power deployment.

The concept of the breakeven cost is premised on the idea that a taller turbine might involve more raw material or otherwise be more expensive to install but that the additional energy produced could offset these incremental costs, depending on the magnitude of the energy improvement and the cost premium incurred. It is also possible that innovation could create the conditions under which energy production increases while overall CapEx decreases. In fact, as suggested earlier, this might be necessary for wind power to become viable as an energy- 
generation resource in some regions. Although anecdotal evidence suggests we may be moving toward this point, we would not necessarily expect increased energy production and lower CapEx to be achieved initially. Increases in energy production per turbine, and reductions in project-level CapEx, however, generally have occurred in concert for much of the last three decades of wind power innovation. Moreover, as a principal benefit of taller turbine innovation is access to turbine- and plant-level economies of scale, it is reasonable to anticipate that these innovations could allow access to better wind resources at higher above ground hub heights while also achieving lower CapEx over time. Numerically, higher values for breakeven costs are generally more advantageous and indicate that there is a relatively greater benefit from moving to taller turbine concepts. As indicated, however, we also must consider that - for sites with relatively low energy production under baseline Today turbine conditions - a high breakeven cost on its own might not justify technology or project investment.

Notwithstanding its limitations, the breakeven cost metric helps to illustrate the costs that innovators must beat to be competitive with state-of-the-art technology available today. In this sense, it is indicative of an innovation cost target that must be achieved simply to be better than the next-best alternative - in this case, the Today technology at an 80-m hub height. The capacity factor change and breakeven cost analysis also begin to inform the potential value of continued tall-turbine technology development in regions that are currently being targeted by wind energy developers, as well as regions that are of less focus to the commercial development community today. The calculated breakeven costs for each of the turbine configurations and hub heights analyzed here are summarized in Figure 18.

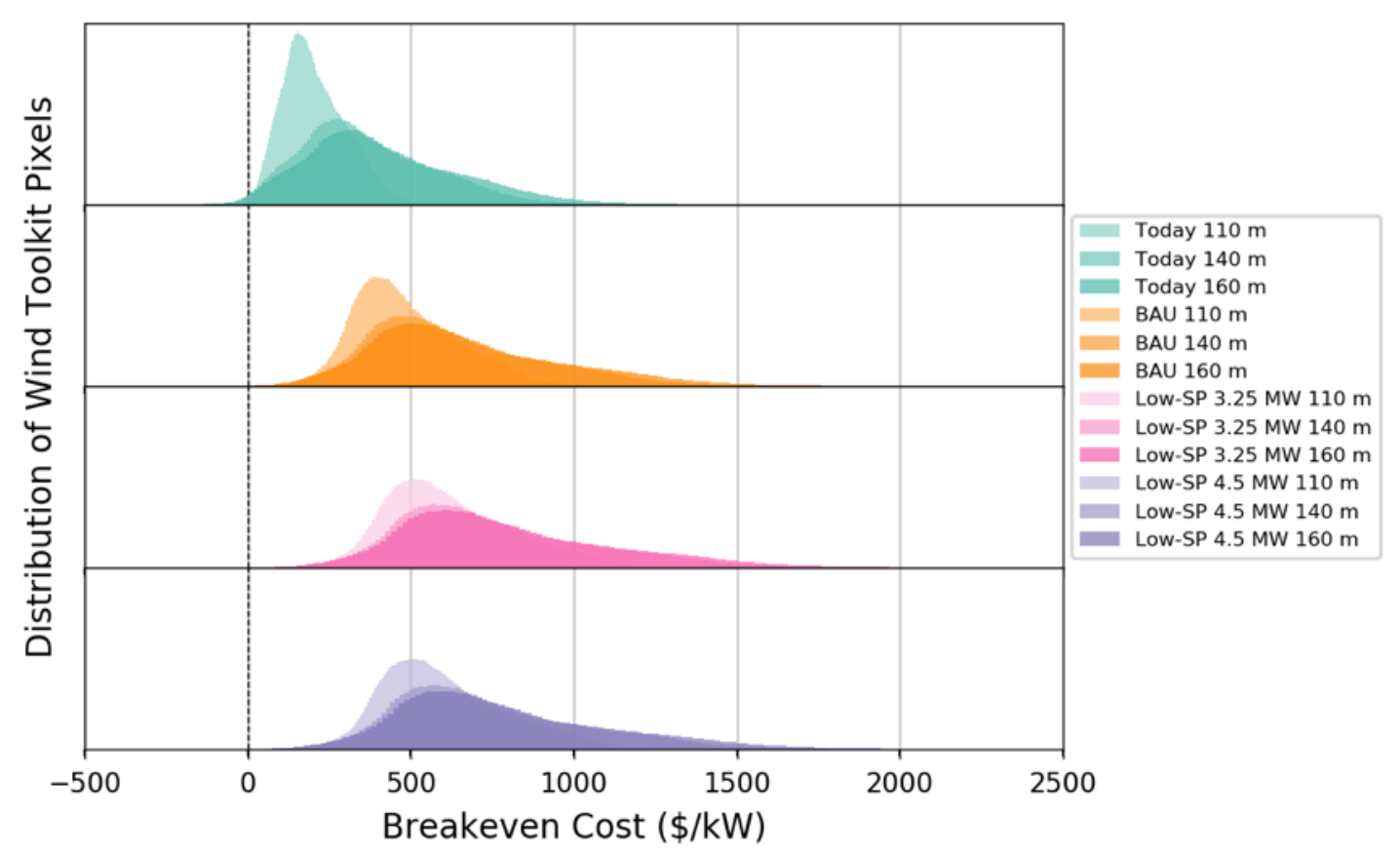

Figure 18. Breakeven costs for all turbines and all hub heights

In addition to the broad distributions in Figure 18, the following maps illustrate the LCOE achieved by the Today turbine (Figure 19) - which constitutes the LCOE from which the breakeven cost is calculated - and show how the estimated breakeven costs (an incremental price premium that would be on top of the estimated capital cost for the Today turbine at $80 \mathrm{~m}$ ) vary 
geospatially across the continental United States (Figures 20-23). For these maps, we focus on the BAU and Low-SP 4.5-MW turbine at $110 \mathrm{~m}$ and $140 \mathrm{~m}$. A complete summary of average breakeven costs by state is provided in Appendix A.

Collectively, these images illustrate that the distribution of breakeven costs across the country is both broad and sizable. In many locations, the breakeven costs are considerable, suggesting that there is significant opportunity to go to higher hub heights. At the same time, these locations also tend to be where the Today turbine estimated LCOE is quite high and therefore simply achieving the breakeven cost will likely be insufficient to drive economic deployment of new wind power.

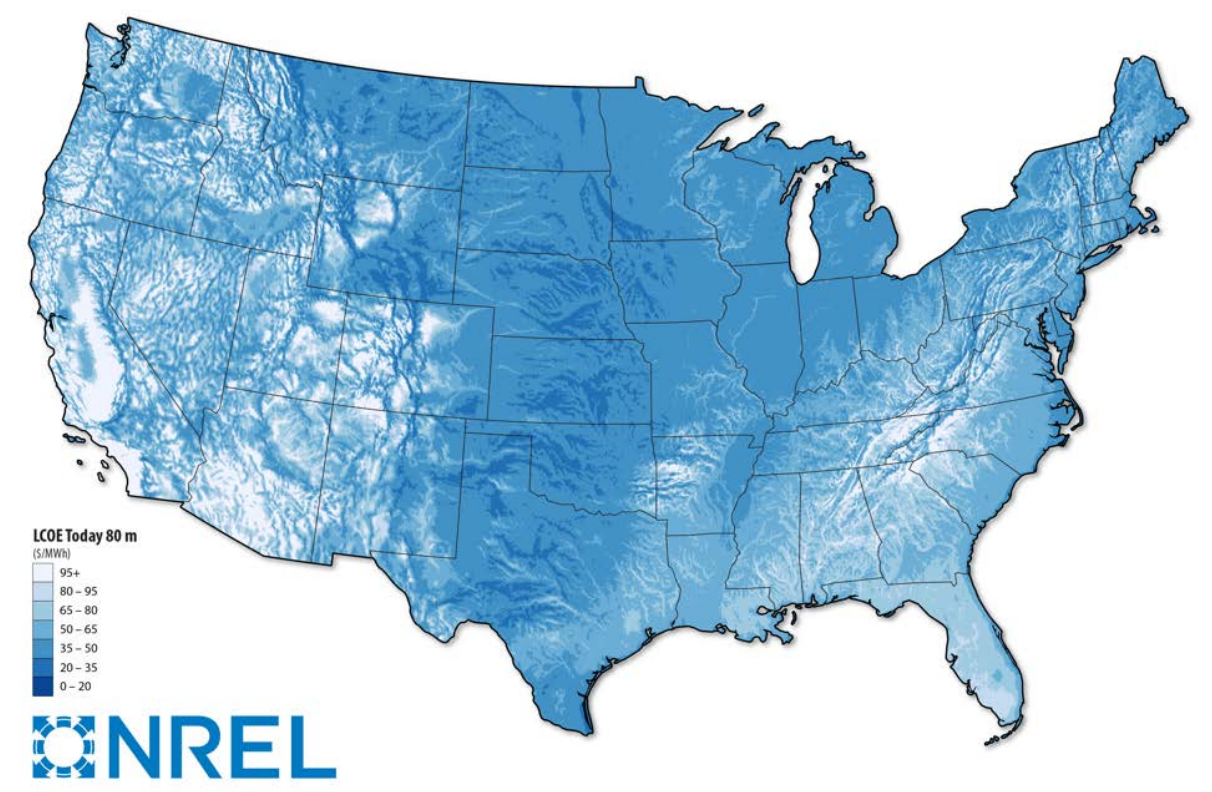

Figure 19. Estimated LCOE for the Today turbine at the $80-\mathrm{m}$ hub height 


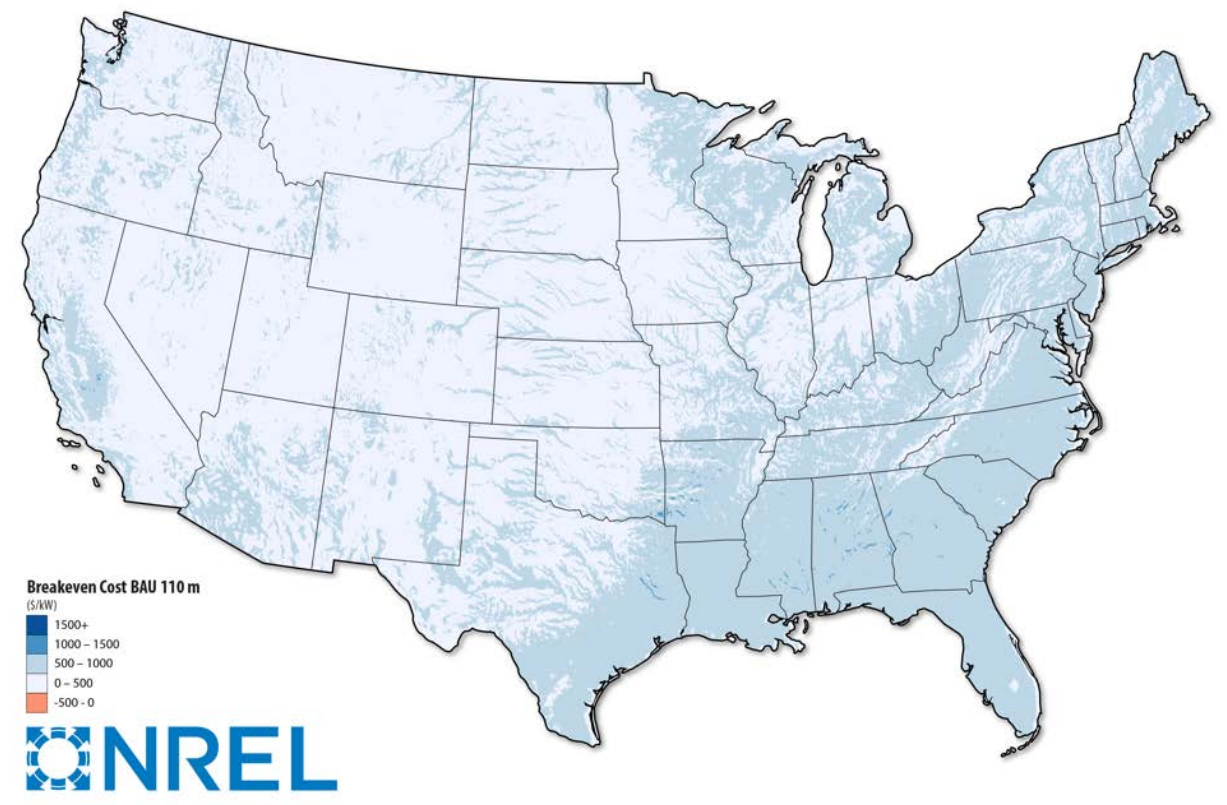

Figure 20. Breakeven costs for the BAU turbine at the 110-m hub height

Note: Breakeven values reported here are the incremental cost premiums that would be added to the CapEx of the Today turbine at $80 \mathrm{~m}$ to achieve the same LCOE as the Today turbine at $80 \mathrm{~m}$.

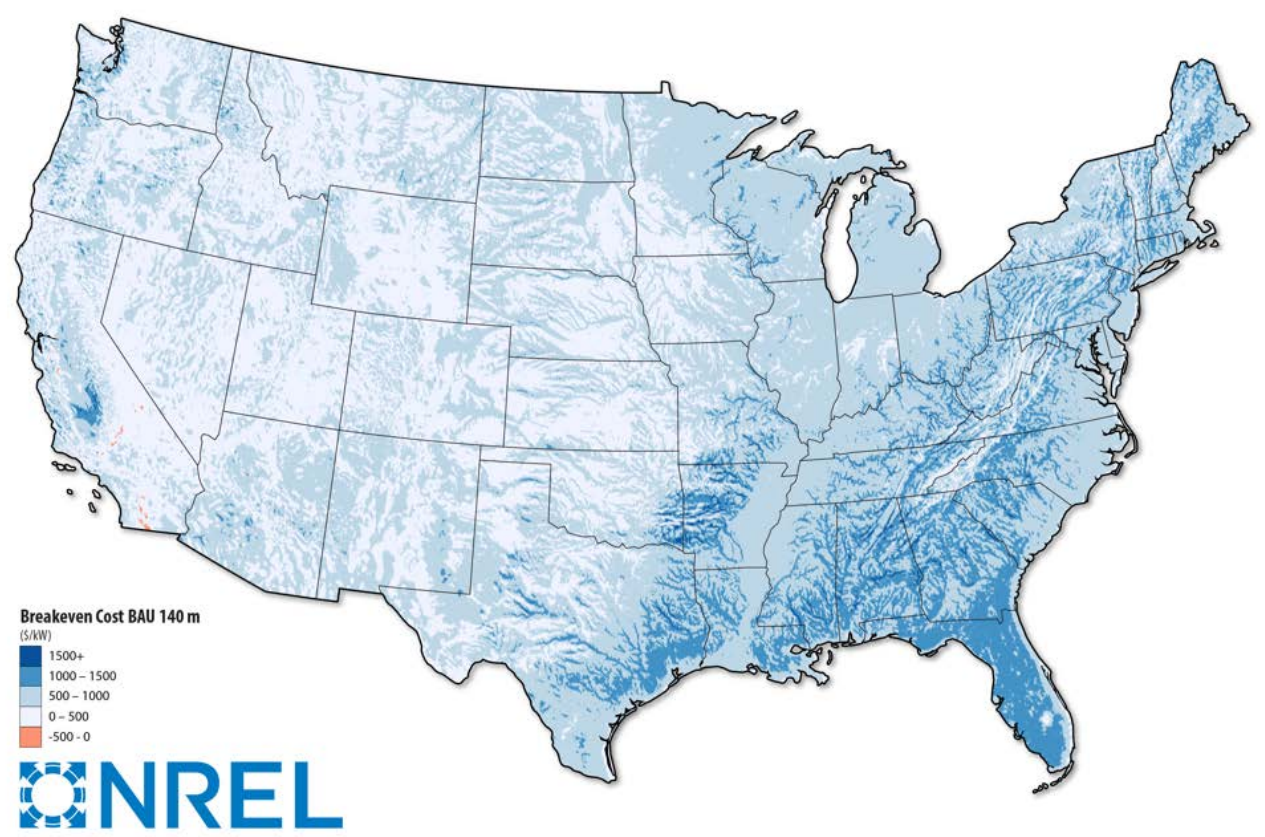

Figure 21. Breakeven costs for the BAU turbine at the 140-m hub height 


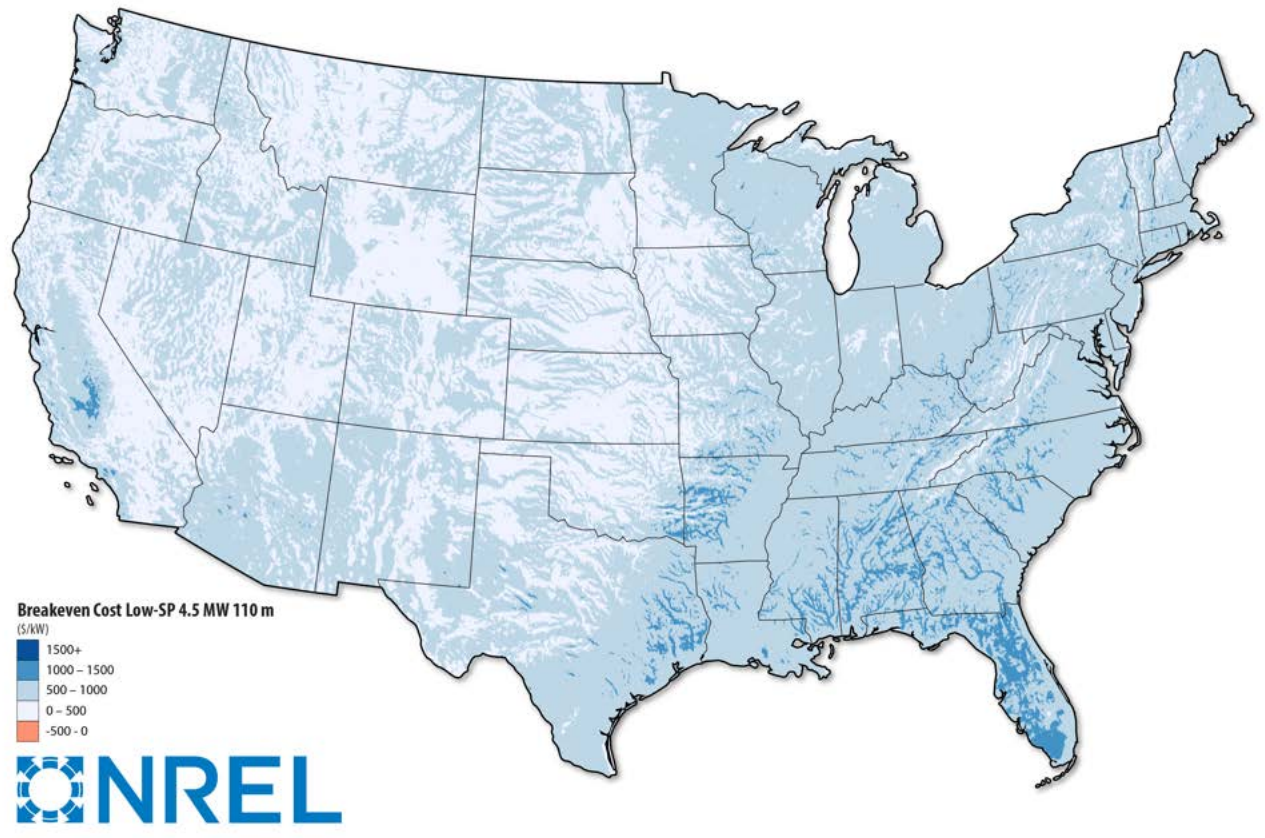

Figure 22. Breakeven costs for the Low-SP 4.5-MW turbine at the 110-m hub height

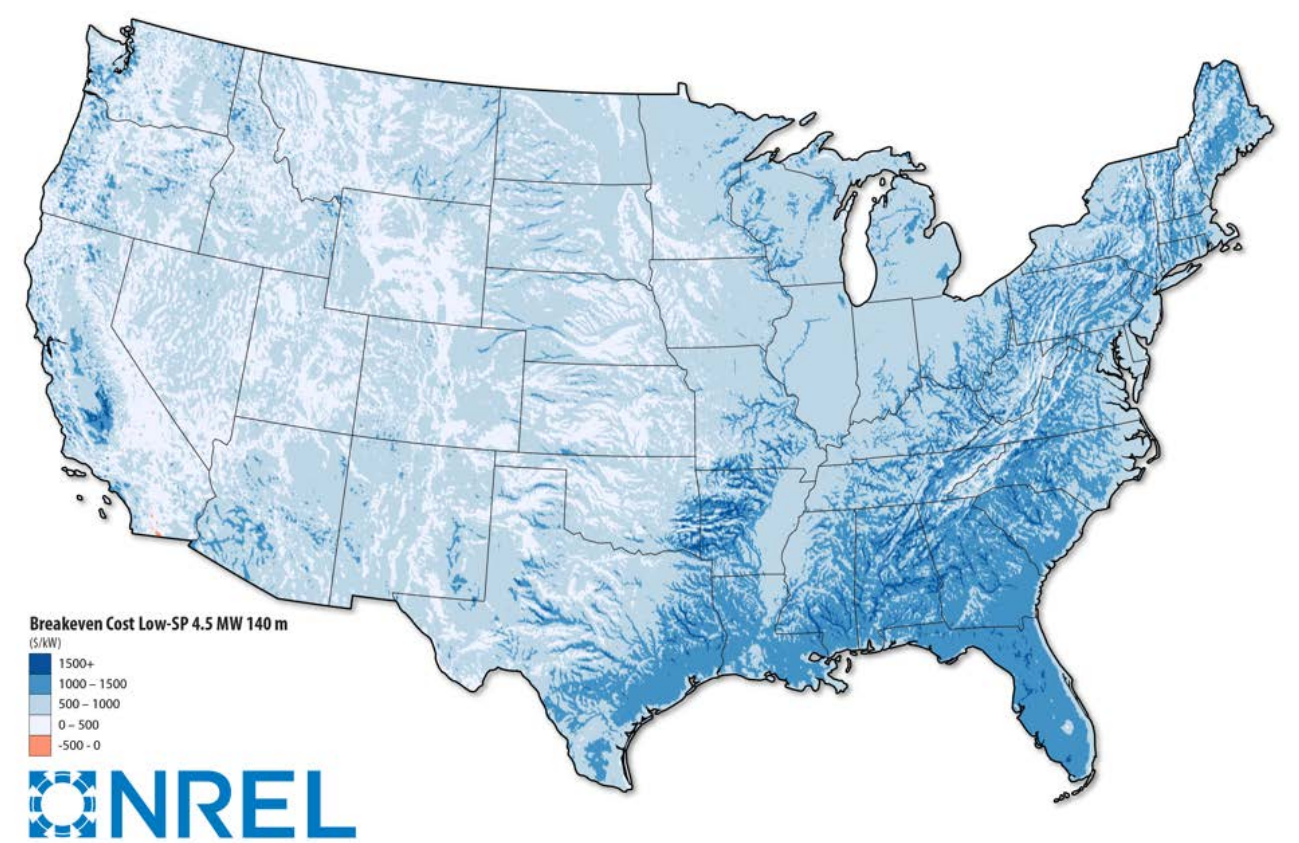

Figure 23. Breakeven costs for the Low-SP 4.5-MW turbine at the 140-m hub height 


\section{Tower Design Options and Related Analysis}

For much of the past two decades, the modern wind industry has been dominated by tubular steel towers also called "cans." Since the mid- to late-2000s, the tubular steel tower has been the industry standard, and tower height trends in the United States largely have plateaued at about 80 $\mathrm{m}$. The dominance of the 80-m tower is, in part, a function of logistics and transport constraints that limit tower-base diameter, and require rapidly increasing quantities of material to get to higher hub heights; and, in part, is a function of the relative cost of energy benefit achieved from realizing higher hub heights. Here, we utilize a systems engineering modeling approach to understand how technology and innovation might impact the future potential of tubular steel tower technology to achieve higher hub heights into the future.

Note: Section 3.1 through Section 3.1.3 is heavily based upon Dykes et al. (2018).

\subsection{Systems Engineering Steel Tower Simulations}

The designs for land-based wind turbine towers must satisfy a number of criteria, or constraints, to be viable for deployment. The goal for tower design always is to minimize mass, and to reduce material costs, and typically labor costs as well. The tower, however, must be able to support the wind turbine for a large variety of operating conditions and extreme events through the turbine's life. Additionally, the tower needs to be manufacturable and transportable. This last design criterion around transportability has become a challenge as turbine designers push toward higher and higher hub heights. For reasons discussed elsewhere herein, as towers grow larger, the ideal design approach is to increase the diameter at the tower base and keep the wall thickness minimal. For transportation on land, however, tower diameters are limited to approximately $4.3 \mathrm{~m}$ dictated by highway and railway overpass heights, which leads to substantial and costly tower designs using conventional technology solutions.

To better understand the potential for steel towers to meet the requisite price points to be viable in the United States, an ideal tall tower modeling analysis was conducted. This effort compares conventional "transportable" tower designs at different hub heights alongside idealized tower designs, with relaxed constraints around transportation and the maximum tower base diameter. In particular, a conventional technology transportable case is compared to a large-diameter steel tower (LDST) design concept with a 6.2-m base diameter as well as an unconstrained base diameter concept potentially accessible through an on-site spiral-welded tower approach. The results compare for each design how tower mass and expected material costs change with increasing hub height, and thus provide insight into the potential of different technical solutions to enable future low-cost tall towers for the wind industry.

\subsubsection{Tower Optimization Method}

Tower design looks at minimizing mass and cost through manipulation of the diameter and thickness of the tower along its length. The main constraints on the design are associated with the tower strength and stiffness, which are driven by the loads that the tower experiences over its operating lifetime. The loads on the tower stem from aerodynamic, gravitational, and inertial loading from the RNA at the tower top as well as drag loads from the wind impinging directly on the tower, blades, and nacelle. Detailed discussion of the tower design process is provided in "Design of Offshore Wind Turbine Towers" (Damiani 2016). 
For this analysis, we use a software tool for Tower Systems Engineering (TowerSE) to optimize the wind turbine tower design to minimize mass by adjusting tower diameter and thicknesses (Ning et al. 2014). TowerSE is a wind turbine tower conceptual design tool that is part of a larger WISDEM toolset (Dykes et al. 2015). The tower-top diameter is fixed so there are two design variables for the diameter - at the base of the tower and at a set point somewhere between the base and top of the tower (which is also a design variable itself). The wall thickness at each of the base, top, and set point are design variables as well (Table 2).

Table 2. Tower Design Variables

\begin{tabular}{lc}
\hline Description & Number of Variables \\
\hline Tower Outer Diameter & 2 \\
Tower Wall Thickness & 3 \\
Tower Set Point for Tapering & 1 \\
\hline
\end{tabular}

The design variables are optimized for minimum tower mass and satisfy constraints caused by key turbine loads (Table 3). We also consider resonance avoidance through a constraint on the tower natural frequencies relative to the RNA frequencies. Depending on the specific case, constraints for manufacturing and transport are applied as well.

Table 3. Tower Design Constraints

\begin{tabular}{lc}
\hline Description & Number of Constraints \\
\hline Utilization against shell and global buckling & 68 \\
Utilization against strength & 34 \\
Natural frequency lower limit & 1 \\
Fatigue damage & 1 \\
\hline Diameter-to-thickness ratio (manufacturability) & 3 \\
Base diameter (transportability) & 1 \\
\hline
\end{tabular}

The methods to calculate the shell buckling, global buckling, fatigue damage, and stresses along the tower for each load case are addressed in prior studies (Ning et al. 2013). The diameter-tothickness ratio constraint ensures weldability of the tower. The base diameter upper-bound constraint is adjusted depending on the tower design case- $4.3 \mathrm{~m}$ for conventional technology, $6.2 \mathrm{~m}$ for LDST technology, and unconstrained as would be the case for on-site spiral-welded technology.

Finally, the frequency constraint lower bound is adjusted based on the type of tower, present for soft-stiff and absent for soft-soft. The frequency constraint is particularly important to the design because it can often be the binding constraint on a soft-stiff design and push the mass up exponentially as towers grow taller and the natural frequencies move lower (for a fixed diameter and thickness profile). A tower designer must be sure that the tower natural frequencies do not overlap with the rotor rotational frequency (1P) and blade passing frequency (3P for a threebladed turbine), where excitations can lead to resonance, large amplitude loads, and increased fatigue damage (see Damiani 2016 for detailed discussion). Conventional tower designs 
historically were soft-stiff and were designed to completely avoid the potential for resonanceinduced loading. For modern wind turbine controls, however, it is possible to control loading through resonance conditions and enable the use of soft-soft wind turbine tower designs with very low natural frequencies that are less stiff and require less thickness in towers with smaller diameters. As shown herein, this has significant implications for the small-diameter towers in tall tower applications.

\subsubsection{Tower Optimization Case Study}

This study examines six different combinations of tower designs for each of six different turbine hub heights for a total of 36 optimization cases (Table 4).

Table 4. Tower Optimization Cases

\begin{tabular}{|c|c|c|}
\hline Tower Configuration & Tower Type & Hub Height \\
\hline $\begin{array}{l}\text { - Conventional (4.3-m base } \\
\text { diameter) }\end{array}$ & $\begin{array}{l}\text { - Soft-stiff (constrained to above } \\
\text { rated rotor } 1 \mathrm{P} \text { ) }\end{array}$ & $\begin{array}{ll}\text { - } & 80 \mathrm{~m} \\
\text { - } & 100 \mathrm{~m}\end{array}$ \\
\hline $\begin{array}{l}\text { - LDST (6.2-m base } \\
\text { diameter) }\end{array}$ & $\begin{array}{l}\text { - Soft-soft (no frequency } \\
\text { constraint) }\end{array}$ & $\begin{array}{l}\text { - } 120 \mathrm{~m} \\
\text { - } \quad 140 \mathrm{~m}\end{array}$ \\
\hline $\begin{array}{l}\text { - Spiral-welded (no base } \\
\text { diameter constraint) }\end{array}$ & & $\begin{array}{l}\text { - } \quad 160 \mathrm{~m} \\
\text { - } \quad 180 \mathrm{~m}\end{array}$ \\
\hline
\end{tabular}

The RNA properties and loads for the study are based on a reference turbine developed by the International Energy Agency (IEA) Wind Task 37 on Wind Energy Systems Engineering (Table 5). The 3.3-MW reference turbine has a rotor diameter of $130 \mathrm{~m}$ and a specific power of roughly $240 \mathrm{~W} / \mathrm{m}^{2}$ (IEA 2017). Although not as low in specific power as some machines that are being produced or are expected to be in production soon, it is an International Electrotechnical Commission (IEC) Class 3A turbine design for low wind speed applications and closer to current U.S. land-based wind turbine technology than other available reference turbine designs.

Table 5. IEA Wind Task 37 Land-Based Low Wind Speed Turbine Configuration Data

\begin{tabular}{|l|c|}
\hline \multicolumn{2}{|c|}{ Wind Turbine Configuration Data } \\
\hline Lead Developer & Technical University of Munich \\
\hline Class and Category & IEC Class 3A \\
\hline Rotor Orientation & Upwind \\
\hline Number of Blades & 3 \\
\hline Control & Variable-speed collective pitch \\
\hline Drivetrain & Geared machine \\
\hline Rated Power & $\sim 3.3 \mathrm{MW}$ \\
\hline Rotor Diameter & $130 \mathrm{~m}$ \\
\hline Hub Height & $110 \mathrm{~m}$ \\
\hline
\end{tabular}


The loads for the turbine were provided by the Technical University of Munich through a comprehensive analysis of the turbine response to various design load cases as defined by IEC design standards for wind turbines (IEC 61400e1 2014). The largest loads for different force and moment components at the tower top were used as input loads to the optimization (including a thrust load of 1,000 kilonewtons $(\mathrm{kN})$ and torsion around the vertical axis of $12,500 \mathrm{kNm}$ ). Fatigue loads were applied based on scaling fatigue loads from the NREL 5-MW reference turbine (Jonkman 2009).

\subsubsection{Results}

Figure 24 shows the results for more traditional soft-stiff tower masses for each of the turbine tower configurations investigated.

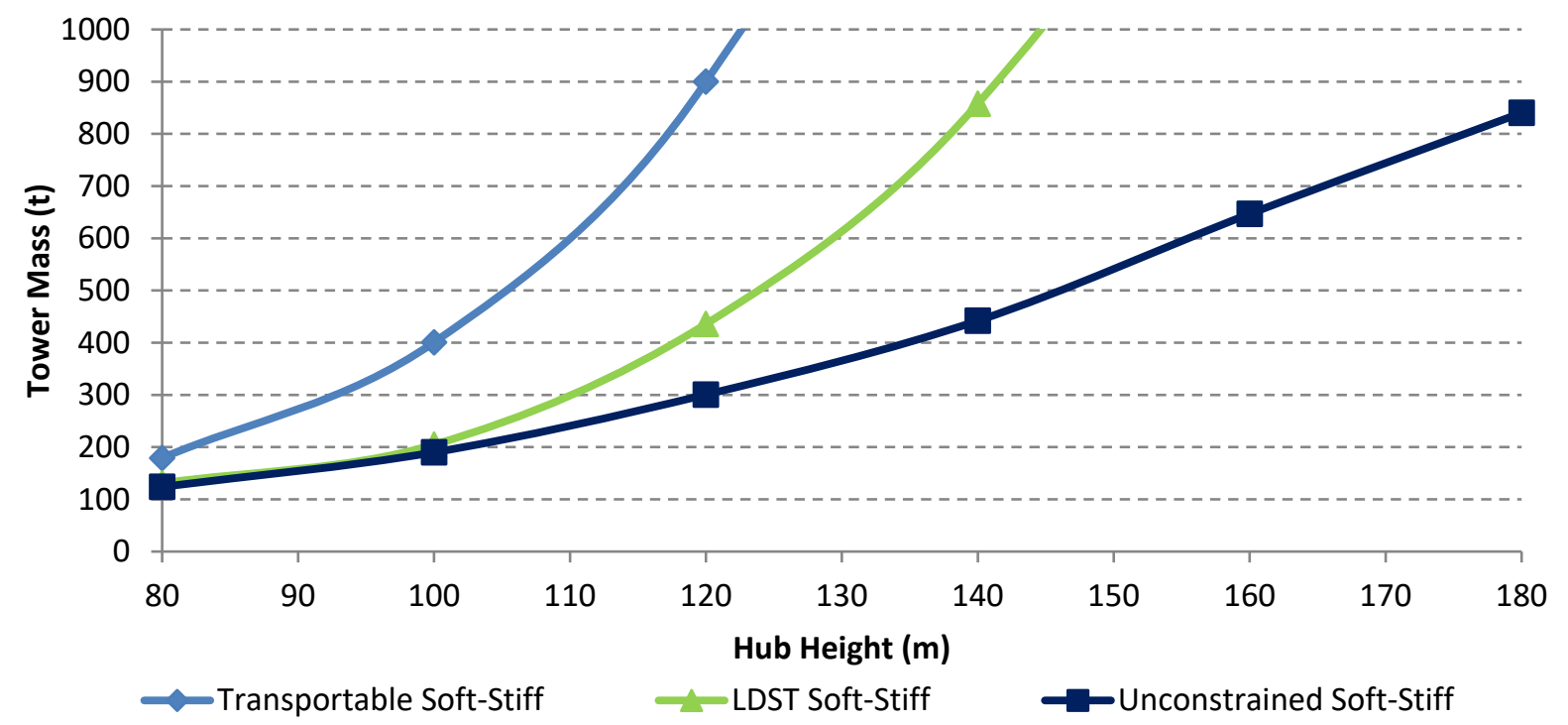

Figure 24. Optimization results for soft-stiff tower design cases

For the transportable towers with a maximum diameter of $4.3 \mathrm{~m}$, the optimizer failed to find a feasible solution for hub heights of $140 \mathrm{~m}$ or more. For the heights that were possible to optimize, the weight grows relatively rapidly with tower height. When the constraint on tower base diameter is relaxed, there are benefits in decreasing mass at all heights. Generally, the need to meet the frequency constraint for soft-stiff towers pushes the wall thickness of smaller-baseddiameter towers to large values so that the overall mass increases. Notwithstanding these results, it is important to note that tower cost is strongly correlated with mass but is not directly proportional to it, due to the specifics of manufacturing processes.

Figure 25 illustrates the shift in the results when looking not just at traditional soft-stiff towers but also examining soft-soft towers where controls are used to avoid 1P resonance with the rotor. 


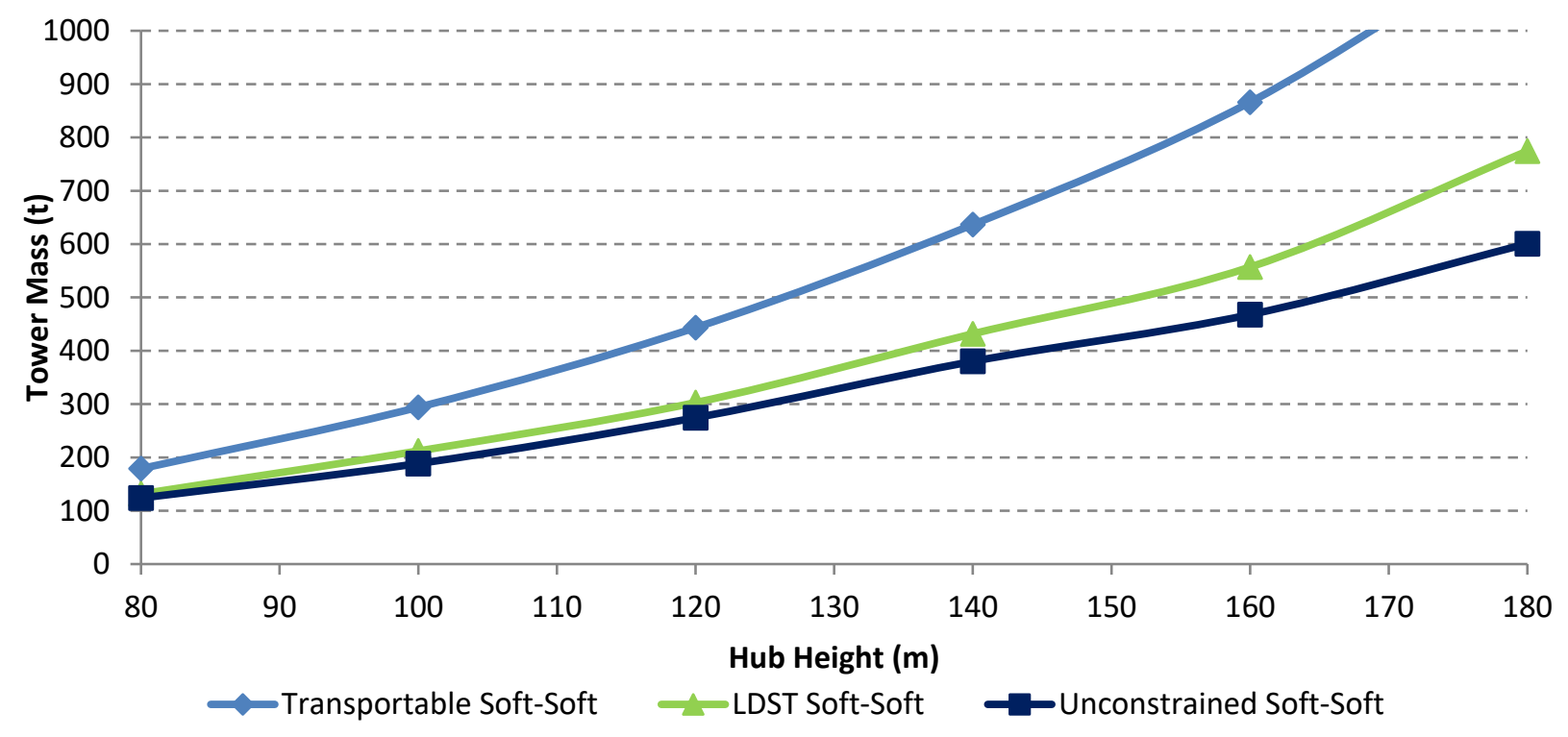

Figure 25. Optimization results for soft-soft tower design cases

Relative to the soft-stiff towers, the mass is reduced in all cases in the soft-soft tower results. The difference is most pronounced in the transportable case with a maximum base diameter of $4.3 \mathrm{~m}$. The optimizer was able to find feasible solutions for all transportable cases, though the 180-m case yielded an optimized mass of 1,200 tons to meet constraints for global buckling. Similarly, the solutions for the LDST and spiral-welded cases all are much lower than before-reduced by as much as 200 tons in the unconstrained case at a 180-m hub height.

Based on data points from actual masses for two transportable towers with hub heights of $120 \mathrm{~m}$ and $140 \mathrm{~m}$, we know that these masses can be higher than the transportable tower masses presently available. This likely is due to the fact that the reference turbine design differs from actual technology and the fact that industry has developed more sophisticated control systems to enable not just soft-soft tower designs but also an overall decrease in loads experienced by the tower. The major impact of these advancements will be in reducing fatigue loads, but controls algorithms and load sets for specific turbines are highly valuable intellectual property in the industry. An example of this is Vestas OptiStop and Active Damping technologies that reduce the overall loads experienced by the towers and allow for a more efficient, lower-weight, and reduced-cost tower design (Montanez 2017). These data demonstrate that, although pursuing novel tower technologies holds promise for growing hub heights, innovation around conventional tubular steel tower designs also holds promise and could extend their competitiveness to higher hub heights. At the same time, when the full suite of controls technologies is applied to LDST and unconstrained or spiral-welded technologies, their masses might be decreased even further with further potential to reduce the cost of wind energy for tall tower applications. 


\subsection{Innovation Opportunities for Additional Alternative Tall Tower Technologies}

In spite of the general dominance of tubular steel towers, manufacturers have continued to explore additional alternative tower technologies. The pursuit of alternative tower concepts is justified on various grounds and can result from a desire to hedge against steel-price volatility or from perceived potential for cost reduction. Alternative tower technologies might use lower-cost materials, such as concrete, or could entail more efficient use of steel, such as lattice or space frame designs. Depending on the specifics of a given concept, they also could offer efficiencies in balance of plant and erection. Notably, many alternative tower concepts offer potential solutions to transport challenges and barriers, and in many cases offer opportunities for larger base diameters than the conventional transport limit of $4.3 \mathrm{~m}$. This is of particular interest to OEMs and wind power plant developers operating in the United States, where long transport distances result in nontrivial cost impacts associated with transportation generally. Of course, alternative tower concepts also have challenges that have precluded their broad-based adoption to date, such as much larger labor fraction and on-site labor rates.

One alternative tower design option is on-site manufacturing, which, in principle, should reduce transportation costs and enable taller towers with the trade-off of potentially more labor in the field at the project site. Fundamentally, on-site manufacturing enables the use of commoditized transport and allows the primary production or assembly processes to occur at or near the wind power plant construction site (e.g., avoiding public roads). Currently, a few tower-technology firms - including Wind Tower Technologies (WTT) and Keystone Tower Systems-have conceived and are actively developing on-site manufacturing strategies. Max Bögl is another firm that has commercial offerings of site-cast concrete in mobile factories.

Here, we explore the current status of various alternative tower designs and discuss the design considerations and attributes associated with each of these technologies. Three specific alternative tower concepts are considered: (1) a full-concrete field-cast tower, (2) a hybrid concrete and tubular steel tower, and (3) a lattice or space frame tower. These three alternative tower concepts considered here have all been explored in some depth by wind turbine manufacturers in the past, and all cases have some operational experience in the wind industry. As they were more quantitatively analyzed and discussed, in terms of mass attributes in Section 3.1, we do not reconsider LDST or spiral-welded towers in this section; however, they are also relevant tower options going forward. ${ }^{5}$ Notably, this short list of alternatives is not intended to be comprehensive. In particular, it does not consider lower technology readiness level potential solutions such as three-dimensional-printed concrete, which, if successful, could resolve at least some of the challenges with the concrete tower concepts detailed in the following sections.

\subsubsection{Full-Concrete Field-Cast Towers}

The full-concrete field-cast tower concept has gained interest from the wind industry as a means to circumvent transportation barriers associated with other tall tower technologies. By pouring the tower on-site in the field, overpass clearance barriers are avoided as are other transport hurdles (e.g., weight) associated with moving large concrete sections often utilized in hybrid

\footnotetext{
${ }^{5}$ Potential challenges associated with these tubular rolled steel variants include significant bolts and on-site assembly costs for the base section of the LDST and the potential needs to set up regional or on-site facilities to manufacturing spiral-welded towers.
} 
concrete and tubular steel concepts. Reliance on concrete as the primary material also offers an opportunity for less sensitivity to steel costs and replaces steel with a lower-cost primary material.

Challenges for full-concrete field-cast concepts include relatively large material quantities, which could erode some of the potential material cost savings associated with lower-cost materials, and a persistent dependence on steel for reinforcing rebar and post-tensioning cables. Additionally, the field-casting and erection process tends to be labor- and time-intensive, increasing labor costs overall and potentially introducing logistics challenges. Moreover, without a self-erecting crane-which has not yet been demonstrated in the field-incremental crane costs could be incurred as the individual sections are cast and ultimately placed on the tower.

In terms of its present status, in the United States, WTT has installed a prototype 115-m hub height (100-m concrete tower, 15-m steel section) tower that utilized concrete annuli that were cast on-site. The WTT tower utilizes a process called "match casting" that provides reduced cycle times during tower installation and less finishing work on the interface of the concrete tower sections. The process involves casting tower sections against one another as they cure; this allows for a precision joint and removes the need for a "wet joint," further decreasing installation cycle time. This process is more widely known as "short line match casting" in civil engineering and the bridge industry and eliminates the need for precision machining of the concrete tower section interface as is typical with factory-cast and highway-transported concrete sections common on hybrid concrete and steel towers.

The WTT technology utilizes concrete that can be produced in the field in most locations in the United States. This approach benefits from having a quarry on or near the wind power plant site. This differs from some hybrid concrete and steel factory-cast sections with compressive strengths of approximately 11,000-13,000 psi. Controlling the quality and strength of these higher-strength mixes can be a challenge in the field. Because the tower segments are assumed to be cast on-site, the moving of the tower segments might only face challenges due to weight and the relatively large diameter. For on-site transport, the additional cost of a specialized trailer, if necessary, and tractor or prime mover are assumed to be limited.

\subsubsection{Hybrid Concrete and Tubular Steel Towers}

Historically, the hybrid concrete and tubular steel tower is the most common type of tower for hub heights above $120 \mathrm{~m}$. Max Bögl and the turbine OEM Enercon are perhaps the most prominent users of these tower designs, which most frequently have been installed in Germany. Hybrid designs typically use $\sim 90 \mathrm{~m}$ of concrete annuli or segmented sections and a 50 - to $80-\mathrm{m}$ steel tubular transportable steel tower. Again, an advantage of the concrete construction is that the tower diameter can be optimized (but still considering the transport limits of the concrete sections), which can minimize the material required to construct the concrete portion of the tower.

The cost estimates provided below assume a 90-m concrete tower and a 50-m steel tower. These towers typically use concrete sections that are cast in a factory and utilize high-strength concrete (11,000-13,000 psi). The tower-section mating surfaces are machined parallel and the tower section typically is transported to the site by truck. A transition piece is placed on top of the concrete sections and is used to attach the tubular steel tower section to the concrete base. The 
transition piece is connected to the base of the steel tubular tower and to steel cables that serve to compress the concrete structure. These cables are post-tensioned after installation of the concrete sections and transition piece, and before the installation of the tubular steel tower segments.

The hybrid concrete-tubular steel tower concept has been pursued explicitly because of its lower sensitivity to fluctuations in steel prices and to avoid transport challenges historically associated with tall steel towers. Hybrid concepts also might provide a viable solution to the geometric constraints within the area covered by the rotor disc. At the same time, transport costs still might be significant because of the need to transport large concrete sections as well as steel sections. Relative to the full-concrete field-cast concept, some labor and material savings could be captured by fabricating the various sections in a centralized manufacturing facility, but this savings potential must be weighed against impacts on transportation costs.

Max Bögl announced the capability of a mobile concrete tower-section manufacturing facility (Max Bögl 2016), which could increase the potential utilization of hybrid concrete towers by reducing the transportation cost and increasing local labor fraction. Relative to a full tubular steel tower, labor and material intensities remain comparatively high. The assembly of the large concrete sections coupled with the joining of the concrete and steel portions of the tower also introduce additional erection-cycle time relative to a tubular steel tower. Notably, as advanced turbine controls have evolved and allowed for alternative steel-tower geometries, LDST-style towers have eroded some of the hybrid concepts market share for tall tower installations in Europe.

\subsubsection{Lattice/Space Frame}

Lattice towers were used for many years in the wind industry, specifically in the 50- to 400-kW turbine size range from the 1980s to1990s. Lattice towers offer very low material quantities and a complete tower can be moved by a conventional highway legal truck, helping to control transport costs. In the 1990s, these towers fell out of favor for various reasons; however, visual aesthetics and bird interactions are the most commonly cited explanations. The lattice tower concept is sensitive to labor cost because of the large number of individual structural members and fasteners as well as a relatively challenging skin (something often desirable for its favorable aesthetics). Installation time, particularly for the skin, is also sensitive to weather delays. Increased erection-cycle time, due to the increase in number of tower sections and the time needed to install the skin of the tower, compounds the risk of costly weather delays. Despite the move away from lattice towers over the past two decades, designer interest has never been fully eliminated.

This analysis relies on a limited number of data points derived from publicly available sources specific to a GE lattice tower prototype. These data were used as a starting point to define material, labor, and installation estimates. GE acquired the rights to a patented lattice tower design originally from Wind Tower Systems LLC. This design uses a pentagonal base with a varying cross section until roughly the bottom of the rotor plane. The acquired patents included multiple self-erecting designs, including a climbing jib crane to erect the tower, and a lifting apparatus that could be used to install the nacelle and rotor without the need for a large crane. GE installed a 97-m prototype in Tehachapi, California, in 2014 and later installed a 139-m tower. Based on its experience, GE cited issues with the skin installation and torsional stiffness as nontrivial challenges. 
Turbine OEM Suzlon is currently offering a 120-m hybrid space frame/tubular steel tower for the Indian market with a total installed capacity of more than $1 \mathrm{GW}$ (Suzlon 2018). This approach might address some of the torsional stiffness issues due to the use of the tubular steel section across the rotor plane, as compared to a full space frame where the lattice structure extends from the yaw ring to the ground. This approach also uses a much smaller rotor diameter $(97 \mathrm{~m}$ and 111 $\mathrm{m}$ versus $\sim 130 \mathrm{~m}$ ) and a much shorter tubular steel tower section than the typical concrete hybrid towers. After clearing the rotor plane, the Suzlon lattice square cross section grows to $\sim 4.9 \mathrm{~m}$ per side or $\sim 6.9 \mathrm{~m}$ diagonally (Suzlon 2018).

Nabrawind has demonstrated a 160-m prototype using its Nabralift system, which is a hybrid tubular steel tower within the rotor plane and has a three-leg lattice structure below the rotor. This system uses much larger and fewer members in the lattice structure than used in the GE concept, which reduces labor. This concept also uses much taller segments than many site-cast concrete segments, which reduces cycle times and labor associated with the turbine installation process.

Lattice or other tower approaches with wide footprints also offer the potential use of alternative foundation designs and potentially significant cost reductions in the foundation than a conventional spread foot foundation - which is nearly universally used in the United States. The wider footprint of the lattice towers and potentially spiral-welded towers could allow for large reductions in foundation material, labor, and cost by using individual foundations under each member, or in the case of the spiral-welded tower, use an annular foundation. This could be combined with other foundation approaches, such as rock or soil anchors or small piers, which could result in further reductions in foundation costs. Further cost reductions in BOS could be realized with towers that enable alternative foundation designs. For example, foundation cost fraction is estimated at approximately $15 \%$ of total BOS cost for the $4.5-\mathrm{MW}$ Low-SP turbine at 110-, 140-, and 160-m hub heights.

\subsubsection{Comparing and Contrasting Competing Tower Alternatives}

To begin to understand potential cost differences among tower technologies, we conducted a basic comparison of the relative attributes of the three identified alternatives. Based on this firstorder assessment, the lattice tower seems attractive. In particular, its material and transport costs are expected to be quite low. As noted earlier, however, there are significant challenges that need to be overcome for this technology to be achieve widespread commercial utilization. Key weaknesses include substantial and relatively high-risk installation costs — with risks being compounded by potential wind delays during construction and skin installation. Moreover, resolving the torsional structural issues could erode at least some, if not all, of the potential opportunity associated with lattice towers. In this vein, jacket-type offshore wind substructures are a comparable structural strategy to the lattice tower but have yet to substantially displace the use of steel monopole substructures in offshore environments of shallow to moderate depth (Smith et al. 2015; Musial et al. 2017). Although not altogether comparable, this suggests that adequately resolving the potential weaknesses of the lattice tower could result in a significantly reduced opportunity for them relative to what is suggested in this initial first-order assessment.

Focusing on the full-concrete field-cast cost characterization, it appears that there are also nontrivial challenges to achieving cost levels consistent with broad-based deployment. Firstorder estimates of potential cost are on par with, but not below, what might be achieved with a 
transportable tubular steel tower of comparable height using current design concepts and manufacturing strategies. Perhaps most challenging from the perspective of fundamentals is that a significant portion of costs is either materials-driven or labor. There certainly is potential to eliminate a large amount of the tower labor cost by having the rebar tied off-site and transported in segments and by improved processes and experience. Self-erecting cranes also could reduce installation and erection costs. It might be more difficult to reduce materials costs.

In the United States, with its relatively large (e.g., 300 mile) transport distances, the factory-cast hybrid concrete and tubular steel tower faces a significant disadvantage. Under these conditions, transport costs are estimated to be significant and potentially prohibitive. Absent these substantial transport costs, it is apparent why the hybrid concept historically has been the tall tower technology of choice. Of course, the magnitude of the transport costs also demonstrate why this approach has lost market share in the tall tower space to the LDST concepts employing advanced controls and "soft-soft" design strategies in recent years. Moreover, material and labor costs for the hybrid concept remain significant even when allowing for substantially shorter transport distances. 


\section{Insights for Tower Design and Innovation}

The previous sections of this report have examined and explored the potential opportunity offered by increased tower height through the lens of wind speed, capacity factor, and LCOE. Additionally, they have explored the potential opportunities afforded by advancements in tubular steel towers, as well as the potential strengths and weaknesses of full-concrete, hybrid, and lattice tower concepts. In this section, we attempt to synthesize the insights generated and posit potential metrics that might be used to characterize the viability of novel tower solutions going forward. Key insights are structured by category and follow the general structure of the report.

\subsection{Analysis Results and Insights}

\subsubsection{Wind Resources}

Based on current data in the Wind Toolkit for calendar year 2012, an increase in hub height from 80 to $110 \mathrm{~m}$ generally results in wind speed increases of 0 to $0.5 \mathrm{~m} / \mathrm{s}$ west of the Rockies, and 0.5 to $1.0 \mathrm{~m} / \mathrm{s}$ east of the Rockies. Additionally, some areas see decreased wind speeds with higher above ground levels, likely owing to unusual topographic features, such as mountainous terrain in California and the Appalachian region. If hub height is increased from 80 to $160 \mathrm{~m}$, portions of the central plains would see wind speed increases of 1.5 to $2.0 \mathrm{~m} / \mathrm{s}$. Additionally, some locations in Pennsylvania, New York, and Maine would see increases of 1.0 to $1.5 \mathrm{~m} / \mathrm{s}$. These results lead to a general finding that increased hub height is accompanied by increased wind resources. However, there are regional and topographical differences that must be recognized. Moreover, as discussed in Section 2, the quantitative results presented depend in no small part on the accuracy and validity of the Wind Toolkit data. Mesoscale wind resource data, particularly at higher above ground levels, could benefit from further validation and study, in addition to the efforts completed to date.

\subsubsection{Capacity Factors}

For the Today turbine, capacity factor generally increased when hub height was increased from 80 to $110 \mathrm{~m}$, with the increases clustered at 5 percentage points or less. At $140 \mathrm{~m}$ relative to 80 $\mathrm{m}$, capacity factor increases exhibited a range from approximately 0 to 10 percentage points with a relatively flat distribution. For the other three turbines examined and focusing on the comparisons within each turbine platform, median capacity factor increases were approximately 2 to 3 percentage points when moving from 110 to $140 \mathrm{~m}$ and approximately 1 percentage point when moving from 140 to $160 \mathrm{~m}$. Generalizing these results indicates that increasing hub heights to 110 and $140 \mathrm{~m}$ drives sizable gains across turbine platforms with seemingly diminishing returns above $140 \mathrm{~m}$. These findings exhibit the same regional and topographical variations observed with the wind resource data. These results are highly dependent on the accuracy of the wind resource data, particularly at the higher above ground levels, and also vary depending on the specific turbine configuration applied. While diminishing returns with higher above ground heights is at least partially intuitive, the uncertainty in the underlying resource data makes it difficult to ascertain the robustness of the observed trends.

\subsubsection{Energy Costs}

Of the four turbines examined, the Low-SP 4.5-MW turbine exhibited the lowest LCOE values. At a 110-m hub height, unsubsidized LCOE for this machine ranged from $\$ 25 / \mathrm{MWh}$ to $\$ 35 / \mathrm{MWh}$ throughout much of the nation's interior wind belt. In the eastern half of the nation, 
LCOE ranged from $\$ 35 / \mathrm{MWh}$ to $\$ 50 / \mathrm{MWh}$. Throughout the Pacific and Intermountain West regions, results were mixed. With hub height increased to $160 \mathrm{~m}$, there was less support for \$25/MWh to \$35/MWh LCOE in the interior wind belt, whereas in some eastern regions LCOE was reduced relative to the $110-\mathrm{m}$ case. This correlates with experience within the wind industry: commercial wind developers' interest in taller towers is emerging in the eastern states, but as yet there is no corresponding drive in the interior wind belt.

Changes in LCOE relative to the estimated LCOE for the Today turbine at $80 \mathrm{~m}$ were also estimated for all four turbines at each Wind Toolkit site (more than 1.85 million nationwide), yielding broad distributions reflecting the wide range of wind resources throughout the nation. For the Low-SP 4.5-MW turbine, the changes in LCOE range from slightly positive to reductions of as much as $\$ 30 / \mathrm{MWh}$, with a broad peak clustered around $\$ 5 / \mathrm{MWh}$ to $\$ 10 / \mathrm{MWh}$. In contrast, LCOE values for the Today turbine at the higher hub heights tend to be greater as hub height is increased. Results for the other two machines are similar to those for the 4.5-MW machine but are less pronounced.

Economically preferred tower heights were determined for each of the four turbines at each Wind Toolkit site. The preferred height - selected from the options of $80 \mathrm{~m}, 110 \mathrm{~m}, 140 \mathrm{~m}$, and $160 \mathrm{~m}$-yielded the lowest LCOE at that site. Of course, not all of these sites would offer an LCOE low enough to be commercially viable. Many would, however, so the results of this exercise provide an indication of preferred tower heights based on recent technology cost and scaling trends. For today's turbine, $80 \mathrm{~m}$ is preferred for more than half of the sites - again consistent with commercial experience in the interior region-but substantial opportunities exist at $110 \mathrm{~m}$ and $140 \mathrm{~m}$ as well. For the three larger turbines, $110 \mathrm{~m}$ is preferred for more than $60 \%$ of all sites, with significant opportunities at $140 \mathrm{~m}$ as well. The $160-\mathrm{m}$ height was preferred only by the Low-SP 4.5-MW turbine, and at only about $2 \%$ of sites.

\subsubsection{Breakeven Costs}

For a 110-m hub height, the analysis found breakeven costs for today's turbine of well under $\$ 500 / \mathrm{kW}$ for many locations. For the Low-SP 4.5-MW turbine, breakeven costs were clustered around $\$ 500 / \mathrm{kW}$, tailing off to about $\$ 1,500 / \mathrm{kW}$. At the $140-\mathrm{m}$ hub height, breakeven costs exhibited a wide distribution with a broad peak. For the Today turbine, breakeven costs were clustered around approximately $\$ 250 / \mathrm{kW}$, tailing off to about $\$ 1,000 / \mathrm{kW}$.

These results provide turbine designers with a rough indication of the cost budget allowable in pursuing economical taller turbines. Of course, beating the breakeven cost could be accomplished with whatever means are available to designers, manufacturers, and installers. These could include changes in design or other machine features, reduced blade costs or a reduced blade mass scaling exponent, advances in tower design or manufacturing, advanced turbine controls, erection economies or other BOS advances, other unforeseen improvements, or combinations of several of these methods.

\subsubsection{Tall Tower Options}

In pursuing higher hub heights at affordable costs, tower cost is a major factor. We examined prospects for tubular steel towers and several other options under consideration. Three tubular steel options were analyzed: transportable tower, with a 4.3-m base diameter; LDST, with a 6.2$\mathrm{m}$ base diameter; and an unconstrained base diameter tower, which might be fabricated on-site 
with spiral-welding techniques. We considered hub heights from 80 to $180 \mathrm{~m}$ and examined both soft-stiff and soft-soft designs.

In the soft-stiff case, the transportable tower becomes uneconomical rapidly as its height is increased. At $80 \mathrm{~m}$, its weight is estimated at 180 tons. At $120 \mathrm{~m}$, its weight has increased to 900 tons. Beyond $120 \mathrm{~m}$, it was determined to be economically impractical. For the LDST case, the 80-m weight is estimated at 130 tons, reflecting the reduced steel thickness allowed by the larger base diameter. At $140 \mathrm{~m}$, its weight has increased to 850 tons. For the unconstrained case, the 140-m tower weight is 440 tons (or about half of the 140-m LDST weight). Clearly, the unconstrained option offers a huge advantage with respect to weight; however, on-site production presents its own nontrivial challenges.

For the soft-soft cases examined, significant weight reductions are estimated relative to soft-stiff options. The transportable tower weight at $140 \mathrm{~m}$ is 440 tons, less than half the weight of the soft-stiff tower at $120 \mathrm{~m}$. Even at $160 \mathrm{~m}$, its weight of 860 tons is less than that of the $120-\mathrm{m}$ soft-stiff tower. The other two tower options also show comparable reductions. In the unconstrained case, the $160-\mathrm{m}$ tower, at 470 tons, is only slightly heavier than the $140-\mathrm{m}$ softstiff tower (440 tons).

It is clear from these results that soft-soft tower designs offer a substantial weight-and thus likely cost - advantage. Even the transportable option that is able to clear today's highway transport constraints becomes feasible at $140 \mathrm{~m}$. The major challenge for soft-soft designs is management of 1P resonances through advanced controls, damping, or some other means. Wind turbine OEMs appear to be making significant progress along these lines, as evidenced by commercial tower weights that are somewhat less than the weights estimated in our analysis.

In addition to steel towers, we also examined prospects and costs for several other tower options, including full-concrete field-cast, hybrid concrete and tubular steel tower, and lattice or space frame. These could offer advantages in transport, erection, and BOS costs, and might allow for larger base diameters, but all are accompanied by much greater labor costs than those of transportable towers. Potential advantages and risks were assessed for each of these options. For installations in the United States, none of these options shows a clear advantage over tubular steel towers. Of the three, the lattice-based approaches seem to offer the greatest potential, based on low material and transport costs. However, there are sizable risks associated with on-site labor requirements, wind conditions during installation, and torsional loads. With the full-concrete field-cast approach, reducing costs below tubular steel presents a major challenge. With the hybrid-concrete approach, large concrete sections are cast in a factory and then transported over long distances. With transportation costs approaching nearly half of total installed tower cost, the prospects for this option appear limited, unless there are logistics or other innovations that can greatly reduce transportation requirements and costs.

\subsection{Analysis Results Discussion}

Overall, this analysis leads to three primary conclusions. First, there is sufficient additional wind resource in the United States at higher above ground levels to warrant the pursuit of technology enabling higher hub heights. Second, tall tower technologies with the greatest potential appear to be tubular steel based on soft-soft design criteria; these towers have gained relative prominence in the industry over the past several years. Third, hub heights of $110 \mathrm{~m}$ to $140 \mathrm{~m}$ have the 
potential to offer some LCOE advantages relative to today's typical turbines, with optimal hub heights potentially varying from these discrete points were a more continuous set of solutions available. Based on the initial first-order cost estimates applied here, LCOE reductions between $\$ 5 / \mathrm{MWh}$ and $\$ 10 / \mathrm{MWh}$, and in some cases even larger, are plausible. Tall tower technologies and solutions could be even more attractive if they are able to incorporate innovation potential not captured here that enhances their economics relative to recent scaling trends.

Given the substantial uncertainties embedded in our cost assumptions and the relative optimism toward higher hub heights and larger machines, however, these findings need to be verified and validated with more resolved and comprehensive cost estimates before they can be deemed robust. More specifically, changes in turbine or BOS CapEx could alter the observed outcomes.

Additionally, our analysis indicates somewhat diminishing returns from hub height increases to $140 \mathrm{~m}$ and subsequently to $160 \mathrm{~m}$. Moreover, potential returns from achieving $140 \mathrm{~m}$ or $160 \mathrm{~m}$ are in locations where estimated LCOEs are relatively high, suggesting that simply making an economic case for a higher hub height in these locations might not be sufficient to support wind deployment in these regions. These results suggest that potential future drivers of higher wind turbine hub heights could be governed by factors beyond the observed improvement in wind resource alone. Alternative drivers could include increased land constraints (as has been observed in Germany), with more limited locations to install wind turbines and therefore a need to maximize the energy generation per turbine. Another alternative driver could be a desire to further increase rotor size and therefore increase hub height to provide sufficient ground clearance.

\subsection{Lessons Learned for Evaluating Tall Tower Opportunities}

This analysis shows that wind resource quality improves in most locations with higher above ground levels, up to at least $160 \mathrm{~m}$. The analysis, however, also shows that the relative value of achieving higher hub heights is not absolute and varies significantly by location. Moreover, the locations where the value is potentially greatest from achieving higher hub heights tend to be places where the wind energy resource is less robust; therefore, economically achieving a higher hub height alone might not be sufficient to make wind power economic in those locations.

Given this context, evaluating the viability of a given tall tower opportunity is both complex and difficult to generalize. Based on our insights from this work, we suggest focusing on LCOE, total CapEx, and breakeven cost as the means of evaluating relative usefulness of a proposed tall tower approach. Consideration of a particular set of site conditions is also important given the variability in value as a function of geospatial variables. Further, tower cost itself is important but can be misleading. Some tower solutions could actually increase tower cost and still result in a lower CapEx if they enable an elegant installation solution that further minimizes BOS cost. Moreover, if computed on a dollars-per-kilowatt $(\$ / \mathrm{kW})$ basis, a solution requires holding the turbine's nameplate capacity constant to avoid manipulating one particular component cost (e.g., tower) simply by increasing or decreasing nameplate capacity; tower scaling and generator scaling are not directly proportional.

The LCOE and total CapEx (or breakeven costs) are of particular importance given the interplay between turbine and plant subsystems, as well as the potential for hub height to impact BOS and operational expenditures. Notably, the most critical innovation enabling soft-soft towers is the 
turbine controls, which now enable the machine to avoid operating conditions that were key design constraints in prior eras. Similarly, going forward, alternative erection techniques that reduce BOS costs could be as critical to realizing the value of higher hub heights as is developing novel tower solutions.

If focusing on a singular metric for evaluating the potential afforded by any given tall tower solution, we propose a focus on breakeven cost - computed at the system or total CapEx level. The value of the metric should also consider the LCOE that might be required to support economic deployment of wind energy in a given region. Based on the analysis conducted here, a system-level breakeven cost of less than $\$ 500 / \mathrm{kW}$ for relatively lower specific power turbines and potentially as low as $\$ 200 / \mathrm{kW}$, particularly for higher specific power turbines, could be sufficient to support an LCOE reduction across much of the country, and also would push lessenergetic wind resource regions further along the path to competitiveness. Stated from a developer's perspective, if a prospective taller-tower solution (110 $\mathrm{m}$ or higher) can be realized at an additional cost of about $\$ 200 / \mathrm{kW}$ (relative to the same turbine on an $80-\mathrm{m}$ tower), that solution is likely to offer wide applicability across the nation. The same would be true at $\$ 500 / \mathrm{kW}$, but to a lesser extent. Depending on the specific focus areas, turbine configuration, and relevant site conditions, and especially if pushing toward higher hub heights (e.g., $140 \mathrm{~m}$, $160 \mathrm{~m}$ ), divergence of higher breakeven costs from this general guidance could be merited. 


\section{Conclusions}

We find the question of optimal wind turbine tower height to be a rich and complex area of research, particularly when considering the problem at the continental scale. The system nature of wind technology and the variability in key input variables across time and space - not least of which is the wind resource - add dimensions to the analysis that require consideration of a great number of potential trade-offs as well as the possibility for multiple equally optimal solutions. Moreover, we have observed that our results are sensitive to changes in key assumptions (e.g., total CapEx and wind shear) that are highly uncertain but, at the same time, the magnitude of the difference in outcomes is not always significant.

Notwithstanding the complexity of the tasks and the array of potential outcomes, our analysis suggests that there are sizable gains to be had by realizing tall tower technologies. At the same time, there may also be diminishing returns to higher hub heights, and locations where the value of higher hub heights is greatest tend to be the areas where wind energy presently is relatively high cost. Based on our current cost assumptions derived from recent vintage technology scaling functions, it is the case across much of the continental United States that the lowest available hub height (e.g., $80 \mathrm{~m}, 110 \mathrm{~m}$ ) often provides the lowest-cost solution. At the same time, taller towers may be critical to increasing the opportunity for wind power across the nation and could become increasingly attractive as innovations drive down the costs required to achieve higher hub heights. Continued tower growth could also be a result of a combination of factors, including land constraints that result in stronger consideration for maximizing energy production per turbine and the need to provide sufficient ground clearance as a function of continued rotor growth.

Future work efforts in this domain are anticipated to benefit from research that quantifies and ultimately reduces the uncertainty of the wind resource data, particularly at higher above ground levels. In addition, more focus on cost estimates including sensitivities, analyzing specific technology opportunities, and analyzing alternative turbine configurations could provide more robust perspectives and insights into the potential for innovative solutions to capture additional value from taller towers. 


\section{References}

American Wind Energy Association (AWEA). 2017. U.S. Wind Industry Annual Market Report: Year Ending 2017. Washington, D.C. http://www.awea.org/market-reports.

AWEA. 2019. U.S. Wind Industry Annual Market Report: Year Ending 2018. Washington, D.C. http://www.awea.org/market-reports.

Damiani, R. 2016. "Design of Offshore Wind Turbine Towers." Offshore Wind Farms Technologies, Design and Operation. ISBN: 978-0-08-100779-2. O'Reilly.

Dykes, K., P. Graf, G. Scott, A. Ning, R. King, Y. Guo, T. Parsons, R. Damiani, F. Felker, P. Veers. 2015. "Introducing WISDEM: An Integrated System Modeling for Wind Turbines and Plant." National Renewable Energy Laboratory (NREL), Golden, CO. NREL/PR-5000-63564. Presented at the Third Wind Energy Systems Engineering Workshop, Boulder, CO, January 14, 2015. https://www.nrel.gov/docs/fy15osti/63564.pdf.

Dykes, K., M. Hand, T. Stehly, P. Veers, M. Robinson, E. Lantz, R. Tusing. 2017. Enabling the SMART Wind Power Plant of the Future Through Science-Based Innovation (Technical Report). National Renewable Energy Laboratory (NREL), Golden, CO. NREL/TP-5000-68123. https://www.nrel.gov/docs/fy17osti/68123.pdf.

Dykes, K., R. Damiani, O. Roberts, E. Lantz. 2018. “Analysis of Ideal Towers for Tall Wind Applications: Preprint.” Golden, CO: National Renewable Energy Laboratory. NREL/CP-500070642. https://www.nrel.gov/docs/fy18osti/70642.pdf.

Energy Information Administration. 2019. "Wind Explained; Electricity Generation from Wind." https://www.eia.gov/energyexplained/index.php?page=wind electricity_generation. Accessed April 26, 2019.

Hand, M.M., ed. 2019. IEA Wind TCP Task 26-Wind Technology, Cost, and Performance Trends in Denmark, Germany, Ireland, Norway, Sweden, the European Union, and the United States: 2008-2016. National Renewable Energy Laboratory (NREL), Golden, CO. NREL/TP6A20.71844.

Deutsche WindGuard. 2018. "Wind Energy Statistics." https://www.windguard.com/windenergy-statistics.html. Accessed April 26, 2019.

International Electrotechnical Commission (IEC). "IEC 61400-1 Ed. 3.1. Wind Turbines - Part 1: Design Requirements," 2014.

Jonkman, J., S. Butterfield, W. Musial, G. Scott. 2009. Definition of a 5-MW Reference Wind Turbine for Offshore System Development (Technical Report). National Renewable Energy Laboratory (NREL), Golden, CO. NREL/TP-500-38060. https://www.nrel.gov/docs/fy09osti/38060.pdf.

Mai, T., E. Lantz, M. Mowers, R. Wiser. 2017. The Value of Wind Technology Innovation: Implications for the U.S. Power System, Wind Industry, Electricity Consumers, and Environment 
(Technical Report). National Renewable Energy Laboratory (NREL), Golden, CO. NREL/TP6A20-70032. https://www.nrel.gov/docs/fy17osti/70032.pdf.

Max Bögl. 2016. https://www.max-boegl.de/en/news/hybrid-tower-system-max-boegl-160-andmobile-factory. Accessed April 28, 2019.

Montanez, M. 2017. "The Low Hanging Fruit of LCOE: How Wind Turbine Controls Can Bridge the Valley.” AWEA Windpower 2017. May 24, 2017.

Musial, W., P. Beiter, P. Schwabe, T. Tian, T. Stehly, P. Spitsen. 2017. 2016 Offshore Wind Technologies Market Report. U.S. Department of Energy, Office of Energy Efficiency \& Renewable Energy, Washington, D.C. DOE/GO-102017-5031.

https://www.energy.gov/eere/wind/downloads/2016-offshore-wind-technologies-market-report.

Nabrawind. 2019. http://www.nabrawind.com. Accessed March 6, 2019.

Ning, S. A., R. Damiani, P. Moriarty. 2013. "Objectives and Constraints for Wind Turbine Optimization." Paper No. AIAA 2013-0201. [Proceedings] 51st AIAA Aerospace Sciences Meeting Including the New Horizons Forum and Aerospace Exposition, January 7-10, 2013, Grapevine, Texas. National Renewable Energy Laboratory (NREL), Golden, CO. CP-500057320.

Ning, A., K. Dykes. 2014. "Understanding the Benefits and Limitations of Increasing Maximum Rotor Tip Speed for Utility-Scale Wind Turbines." Journal of Physics: Conference Series. Vol. 524(1); 10 pp. http://dx.doi.org/10.1088/1742-6596/524/1/012087.

Smith, A., T. Stehly, W. Musial. 2015. 2014-2015 Offshore Wind Technologies Market Report (Technical Report). National Renewable Energy Laboratory (NREL), Golden, CO. NREL/TP5000-64283. https://www.nrel.gov/docs/fy15osti/64283.pdf.

Stehly, T., P. Beiter, D. Heimiller, G. Scott. 2018. 2017 Cost of Wind Energy Review (Technical Report). National Renewable Energy Laboratory (NREL), Golden, CO. NREL/TP-6A2072167. https://www.nrel.gov/docs/fy18osti/72167.

Suzlon. 2018. "S111 Wind Turbine Generator." https://www.suzlon.com/in-en/energysolutions/s111-wind-turbine-generator. Accessed April 29, 2019.

Wiser, R. H., and M. Bolinger. 2018. 2017 Wind Technologies Market Report. U.S. Department of Energy, Office of Energy Efficiency \& Renewable Energy. Washington, D.C.

https://www.energy.gov/eere/wind/downloads/2017-wind-technologies-market-report.

Wiser, R. H., M. Bolinger, E. Lantz. Forthcoming. Assessing Wind Power Operating Costs in the United States: Results from a Survey of Wind Industry Experts. Submitted to Renewable Energy Focus.

Vitina, A., S. Lüers, A.-K. Wallasch, V. Berkhout, A. Duffy, B. Cleary, L. I. Husabø, D. E. Weir, R. Lacal-Arántegui, M. M. Hand, E. Lantz, K. Belyeu, R. H. Wiser, M. Bolinger, B. Hoen. 
2015. IEA Wind Task 26: Wind Technology, Cost, and Performance Trends in Denmark, Germany, Ireland, Norway, the European Union, and the United States: 2007-2012. National Renewable Energy Laboratory (NREL), Golden, CO. NREL/TP-6A20-64332. https://www.nrel.gov/docs/fy15osti/64332.pdf.

Zayas, J., M. Derby, P. Gilman, S. Ananthan, E. Lantz, J. Cotrell, F. Beck, R. Tusing. 2015. Enabling Wind Power Nationwide. U.S. Department of Energy, Washington, D.C. https://www.energy.gov/sites/prod/files/2015/05/f22/Enabling\%20Wind\%20Power\%20Nationwi de 18MAY2015_FINAL.pdf. 


\section{Appendix A. Supplemental Input and Results Data}

Table A1. Detailed Levelized Cost of Energy Cost Inputs

\begin{tabular}{|c|c|c|c|c|}
\hline & Today & $\begin{array}{c}\text { Low } \\
\text { Specific } \\
\text { Power (SP) } \\
4.5\end{array}$ & $\begin{array}{c}\text { Business } \\
\text { as Usual } \\
\text { (BAU) }\end{array}$ & $\begin{array}{l}\text { LoW-SP } \\
3.25 \mathrm{MW}\end{array}$ \\
\hline Nameplate Capacity (megawatts [MW]) & 2.32 & 4.50 & 3.30 & 3.25 \\
\hline Rotor Diameter (meters [m]) & 113 & 194 & 156 & 166 \\
\hline Specific Power (watts $(W) / m^{2}$ ) & 231 & 152 & 173 & 150 \\
\hline $\begin{array}{l}\text { Hub Height } 80 \mathrm{~m} \text {, Tower Cost (\$/kilowatt } \\
{[\mathrm{kW}] \text { ) }}\end{array}$ & $\$ 198$ & - & - & - \\
\hline Hub Height 110 m, Tower Cost (\$/kW) & $\$ 378$ & $\$ 195$ & $\$ 266$ & $\$ 270$ \\
\hline Hub Height 140 m, Tower Cost ( $\$ / k W)$ & $\$ 616$ & $\$ 318$ & $\$ 433$ & $\$ 440$ \\
\hline Hub Height 160 m, Tower Cost (\$/kW) & $\$ 808$ & $\$ 416$ & $\$ 568$ & $\$ 577$ \\
\hline $\begin{array}{l}\text { Turbine Rotor Nacelle Assembly }(\$ / \mathrm{kW}) \text {, } \\
\text { Blade Exp }=2.2\end{array}$ & $\$ 562$ & $\$ 802$ & $\$ 695$ & $\$ 779$ \\
\hline $\begin{array}{l}\text { Balance of Station (BOS) (\$/kW), Hub } \\
\text { Height } 80 \mathrm{~m}\end{array}$ & $\$ 317$ & - & - & - \\
\hline BOS (\$/kW), Hub Height 110 m & $\$ 330$ & $\$ 206$ & $\$ 258$ & $\$ 258$ \\
\hline BOS (\$/kW), Hub Height 140 m & $\$ 343$ & $\$ 212$ & $\$ 274$ & $\$ 274$ \\
\hline BOS (\$/kW), Hub Height 160 m & $\$ 352$ & $\$ 215$ & $\$ 292$ & $\$ 292$ \\
\hline $\begin{array}{l}\text { Capital Expenditures (CapEx) }(\$ / \mathrm{kW}) \text {, blade } \\
\text { Exp }=2.2,80 \mathrm{~m}\end{array}$ & $\$ 1,077$ & - & - & - \\
\hline CapEx $(\$ / k W)$, blade $\operatorname{Exp}=2.2,110 \mathrm{~m}$ & $\$ 1,270$ & $\$ 1,203$ & $\$ 1,218$ & $\$ 1,306$ \\
\hline CapEx $(\$ / k W)$, blade Exp $=2.2,140 \mathrm{~m}$ & $\$ 1,521$ & $\$ 1,331$ & $\$ 1,402$ & $\$ 1,492$ \\
\hline CapEx $(\$ / k W)$, blade $\operatorname{Exp}=2.2,160 \mathrm{~m}$ & $\$ 1,722$ & $\$ 1,433$ & $\$ 1,555$ & $\$ 1,648$ \\
\hline $\begin{array}{l}\text { CapEx }(\$ / k W) \text {, blade Exp }=2.2,80 \mathrm{~m} \text {, } \\
\$ 200 / \mathrm{kW} \text { tower }\end{array}$ & $\$ 1,077$ & - & - & - \\
\hline $\begin{array}{c}\text { CapEx }(\$ / k W), \text { blade Exp }=2.2,110 \mathrm{~m} \text {, } \\
\$ 200 / \mathrm{kW} \text { tower }\end{array}$ & $\$ 1,092$ & $\$ 1,208$ & $\$ 1,153$ & $\$ 1,237$ \\
\hline $\begin{array}{l}\text { CapEx }(\$ / k W), \text { blade Exp }=2.2,140 \mathrm{~m} \text {, } \\
\$ 200 / \mathrm{kW} \text { tower }\end{array}$ & $\$ 1,105$ & $\$ 1,213$ & $\$ 1,168$ & $\$ 1,252$ \\
\hline $\begin{array}{l}\text { CapEx }(\$ / \mathrm{kW}) \text {, blade Exp }=2.2,160 \mathrm{~m} \text {, } \\
\$ 200 / \mathrm{kW} \text { tower }\end{array}$ & $\$ 1,114$ & $\$ 1,217$ & $\$ 1,187$ & $\$ 1,271$ \\
\hline
\end{tabular}


Table A2. Net Capacity Factor Change Statistics, Relative to the Today Turbine at $80 \mathrm{~m}$ (Percentage Points)

\begin{tabular}{lccc}
\hline Turbine Configuration & Median & 25th Percentile & 75th Percentile \\
\hline Today $110 \mathrm{~m}$ & 3.8 & 2.1 & 4.7 \\
\hline Today $140 \mathrm{~m}$ & 6.67 & 3.6 & 8.5 \\
\hline Today $160 \mathrm{~m}$ & 7.5 & 4.1 & 9.7 \\
\hline Business as usual (BAU) & & & \\
110 m & 8.8 & 6.2 & 10.0 \\
BAU $140 \mathrm{~m}$ & 11.3 & 7.6 & 13.4 \\
BAU $160 \mathrm{~m}$ & 12.1 & 8.1 & 14.4 \\
Low-SP 3.25 MW, $110 \mathrm{~m}$ & 11.1 & 8.2 & 12.5 \\
\hline Low-SP 3.25 MW, $140 \mathrm{~m}$ & 13.4 & 9.5 & 15.6 \\
\hline Low-SP 3.25 MW, $160 \mathrm{~m}$ & 14.2 & 10.0 & 16.7 \\
\hline Low-SP 4.5 MW, $110 \mathrm{~m}$ & 10.9 & 8.0 & 12.2 \\
\hline Low-SP 4.5 MW, $140 \mathrm{~m}$ & 13.2 & 9.3 & 15.4 \\
\hline Low-SP 4.5 MW, $160 \mathrm{~m}$ & 13.9 & 9.8 & 16.4 \\
\hline
\end{tabular}




\section{Table A3. Net Capacity Factor Breakpoints}

(Percentage of pixels with an increase greater than 5, 10, and 15 percentage points as listed in the column head of the table, relative to the Today turbine at $80 \mathrm{~m}$ )

\begin{tabular}{lccc}
\hline Turbine Configuration & $\mathbf{5}$ & $\mathbf{1 0}$ & $\mathbf{1 5}$ \\
\hline Today $110 \mathrm{~m}$ & $15.3 \%$ & $0.0 \%$ & $0.0 \%$ \\
\hline Today $140 \mathrm{~m}$ & $65.0 \%$ & $8.4 \%$ & $0.0 \%$ \\
\hline Today $160 \mathrm{~m}$ & $69.6 \%$ & $21.6 \%$ & $0.3 \%$ \\
\hline BAU $110 \mathrm{~m}$ & $86.5 \%$ & $25.0 \%$ & $0.0 \%$ \\
\hline BAU $140 \mathrm{~m}$ & $90.9 \%$ & $61.1 \%$ & $8.8 \%$ \\
\hline BAU 160 m & $91.7 \%$ & $65.3 \%$ & $19.4 \%$ \\
Low-SP 3.25 MW, $110 \mathrm{~m}$ & $95.8 \%$ & $62.4 \%$ & $0.9 \%$ \\
\hline Low-SP 3.25 MW, $140 \mathrm{~m}$ & $96.6 \%$ & $72.6 \%$ & $32.7 \%$ \\
\hline Low-SP 3.25 MW, $160 \mathrm{~m}$ & $96.6 \%$ & $75.0 \%$ & $42.3 \%$ \\
\hline Low-SP 4.5 MW, 110 m & $95.3 \%$ & $60.5 \%$ & $0.6 \%$ \\
\hline Low-SP 4.5 MW, 140 m & $96.2 \%$ & $71.6 \%$ & $29.8 \%$ \\
\hline Low-SP 4.5 MW, 160 m & $96.3 \%$ & $74.0 \%$ & $40.1 \%$ \\
\hline
\end{tabular}


Table A4. Levelized Cost of Energy Summary Statistics (\$/megawatt-hour [MWh])

\begin{tabular}{|c|c|c|c|}
\hline Turbine Configuration & Median & 25th Percentile & 75th Percentile \\
\hline Today $80 \mathrm{~m}$ & $\$ 51$ & $\$ 41$ & $\$ 66$ \\
\hline Today 110 m & $\$ 51$ & $\$ 41$ & $\$ 64$ \\
\hline Today $140 \mathrm{~m}$ & $\$ 52$ & $\$ 44$ & $\$ 66$ \\
\hline Today 160 m & $\$ 56$ & $\$ 47$ & $\$ 71$ \\
\hline BAU $110 \mathrm{~m}$ & $\$ 42$ & $\$ 35$ & $\$ 53$ \\
\hline BAU $140 \mathrm{~m}$ & $\$ 43$ & $\$ 37$ & $\$ 54$ \\
\hline BAU $160 \mathrm{~m}$ & $\$ 46$ & $\$ 39$ & $\$ 57$ \\
\hline Low-SP $3.25 \mathrm{MW}, 110 \mathrm{~m}$ & $\$ 42$ & $\$ 35$ & $\$ 52$ \\
\hline Low-SP $3.25 \mathrm{MW}, 140 \mathrm{~m}$ & $\$ 43$ & $\$ 37$ & $\$ 53$ \\
\hline Low-SP 3.25 MW, $160 \mathrm{~m}$ & $\$ 45$ & $\$ 39$ & $\$ 56$ \\
\hline Low-SP $4.5 \mathrm{MW}, 110 \mathrm{~m}$ & $\$ 40$ & $\$ 34$ & $\$ 49$ \\
\hline Low-SP $4.5 \mathrm{MW}, 140 \mathrm{~m}$ & $\$ 40$ & $\$ 34$ & $\$ 49$ \\
\hline Low-SP 4.5 MW, $160 \mathrm{~m}$ & $\$ 41$ & $\$ 35$ & $\$ 51$ \\
\hline
\end{tabular}




\section{Table A5. Levelized Cost of Energy Breakpoints}

(Percentage of pixels with an LCOE less than the dollar values listed in the column head of the table)

\begin{tabular}{|c|c|c|c|}
\hline Turbine Configuration & $\$ 30 / \mathrm{MWh}$ & $\$ 40 / M W h$ & $\$ 50 / \mathrm{MWh}$ \\
\hline Today $80 \mathrm{~m}$ & $0.4 \%$ & $20.9 \%$ & $47.8 \%$ \\
\hline Today $110 \mathrm{~m}$ & $0.1 \%$ & $20.0 \%$ & $48.8 \%$ \\
\hline Today $140 \mathrm{~m}$ & $0.0 \%$ & $9.3 \%$ & $44.5 \%$ \\
\hline Today $160 \mathrm{~m}$ & $0.0 \%$ & $0.8 \%$ & $36.4 \%$ \\
\hline BAU $110 \mathrm{~m}$ & $1.3 \%$ & $43.0 \%$ & $69.0 \%$ \\
\hline BAU $140 \mathrm{~m}$ & $0.1 \%$ & $39.4 \%$ & $66.9 \%$ \\
\hline BAU $160 \mathrm{~m}$ & $0.0 \%$ & $30.0 \%$ & $61.2 \%$ \\
\hline Low-SP $3.25 \mathrm{MW}, 110 \mathrm{~m}$ & $1.0 \%$ & $44.3 \%$ & $71.1 \%$ \\
\hline Low-SP $3.25 \mathrm{MW}, 140 \mathrm{~m}$ & $0.1 \%$ & $40.0 \%$ & $68.6 \%$ \\
\hline Low-SP $3.25 \mathrm{MW}, 160 \mathrm{~m}$ & $0.0 \%$ & $30.2 \%$ & $62.5 \%$ \\
\hline Low-SP $4.5 \mathrm{MW}, 110 \mathrm{~m}$ & $5.4 \%$ & $50.9 \%$ & $76.2 \%$ \\
\hline Low-SP $4.5 \mathrm{MW}, 140 \mathrm{~m}$ & $1.2 \%$ & $50.6 \%$ & $76.3 \%$ \\
\hline Low-SP $4.5 \mathrm{MW}, 160 \mathrm{~m}$ & $0.2 \%$ & $46.3 \%$ & $73.6 \%$ \\
\hline
\end{tabular}


Table A6. Average State Levelized Cost of Energy (\$/MWh)

\begin{tabular}{|c|c|c|c|c|c|c|c|c|c|c|c|c|c|}
\hline State & $\begin{array}{c}\text { Today } \\
80 \mathrm{~m}\end{array}$ & $\begin{array}{l}\text { Today } \\
110 \mathrm{~m}\end{array}$ & $\begin{array}{l}\text { Today } \\
140 \mathrm{~m}\end{array}$ & $\begin{array}{l}\text { Today } \\
160 \mathrm{~m}\end{array}$ & $\begin{array}{c}\text { BAU } \\
110 \mathrm{~m}\end{array}$ & $\begin{array}{c}\text { BAU } \\
140 \mathrm{~m}\end{array}$ & $\begin{array}{c}\text { BAU } \\
160 \mathrm{~m}\end{array}$ & $\begin{array}{c}\text { Low- } \\
\text { SP } \\
3.25 \\
\text { MW } \\
110 \mathrm{~m}\end{array}$ & $\begin{array}{c}\text { Low- } \\
\text { SP } \\
3.25 \\
\text { MW } \\
140 \mathrm{~m}\end{array}$ & $\begin{array}{c}\text { Low- } \\
\text { SP } \\
3.25 \\
\text { MW } \\
160 \mathrm{~m}\end{array}$ & $\begin{array}{c}\text { Low- } \\
\text { SP } 4.5 \\
\text { MW } \\
110 \mathrm{~m}\end{array}$ & $\begin{array}{c}\text { Low- } \\
\text { SP } 4.5 \\
\text { MW } \\
140 \mathrm{~m}\end{array}$ & $\begin{array}{c}\text { Low- } \\
\text { SP } 4.5 \\
\text { MW } \\
160 \mathrm{~m}\end{array}$ \\
\hline $\mathrm{AL}$ & $\$ 72$ & $\$ 66$ & $\$ 64$ & $\$ 67$ & $\$ 54$ & $\$ 52$ & $\$ 54$ & $\$ 52$ & $\$ 51$ & $\$ 53$ & $\$ 50$ & $\$ 47$ & $\$ 48$ \\
\hline$A R$ & $\$ 57$ & $\$ 53$ & $\$ 53$ & $\$ 55$ & $\$ 44$ & $\$ 43$ & $\$ 45$ & $\$ 43$ & $\$ 43$ & $\$ 45$ & $\$ 41$ & $\$ 40$ & $\$ 41$ \\
\hline$A Z$ & $\$ 81$ & $\$ 83$ & $\$ 90$ & $\$ 97$ & $\$ 68$ & $\$ 72$ & $\$ 77$ & $\$ 66$ & $\$ 70$ & $\$ 75$ & $\$ 63$ & $\$ 65$ & $\$ 68$ \\
\hline CA & $\$ 105$ & $\$ 108$ & $\$ 118$ & $\$ 129$ & $\$ 88$ & $\$ 95$ & $\$ 102$ & $\$ 86$ & $\$ 93$ & $\$ 99$ & $\$ 82$ & $\$ 86$ & $\$ 90$ \\
\hline $\mathrm{CO}$ & $\$ 63$ & $\$ 65$ & $\$ 71$ & $\$ 77$ & $\$ 55$ & $\$ 58$ & $\$ 62$ & $\$ 54$ & $\$ 58$ & $\$ 61$ & $\$ 51$ & $\$ 53$ & $\$ 56$ \\
\hline CT & $\$ 55$ & $\$ 52$ & $\$ 51$ & $\$ 54$ & $\$ 43$ & $\$ 42$ & $\$ 44$ & $\$ 42$ & $\$ 42$ & $\$ 43$ & $\$ 40$ & $\$ 39$ & $\$ 39$ \\
\hline DC & $\$ 68$ & $\$ 63$ & $\$ 61$ & $\$ 64$ & $\$ 52$ & $\$ 50$ & $\$ 52$ & $\$ 51$ & $\$ 49$ & $\$ 51$ & $\$ 48$ & $\$ 46$ & $\$ 46$ \\
\hline DE & $\$ 49$ & $\$ 47$ & $\$ 49$ & $\$ 52$ & $\$ 39$ & $\$ 41$ & $\$ 43$ & $\$ 39$ & $\$ 40$ & $\$ 42$ & $\$ 37$ & $\$ 37$ & $\$ 38$ \\
\hline $\mathrm{FL}$ & $\$ 74$ & $\$ 68$ & $\$ 67$ & $\$ 71$ & $\$ 54$ & $\$ 53$ & $\$ 55$ & $\$ 52$ & $\$ 52$ & $\$ 54$ & $\$ 49$ & $\$ 48$ & $\$ 49$ \\
\hline GA & $\$ 70$ & $\$ 65$ & $\$ 63$ & $\$ 67$ & $\$ 52$ & $\$ 51$ & $\$ 53$ & $\$ 51$ & $\$ 50$ & $\$ 52$ & $\$ 48$ & $\$ 47$ & $\$ 48$ \\
\hline IA & $\$ 39$ & $\$ 39$ & $\$ 41$ & $\$ 44$ & $\$ 33$ & $\$ 35$ & $\$ 37$ & $\$ 34$ & $\$ 35$ & $\$ 37$ & $\$ 32$ & $\$ 32$ & $\$ 34$ \\
\hline ID & $\$ 66$ & $\$ 68$ & $\$ 74$ & $\$ 80$ & $\$ 57$ & $\$ 60$ & $\$ 64$ & $\$ 56$ & $\$ 59$ & $\$ 63$ & $\$ 53$ & $\$ 55$ & $\$ 57$ \\
\hline IL & $\$ 44$ & $\$ 43$ & $\$ 45$ & $\$ 48$ & $\$ 37$ & $\$ 38$ & $\$ 40$ & $\$ 36$ & $\$ 38$ & $\$ 40$ & $\$ 35$ & $\$ 35$ & $\$ 36$ \\
\hline IN & $\$ 46$ & $\$ 45$ & $\$ 48$ & $\$ 51$ & $\$ 38$ & $\$ 40$ & $\$ 42$ & $\$ 38$ & $\$ 40$ & $\$ 42$ & $\$ 36$ & $\$ 37$ & $\$ 38$ \\
\hline KS & $\$ 38$ & $\$ 38$ & $\$ 40$ & $\$ 44$ & $\$ 33$ & $\$ 35$ & $\$ 37$ & $\$ 33$ & $\$ 35$ & $\$ 37$ & $\$ 31$ & $\$ 32$ & $\$ 34$ \\
\hline $\mathrm{KY}$ & $\$ 59$ & $\$ 56$ & $\$ 56$ & $\$ 60$ & $\$ 47$ & $\$ 47$ & $\$ 49$ & $\$ 46$ & $\$ 46$ & $\$ 49$ & $\$ 43$ & $\$ 43$ & $\$ 44$ \\
\hline LA & $\$ 61$ & $\$ 57$ & $\$ 57$ & $\$ 61$ & $\$ 46$ & $\$ 47$ & $\$ 49$ & $\$ 45$ & $\$ 46$ & $\$ 48$ & $\$ 43$ & $\$ 42$ & $\$ 44$ \\
\hline MA & $\$ 52$ & $\$ 50$ & $\$ 50$ & $\$ 52$ & $\$ 41$ & $\$ 41$ & $\$ 43$ & $\$ 41$ & $\$ 41$ & $\$ 43$ & $\$ 39$ & $\$ 38$ & $\$ 39$ \\
\hline MD & $\$ 55$ & $\$ 53$ & $\$ 54$ & $\$ 57$ & $\$ 44$ & $\$ 44$ & $\$ 47$ & $\$ 43$ & $\$ 44$ & $\$ 46$ & $\$ 41$ & $\$ 41$ & $\$ 42$ \\
\hline $\mathrm{ME}$ & $\$ 51$ & $\$ 49$ & $\$ 49$ & $\$ 51$ & $\$ 41$ & $\$ 40$ & $\$ 42$ & $\$ 40$ & $\$ 40$ & $\$ 42$ & $\$ 38$ & $\$ 37$ & $\$ 38$ \\
\hline MI & $\$ 45$ & $\$ 43$ & $\$ 45$ & $\$ 48$ & $\$ 37$ & $\$ 38$ & $\$ 40$ & $\$ 36$ & $\$ 37$ & $\$ 40$ & $\$ 34$ & $\$ 35$ & $\$ 36$ \\
\hline
\end{tabular}




\begin{tabular}{|c|c|c|c|c|c|c|c|c|c|c|c|c|c|}
\hline State & $\begin{array}{l}\text { Today } \\
80 \mathrm{~m}\end{array}$ & $\begin{array}{l}\text { Today } \\
110 \mathrm{~m}\end{array}$ & $\begin{array}{l}\text { Today } \\
140 \mathrm{~m}\end{array}$ & $\begin{array}{l}\text { Today } \\
160 \text { m }\end{array}$ & $\begin{array}{c}\text { BAU } \\
110 \mathrm{~m}\end{array}$ & $\begin{array}{c}\text { BAU } \\
140 \mathrm{~m}\end{array}$ & $\begin{array}{c}\text { BAU } \\
160 \mathrm{~m}\end{array}$ & $\begin{array}{c}\text { Low- } \\
\text { SP } \\
3.25 \\
\text { MW } \\
110 \mathrm{~m}\end{array}$ & $\begin{array}{c}\text { Low- } \\
\text { SP } \\
3.25 \\
\text { MW } \\
140 \mathrm{~m}\end{array}$ & $\begin{array}{c}\text { Low- } \\
\text { SP } \\
3.25 \\
\text { MW } \\
160 \mathrm{~m}\end{array}$ & $\begin{array}{c}\text { Low- } \\
\text { SP } 4.5 \\
\text { MW } \\
110 \mathrm{~m}\end{array}$ & $\begin{array}{c}\text { Low- } \\
\text { SP } 4.5 \\
\text { MW } \\
140 \mathrm{~m}\end{array}$ & $\begin{array}{c}\text { Low- } \\
\text { SP } 4.5 \\
\text { MW } \\
160 \mathrm{~m}\end{array}$ \\
\hline MN & $\$ 42$ & $\$ 41$ & $\$ 43$ & $\$ 46$ & $\$ 35$ & $\$ 37$ & $\$ 39$ & $\$ 35$ & $\$ 37$ & $\$ 39$ & $\$ 33$ & $\$ 34$ & $\$ 35$ \\
\hline $\mathrm{MO}$ & $\$ 45$ & $\$ 43$ & $\$ 45$ & $\$ 48$ & $\$ 37$ & $\$ 38$ & $\$ 40$ & $\$ 37$ & $\$ 38$ & $\$ 40$ & $\$ 35$ & $\$ 35$ & $\$ 36$ \\
\hline MS & $\$ 62$ & $\$ 57$ & $\$ 57$ & $\$ 60$ & $\$ 47$ & $\$ 47$ & $\$ 49$ & $\$ 46$ & $\$ 46$ & $\$ 48$ & $\$ 44$ & $\$ 43$ & $\$ 44$ \\
\hline MT & $\$ 48$ & $\$ 49$ & $\$ 52$ & $\$ 56$ & $\$ 42$ & $\$ 44$ & $\$ 47$ & $\$ 42$ & $\$ 44$ & $\$ 47$ & $\$ 40$ & $\$ 41$ & $\$ 42$ \\
\hline $\mathrm{NC}$ & $\$ 66$ & $\$ 62$ & $\$ 63$ & $\$ 66$ & $\$ 51$ & $\$ 51$ & $\$ 53$ & $\$ 50$ & $\$ 50$ & $\$ 53$ & $\$ 48$ & $\$ 47$ & $\$ 48$ \\
\hline ND & $\$ 39$ & $\$ 40$ & $\$ 42$ & $\$ 45$ & $\$ 34$ & $\$ 35$ & $\$ 38$ & $\$ 34$ & $\$ 36$ & $\$ 38$ & $\$ 32$ & $\$ 33$ & $\$ 34$ \\
\hline NE & $\$ 38$ & $\$ 39$ & $\$ 41$ & $\$ 44$ & $\$ 33$ & $\$ 35$ & $\$ 37$ & $\$ 33$ & $\$ 35$ & $\$ 37$ & $\$ 32$ & $\$ 32$ & $\$ 34$ \\
\hline $\mathrm{NH}$ & $\$ 57$ & $\$ 55$ & $\$ 56$ & $\$ 58$ & $\$ 46$ & $\$ 46$ & $\$ 48$ & $\$ 45$ & $\$ 45$ & $\$ 47$ & $\$ 43$ & $\$ 42$ & $\$ 43$ \\
\hline $\mathrm{NJ}$ & $\$ 55$ & $\$ 52$ & $\$ 52$ & $\$ 55$ & $\$ 43$ & $\$ 43$ & $\$ 45$ & $\$ 42$ & $\$ 42$ & $\$ 44$ & $\$ 40$ & $\$ 39$ & $\$ 40$ \\
\hline NM & $\$ 59$ & $\$ 60$ & $\$ 65$ & $\$ 69$ & $\$ 50$ & $\$ 53$ & $\$ 56$ & $\$ 50$ & $\$ 52$ & $\$ 55$ & $\$ 47$ & $\$ 48$ & $\$ 50$ \\
\hline NV & $\$ 66$ & $\$ 69$ & $\$ 77$ & $\$ 83$ & $\$ 58$ & $\$ 63$ & $\$ 67$ & $\$ 58$ & $\$ 62$ & $\$ 66$ & $\$ 55$ & $\$ 57$ & $\$ 60$ \\
\hline NY & $\$ 52$ & $\$ 51$ & $\$ 51$ & $\$ 54$ & $\$ 42$ & $\$ 42$ & $\$ 44$ & $\$ 42$ & $\$ 42$ & $\$ 44$ & $\$ 40$ & $\$ 39$ & $\$ 40$ \\
\hline $\mathrm{OH}$ & $\$ 52$ & $\$ 50$ & $\$ 51$ & $\$ 54$ & $\$ 42$ & $\$ 42$ & $\$ 45$ & $\$ 41$ & $\$ 42$ & $\$ 44$ & $\$ 39$ & $\$ 39$ & $\$ 40$ \\
\hline OK & $\$ 40$ & $\$ 40$ & $\$ 42$ & $\$ 45$ & $\$ 34$ & $\$ 35$ & $\$ 38$ & $\$ 34$ & $\$ 36$ & $\$ 38$ & $\$ 32$ & $\$ 33$ & $\$ 34$ \\
\hline OR & $\$ 65$ & $\$ 67$ & $\$ 72$ & $\$ 77$ & $\$ 56$ & $\$ 59$ & $\$ 63$ & $\$ 56$ & $\$ 58$ & $\$ 62$ & $\$ 53$ & $\$ 54$ & $\$ 56$ \\
\hline PA & $\$ 57$ & $\$ 55$ & $\$ 54$ & $\$ 57$ & $\$ 45$ & $\$ 45$ & $\$ 46$ & $\$ 44$ & $\$ 44$ & $\$ 46$ & $\$ 42$ & $\$ 41$ & $\$ 42$ \\
\hline RI & $\$ 47$ & $\$ 45$ & $\$ 46$ & $\$ 49$ & $\$ 38$ & $\$ 38$ & $\$ 40$ & $\$ 37$ & $\$ 38$ & $\$ 40$ & $\$ 35$ & $\$ 35$ & $\$ 36$ \\
\hline SC & $\$ 69$ & $\$ 64$ & $\$ 64$ & $\$ 67$ & $\$ 52$ & $\$ 52$ & $\$ 54$ & $\$ 51$ & $\$ 51$ & $\$ 53$ & $\$ 49$ & $\$ 47$ & $\$ 48$ \\
\hline SD & $\$ 40$ & $\$ 41$ & $\$ 43$ & $\$ 46$ & $\$ 35$ & $\$ 37$ & $\$ 39$ & $\$ 35$ & $\$ 37$ & $\$ 39$ & $\$ 33$ & $\$ 34$ & $\$ 35$ \\
\hline TN & $\$ 65$ & $\$ 62$ & $\$ 62$ & $\$ 65$ & $\$ 51$ & $\$ 51$ & $\$ 53$ & $\$ 50$ & $\$ 50$ & $\$ 52$ & $\$ 48$ & $\$ 46$ & $\$ 48$ \\
\hline TX & $\$ 47$ & $\$ 46$ & $\$ 47$ & $\$ 50$ & $\$ 38$ & $\$ 39$ & $\$ 41$ & $\$ 38$ & $\$ 39$ & $\$ 41$ & $\$ 36$ & $\$ 36$ & $\$ 37$ \\
\hline UT & $\$ 69$ & $\$ 72$ & $\$ 79$ & $\$ 86$ & $\$ 61$ & $\$ 66$ & $\$ 70$ & $\$ 60$ & $\$ 65$ & $\$ 69$ & $\$ 57$ & $\$ 60$ & $\$ 63$ \\
\hline
\end{tabular}




\begin{tabular}{|c|c|c|c|c|c|c|c|c|c|c|c|c|c|}
\hline State & $\begin{array}{l}\text { Today } \\
80 \mathrm{~m}\end{array}$ & $\begin{array}{l}\text { Today } \\
110 \mathrm{~m}\end{array}$ & $\begin{array}{l}\text { Today } \\
140 \mathrm{~m}\end{array}$ & $\begin{array}{l}\text { Today } \\
160 \mathrm{~m}\end{array}$ & $\begin{array}{c}\text { BAU } \\
110 \mathrm{~m}\end{array}$ & $\begin{array}{c}\text { BAU } \\
140 \mathrm{~m}\end{array}$ & $\begin{array}{c}\text { BAU } \\
160 \mathrm{~m}\end{array}$ & $\begin{array}{c}\text { Low- } \\
\text { SP } \\
3.25 \\
\text { MW } \\
110 \mathrm{~m}\end{array}$ & $\begin{array}{c}\text { Low- } \\
\text { SP } \\
3.25 \\
\text { MW } \\
140 \mathrm{~m}\end{array}$ & $\begin{array}{c}\text { Low- } \\
\text { SP } \\
3.25 \\
\text { MW } \\
160 \mathrm{~m}\end{array}$ & $\begin{array}{c}\text { Low- } \\
\text { SP 4.5 } \\
\text { MW } \\
110 \mathrm{~m}\end{array}$ & $\begin{array}{c}\text { Low- } \\
\text { SP 4.5 } \\
\text { MW } \\
140 \mathrm{~m}\end{array}$ & $\begin{array}{c}\text { Low- } \\
\text { SP 4.5 } \\
\text { MW } \\
160 \mathrm{~m}\end{array}$ \\
\hline VA & $\$ 66$ & $\$ 63$ & $\$ 63$ & $\$ 66$ & $\$ 52$ & $\$ 51$ & $\$ 54$ & $\$ 51$ & $\$ 51$ & $\$ 53$ & $\$ 48$ & $\$ 47$ & $\$ 48$ \\
\hline VT & $\$ 55$ & $\$ 54$ & $\$ 55$ & $\$ 58$ & $\$ 45$ & $\$ 45$ & $\$ 47$ & $\$ 44$ & $\$ 44$ & $\$ 46$ & $\$ 42$ & $\$ 41$ & $\$ 42$ \\
\hline WA & $\$ 64$ & $\$ 66$ & $\$ 71$ & $\$ 77$ & $\$ 56$ & $\$ 59$ & $\$ 63$ & $\$ 55$ & $\$ 58$ & $\$ 62$ & $\$ 53$ & $\$ 54$ & $\$ 56$ \\
\hline WI & $\$ 46$ & $\$ 45$ & $\$ 46$ & $\$ 49$ & $\$ 38$ & $\$ 38$ & $\$ 40$ & $\$ 37$ & $\$ 38$ & $\$ 40$ & $\$ 35$ & $\$ 35$ & $\$ 36$ \\
\hline WV & $\$ 66$ & $\$ 63$ & $\$ 63$ & $\$ 67$ & $\$ 52$ & $\$ 52$ & $\$ 54$ & $\$ 51$ & $\$ 52$ & $\$ 54$ & $\$ 49$ & $\$ 48$ & $\$ 49$ \\
\hline WY & $\$ 50$ & $\$ 52$ & $\$ 56$ & $\$ 60$ & $\$ 44$ & $\$ 47$ & $\$ 50$ & $\$ 44$ & $\$ 46$ & $\$ 49$ & $\$ 42$ & $\$ 43$ & $\$ 45$ \\
\hline
\end{tabular}


Table A7. Average State Breakeven Cost $(\$ / k W)$

\begin{tabular}{|c|c|c|c|c|c|c|c|c|c|c|c|c|}
\hline State & $\begin{array}{l}\text { Today } \\
110 \mathrm{~m}\end{array}$ & $\begin{array}{l}\text { Today } \\
140 \mathrm{~m}\end{array}$ & $\begin{array}{l}\text { Today } \\
160 \mathrm{~m}\end{array}$ & $\begin{array}{c}\text { BAU } \\
110 \mathrm{~m}\end{array}$ & $\begin{array}{l}\text { BAU } \\
140 \mathrm{~m}\end{array}$ & $\begin{array}{c}\text { BAU } \\
160 \mathrm{~m}\end{array}$ & $\begin{array}{c}\text { Low-SP } \\
3.25 \\
\text { MW } 110 \\
\mathrm{~m}\end{array}$ & $\begin{array}{c}\text { Low-SP } \\
3.25 \\
\text { MW } 140 \\
\mathrm{~m}\end{array}$ & $\begin{array}{c}\text { Low-SP } \\
3.25 \\
\text { MW } 160 \\
m\end{array}$ & $\begin{array}{c}\text { Low-SP } \\
4.5 \mathrm{MW} \\
110 \mathrm{~m}\end{array}$ & $\begin{array}{l}\text { Low-SP } \\
4.5 \mathrm{MW} \\
140 \mathrm{~m}\end{array}$ & $\begin{array}{l}\text { Low-SP } \\
4.5 \mathrm{MW} \\
160 \mathrm{~m}\end{array}$ \\
\hline AL & $\$ 412$ & $\$ 793$ & $\$ 917$ & $\$ 849$ & $\$ 1,208$ & $\$ 1,325$ & $\$ 1,059$ & $\$ 1,406$ & $\$ 1,520$ & $\$ 1,037$ & $\$ 1,385$ & $\$ 1,499$ \\
\hline AR & $\$ 352$ & $\$ 667$ & $\$ 772$ & $\$ 726$ & $\$ 1,017$ & $\$ 1,116$ & $\$ 902$ & $\$ 1,182$ & $\$ 1,277$ & $\$ 883$ & $\$ 1,165$ & $\$ 1,260$ \\
\hline$A Z$ & $\$ 166$ & $\$ 266$ & $\$ 302$ & $\$ 532$ & $\$ 628$ & $\$ 662$ & $\$ 713$ & $\$ 806$ & $\$ 838$ & $\$ 694$ & $\$ 787$ & $\$ 819$ \\
\hline CA & $\$ 146$ & $\$ 221$ & $\$ 245$ & $\$ 470$ & $\$ 537$ & $\$ 558$ & $\$ 631$ & $\$ 694$ & $\$ 713$ & $\$ 614$ & $\$ 677$ & $\$ 697$ \\
\hline $\mathrm{CO}$ & $\$ 151$ & $\$ 254$ & $\$ 290$ & $\$ 446$ & $\$ 540$ & $\$ 573$ & $\$ 587$ & $\$ 677$ & $\$ 708$ & $\$ 572$ & $\$ 662$ & $\$ 694$ \\
\hline CT & $\$ 332$ & $\$ 669$ & $\$ 790$ & $\$ 715$ & $\$ 1,038$ & $\$ 1,149$ & $\$ 898$ & $\$ 1,210$ & $\$ 1,316$ & $\$ 879$ & $\$ 1,192$ & $\$ 1,299$ \\
\hline DC & $\$ 373$ & $\$ 771$ & $\$ 919$ & $\$ 773$ & $\$ 1,165$ & $\$ 1,309$ & $\$ 967$ & $\$ 1,353$ & $\$ 1,494$ & $\$ 946$ & $\$ 1,333$ & $\$ 1,475$ \\
\hline $\mathrm{DE}$ & $\$ 285$ & $\$ 504$ & $\$ 571$ & $\$ 628$ & $\$ 818$ & $\$ 878$ & $\$ 788$ & $\$ 965$ & $\$ 1,021$ & $\$ 771$ & $\$ 949$ & $\$ 1,006$ \\
\hline $\mathrm{FL}$ & $\$ 394$ & $\$ 736$ & $\$ 848$ & $\$ 893$ & $\$ 1,220$ & $\$ 1,327$ & $\$ 1,138$ & $\$ 1,455$ & $\$ 1,558$ & $\$ 1,112$ & $\$ 1,430$ & $\$ 1,534$ \\
\hline GA & $\$ 399$ & $\$ 758$ & $\$ 876$ & $\$ 839$ & $\$ 1,184$ & $\$ 1,297$ & $\$ 1,054$ & $\$ 1,388$ & $\$ 1,499$ & $\$ 1,031$ & $\$ 1,367$ & $\$ 1,477$ \\
\hline IA & $\$ 228$ & $\$ 393$ & $\$ 440$ & $\$ 481$ & $\$ 617$ & $\$ 657$ & $\$ 594$ & $\$ 718$ & $\$ 756$ & $\$ 583$ & $\$ 707$ & $\$ 746$ \\
\hline ID & $\$ 150$ & $\$ 253$ & $\$ 291$ & $\$ 462$ & $\$ 560$ & $\$ 596$ & $\$ 612$ & $\$ 708$ & $\$ 743$ & $\$ 596$ & $\$ 692$ & $\$ 727$ \\
\hline IL & $\$ 262$ & $\$ 455$ & $\$ 512$ & $\$ 560$ & $\$ 723$ & $\$ 774$ & $\$ 695$ & $\$ 847$ & $\$ 895$ & $\$ 681$ & $\$ 834$ & $\$ 882$ \\
\hline IN & $\$ 254$ & $\$ 442$ & $\$ 497$ & $\$ 561$ & $\$ 725$ & $\$ 774$ & $\$ 704$ & $\$ 857$ & $\$ 903$ & $\$ 689$ & $\$ 843$ & $\$ 890$ \\
\hline KS & $\$ 208$ & $\$ 352$ & $\$ 392$ & $\$ 450$ & $\$ 567$ & $\$ 601$ & $\$ 559$ & $\$ 665$ & $\$ 697$ & $\$ 548$ & $\$ 655$ & $\$ 687$ \\
\hline $\mathrm{KY}$ & $\$ 315$ & $\$ 587$ & $\$ 672$ & $\$ 665$ & $\$ 917$ & $\$ 997$ & $\$ 833$ & $\$ 1,075$ & $\$ 1,151$ & $\$ 815$ & $\$ 1,058$ & $\$ 1,135$ \\
\hline LA & $\$ 366$ & $\$ 662$ & $\$ 755$ & $\$ 789$ & $\$ 1,059$ & $\$ 1,144$ & $\$ 991$ & $\$ 1,246$ & $\$ 1,329$ & $\$ 969$ & $\$ 1,227$ & $\$ 1,309$ \\
\hline MA & $\$ 307$ & $\$ 603$ & $\$ 708$ & $\$ 662$ & $\$ 938$ & $\$ 1,033$ & $\$ 829$ & $\$ 1,092$ & $\$ 1,183$ & $\$ 811$ & $\$ 1,076$ & $\$ 1,167$ \\
\hline MD & $\$ 294$ & $\$ 549$ & $\$ 634$ & $\$ 645$ & $\$ 880$ & $\$ 959$ & $\$ 811$ & $\$ 1,036$ & $\$ 1,112$ & $\$ 794$ & $\$ 1,020$ & $\$ 1,096$ \\
\hline ME & $\$ 306$ & $\$ 616$ & $\$ 726$ & $\$ 658$ & $\$ 948$ & $\$ 1,048$ & $\$ 822$ & $\$ 1,100$ & $\$ 1,195$ & $\$ 805$ & $\$ 1,084$ & $\$ 1,180$ \\
\hline MI & $\$ 274$ & $\$ 502$ & $\$ 573$ & $\$ 588$ & $\$ 784$ & $\$ 845$ & $\$ 731$ & $\$ 913$ & $\$ 969$ & $\$ 716$ & $\$ 899$ & $\$ 956$ \\
\hline MN & $\$ 245$ & $\$ 434$ & $\$ 491$ & $\$ 531$ & $\$ 690$ & $\$ 739$ & $\$ 660$ & $\$ 806$ & $\$ 852$ & $\$ 646$ & $\$ 794$ & $\$ 840$ \\
\hline
\end{tabular}




\begin{tabular}{|c|c|c|c|c|c|c|c|c|c|c|c|c|}
\hline State & $\begin{array}{l}\text { Today } \\
110 \mathrm{~m}\end{array}$ & $\begin{array}{l}\text { Today } \\
140 \mathrm{~m}\end{array}$ & $\begin{array}{l}\text { Today } \\
160 \mathrm{~m}\end{array}$ & $\begin{array}{c}\text { BAU } \\
110 \mathrm{~m}\end{array}$ & $\begin{array}{l}\text { BAU } \\
140 \mathrm{~m}\end{array}$ & $\begin{array}{c}\text { BAU } \\
160 \mathrm{~m}\end{array}$ & $\begin{array}{c}\text { Low-SP } \\
3.25 \\
\text { MW } 110 \\
\mathrm{~m}\end{array}$ & $\begin{array}{c}\text { Low-SP } \\
3.25 \\
\text { MW } 140 \\
\text { m }\end{array}$ & $\begin{array}{c}\text { Low-SP } \\
3.25 \\
\text { MW } 160 \\
\mathrm{~m}\end{array}$ & $\begin{array}{c}\text { Low-SP } \\
4.5 \mathrm{MW} \\
110 \mathrm{~m}\end{array}$ & $\begin{array}{c}\text { Low-SP } \\
4.5 \mathrm{MW} \\
140 \mathrm{~m}\end{array}$ & $\begin{array}{c}\text { Low-SP } \\
4.5 \mathrm{MW} \\
160 \mathrm{~m}\end{array}$ \\
\hline MO & $\$ 285$ & $\$ 509$ & $\$ 575$ & $\$ 583$ & $\$ 775$ & $\$ 833$ & $\$ 719$ & $\$ 897$ & $\$ 953$ & $\$ 705$ & $\$ 885$ & $\$ 940$ \\
\hline MS & $\$ 378$ & $\$ 694$ & $\$ 793$ & $\$ 779$ & $\$ 1,070$ & $\$ 1,162$ & $\$ 969$ & $\$ 1,247$ & $\$ 1,336$ & $\$ 949$ & $\$ 1,228$ & $\$ 1,317$ \\
\hline MT & $\$ 158$ & $\$ 286$ & $\$ 330$ & $\$ 415$ & $\$ 531$ & $\$ 572$ & $\$ 534$ & $\$ 645$ & $\$ 684$ & $\$ 522$ & $\$ 633$ & $\$ 672$ \\
\hline $\mathrm{NC}$ & $\$ 331$ & $\$ 625$ & $\$ 725$ & $\$ 716$ & $\$ 994$ & $\$ 1,089$ & $\$ 901$ & $\$ 1,170$ & $\$ 1,263$ & $\$ 881$ & $\$ 1,152$ & $\$ 1,244$ \\
\hline ND & $\$ 216$ & $\$ 381$ & $\$ 430$ & $\$ 485$ & $\$ 623$ & $\$ 665$ & $\$ 606$ & $\$ 733$ & $\$ 772$ & $\$ 593$ & $\$ 721$ & $\$ 761$ \\
\hline $\mathrm{NE}$ & $\$ 207$ & $\$ 360$ & $\$ 406$ & $\$ 460$ & $\$ 588$ & $\$ 626$ & $\$ 574$ & $\$ 690$ & $\$ 726$ & $\$ 562$ & $\$ 680$ & $\$ 716$ \\
\hline $\mathrm{NH}$ & $\$ 262$ & $\$ 534$ & $\$ 638$ & $\$ 599$ & $\$ 865$ & $\$ 964$ & $\$ 759$ & $\$ 1,019$ & $\$ 1,115$ & $\$ 742$ & $\$ 1,003$ & $\$ 1,099$ \\
\hline NJ & $\$ 326$ & $\$ 629$ & $\$ 732$ & $\$ 702$ & $\$ 984$ & $\$ 1,078$ & $\$ 882$ & $\$ 1,151$ & $\$ 1,241$ & $\$ 863$ & $\$ 1,133$ & $\$ 1,224$ \\
\hline NM & $\$ 174$ & $\$ 304$ & $\$ 351$ & $\$ 491$ & $\$ 615$ & $\$ 659$ & $\$ 644$ & $\$ 764$ & $\$ 806$ & $\$ 628$ & $\$ 748$ & $\$ 791$ \\
\hline NV & $\$ 116$ & $\$ 178$ & $\$ 201$ & $\$ 414$ & $\$ 472$ & $\$ 494$ & $\$ 558$ & $\$ 614$ & $\$ 635$ & $\$ 542$ & $\$ 599$ & $\$ 620$ \\
\hline NY & $\$ 268$ & $\$ 526$ & $\$ 619$ & $\$ 603$ & $\$ 847$ & $\$ 933$ & $\$ 761$ & $\$ 996$ & $\$ 1,078$ & $\$ 745$ & $\$ 980$ & $\$ 1,063$ \\
\hline $\mathrm{OH}$ & $\$ 293$ & $\$ 534$ & $\$ 607$ & $\$ 631$ & $\$ 849$ & $\$ 914$ & $\$ 790$ & $\$ 996$ & $\$ 1,058$ & $\$ 773$ & $\$ 980$ & $\$ 1,043$ \\
\hline OK & $\$ 239$ & $\$ 423$ & $\$ 478$ & $\$ 500$ & $\$ 654$ & $\$ 701$ & $\$ 618$ & $\$ 758$ & $\$ 802$ & $\$ 605$ & $\$ 747$ & $\$ 791$ \\
\hline OR & $\$ 158$ & $\$ 281$ & $\$ 326$ & $\$ 458$ & $\$ 577$ & $\$ 620$ & $\$ 604$ & $\$ 719$ & $\$ 761$ & $\$ 588$ & $\$ 704$ & $\$ 746$ \\
\hline PA & $\$ 304$ & $\$ 617$ & $\$ 733$ & $\$ 667$ & $\$ 969$ & $\$ 1,078$ & $\$ 840$ & $\$ 1,134$ & $\$ 1,239$ & $\$ 821$ & $\$ 1,117$ & $\$ 1,222$ \\
\hline RI & $\$ 299$ & $\$ 568$ & $\$ 658$ & $\$ 649$ & $\$ 894$ & $\$ 976$ & $\$ 814$ & $\$ 1,046$ & $\$ 1,123$ & $\$ 797$ & $\$ 1,030$ & $\$ 1,108$ \\
\hline SC & $\$ 381$ & $\$ 718$ & $\$ 829$ & $\$ 806$ & $\$ 1,125$ & $\$ 1,231$ & $\$ 1,012$ & $\$ 1,322$ & $\$ 1,424$ & $\$ 990$ & $\$ 1,301$ & $\$ 1,404$ \\
\hline SD & $\$ 204$ & $\$ 363$ & $\$ 413$ & $\$ 464$ & $\$ 601$ & $\$ 643$ & $\$ 582$ & $\$ 708$ & $\$ 748$ & $\$ 569$ & $\$ 697$ & $\$ 737$ \\
\hline TN & $\$ 319$ & $\$ 606$ & $\$ 702$ & $\$ 689$ & $\$ 961$ & $\$ 1,052$ & $\$ 867$ & $\$ 1,130$ & $\$ 1,218$ & $\$ 849$ & $\$ 1,112$ & $\$ 1,201$ \\
\hline TX & $\$ 273$ & $\$ 499$ & $\$ 572$ & $\$ 611$ & $\$ 807$ & $\$ 869$ & $\$ 766$ & $\$ 947$ & $\$ 1,004$ & $\$ 750$ & $\$ 932$ & $\$ 990$ \\
\hline UT & $\$ 122$ & $\$ 194$ & $\$ 220$ & $\$ 405$ & $\$ 471$ & $\$ 496$ & $\$ 540$ & $\$ 604$ & $\$ 627$ & $\$ 526$ & $\$ 590$ & $\$ 613$ \\
\hline VA & $\$ 310$ & $\$ 595$ & $\$ 697$ & $\$ 684$ & $\$ 960$ & $\$ 1,057$ & $\$ 865$ & $\$ 1,134$ & $\$ 1,229$ & $\$ 846$ & $\$ 1,116$ & $\$ 1,211$ \\
\hline VT & $\$ 246$ & $\$ 494$ & $\$ 592$ & $\$ 586$ & $\$ 831$ & $\$ 925$ & $\$ 749$ & $\$ 990$ & $\$ 1,080$ & $\$ 731$ & $\$ 973$ & $\$ 1,064$ \\
\hline
\end{tabular}




\begin{tabular}{|c|c|c|c|c|c|c|c|c|c|c|c|c|}
\hline State & $\begin{array}{l}\text { Today } \\
110 \mathrm{~m}\end{array}$ & $\begin{array}{l}\text { Today } \\
140 \mathrm{~m}\end{array}$ & $\begin{array}{l}\text { Today } \\
160 \mathrm{~m}\end{array}$ & $\begin{array}{c}\text { BAU } \\
110 \mathrm{~m}\end{array}$ & $\begin{array}{c}\text { BAU } \\
140 \mathrm{~m}\end{array}$ & $\begin{array}{c}\text { BAU } \\
160 \mathrm{~m}\end{array}$ & $\begin{array}{c}\text { Low-SP } \\
3.25 \\
\text { MW } 110 \\
\mathrm{~m}\end{array}$ & $\begin{array}{c}\text { Low-SP } \\
3.25 \\
\text { MW } 140 \\
\text { m }\end{array}$ & $\begin{array}{c}\text { Low-SP } \\
3.25 \\
\text { MW } 160 \\
m\end{array}$ & $\begin{array}{l}\text { Low-SP } \\
4.5 \mathrm{MW} \\
110 \mathrm{~m}\end{array}$ & $\begin{array}{l}\text { Low-SP } \\
4.5 \mathrm{MW} \\
140 \mathrm{~m}\end{array}$ & $\begin{array}{l}\text { Low-SP } \\
4.5 \mathrm{MW} \\
160 \mathrm{~m}\end{array}$ \\
\hline WA & $\$ 159$ & $\$ 278$ & $\$ 320$ & $\$ 447$ & $\$ 558$ & $\$ 597$ & $\$ 585$ & $\$ 692$ & $\$ 728$ & $\$ 571$ & $\$ 678$ & $\$ 714$ \\
\hline WI & $\$ 296$ & $\$ 543$ & $\$ 619$ & $\$ 618$ & $\$ 833$ & $\$ 899$ & $\$ 766$ & $\$ 965$ & $\$ 1,027$ & $\$ 751$ & $\$ 951$ & $\$ 1,014$ \\
\hline WV & $\$ 295$ & $\$ 575$ & $\$ 673$ & $\$ 652$ & $\$ 920$ & $\$ 1,012$ & $\$ 824$ & $\$ 1,085$ & $\$ 1,173$ & $\$ 806$ & $\$ 1,067$ & $\$ 1,156$ \\
\hline WY & $\$ 140$ & $\$ 248$ & $\$ 287$ & $\$ 395$ & $\$ 496$ & $\$ 532$ & $\$ 515$ & $\$ 612$ & $\$ 646$ & $\$ 502$ & $\$ 600$ & $\$ 634$ \\
\hline
\end{tabular}

